\title{
Uso de auriculares musicales y el conocimiento de los efectos en la salud
}

Use of musical headphones and knowledge of health effects.

Jaimes-Socha, Vanessa-Zuley*1; Arevalo-Lanzziano, Slendy-Liliana*2; Pinto-Peñaloza; Maryelis-Andrea*3; Ramos-Navarro, Yaris-Patricia*4; Romero-Pantoja, Marlon-Francisco*5; Sierra-Peñaloza, Ebreidy-Yuranny*6; Vega-Cataño, María-Gabriela*7.

Como citar este artículo: Jaimes-Socha, Vanessa-Zuley; Arevalo-Lanzziano, Slendy-Liliana; Pinto-Peñaloza; Maryelis-Andrea; Ramos-Navarro, Yaris-Patricia; Romero-Pantoja, Marlon-Francisco; Sierra-Peñaloza, Ebreidy-Yuranny; Vega-Cataño, María-Gabriela. Uso de auriculares musicales y el conocimiento de los efectos en la salud. Revistas Signos Fónicos. 2019; 5(2):97-150.

Correspondencia autor: audiologa_vjs@hotmail.com, (Vanessa Zuley Jaimes Socha)

Recibido: Junio 20, 2019.

Aprobado: Octubre 1, 2019.

\section{RESUMEN}

INTRODUCCIÓN: Esta investigación tiene como objetivo determinar el uso de auriculares musicales y el conocimiento de la Facultad de Salud de ciencias básicas y la facultad de artes y humanidades de la Universidad de Pamplona sede principal, debido a que el uso de auriculares a altas intensidades está directamente relacionado con el riesgo de sufrir un daño auditivo. MÉTODOS: Teniendo en cuenta la naturaleza del problema y el objetivo planteado, esta investigación tiene un enfoque cuantitativo de tipo descriptivo. La selección de la muestra se realizó mediante muestreo aleatorio simple respecto del número total de estudiantes de las facultades mencionadas anteriormente, así como el cumplimiento de los criterios de inclusión y exclusión. RESULTADOS: Respecto al tiempo de uso de los auriculares lo el $90 \%$ de los estudiantes lo hacen inadecuadamente y el $10 \%$ adecuadamente, el $80 \%$ de los estudiantes no conocen los efectos que los auriculares causan en la salud. ANÁLISIS Y DISCUSIÓN: El análisis muestra que gran parte de la población hacen uso inadecuado y desconocen los efectos en la salud que pueden llegar a causar estos dispositivos. CONCLUSIONES: Se observó una alta tasa de uso excesivo de auriculares musicales en estudiantes pertenecientes a la Facultad de Salud, Ciencias Básicas y Facultad de Artes y Humanidades. Por lo tanto, radica la importancia de crear conciencia entre los estudiantes sobre los efectos nocivos causados por el uso excesivo de auriculares y contribuir al diagnóstico temprano en caso de que exista algún tipo de discapacidad auditiva.

PALABRAS CLAVES: Audición, estudiantes, reproductor MP3, ruido, pérdidas auditivas.

\footnotetext{
1Fonoaudióloga, Doctorando en Fonoaudiología, audiologa vjs@hotmail.com, Orcid: 0000-00032646-1190, Universidad del Museo Social Argentino, Argentina.

2^Practicante de Fonoaudiología, slanzziano12@gmail.com, Orcid: 0000-0001-9231-8734, Colombia. 3×Practicante de Fonoaudiología, maryelispinto@gmail.com, Orcid: 0000-0003-4406-5327, Colombia. 4^Practicante de Fonoaudiología, enyaris2313@gmail.com, Orcid: 0000-0001-7676-0362, Colombia. 5^Practicante de Fonoaudiología, marlon678rp@gmail.com, Orcid: 0000-0003-1444-7527, Colombia. 6Practicante de Fonoaudiología, yuranny.sierra19@gmail.com, Orcid: 0000-0002-3138-994X, Colombia. 7*Practicante de Fonoaudiología, mariagabrielavegacatano@gmail.com , Orcid: 0000-0002-4551-5601, Colombia
} 


\section{ABSTRACT}

INTRODUCTION: This research aims to determine the use of musical headphones and the knowledge of the Faculty of Health of Basic Sciences and the Faculty of Arts and Humanities of the University of Pamplona headquarters, because the use of headphones at high intensities is directly related with the risk of hearing damage. METHODS: Taking into account the nature of the problem and the objective, this research has a quantitative approach of a descriptive type. The sample selection was made by simple random sampling with respect to the total number of students of the faculties mentioned above, as well as the fulfillment of the inclusion and exclusion criteria. RESULTS: Regarding the use of the headphones, $90 \%$ of the students do it improperly and $10 \%$ adequately, $80 \%$ of the students do not know the effects that the headphones cause on their health. ANALYSIS AND DISCUSSION: The analysis shows that a large part of the population makes inappropriate use and are unaware of the health effects that these devices can cause. CONCLUSIONS: a high rate of excessive use of musical headphones was observed in students belonging to the Faculty of Health, Basic Sciences and Faculty of Arts and Humanities. Therefore, lies the importance of raising awareness among students about the harmful effects caused by the excessive use of headphones and contributing to the early diagnosis in case there is any type of hearing impairment for the improvement of optimal hearing health.

KEYWORDS: Audition, students, MP3 player, noise, hearing loss.

\section{INTRODUCCIÓN}

La audición es un proceso complejo y de vital importancia en la vida de los seres humanos, más de lo que se considera habitualmente. El proceso de la audición inicia desde la llegada del sonido al tímpano hasta la percepción de este, y desde que la señal choca con la membrana timpánica, la cual va siendo sometida a una serie de transformaciones hasta llegar a convertirse en señal eléctrica.(1) Esta señal es transferida desde el oído a través de complejas redes neuronales a diferentes áreas del cerebro para su análisis y comprensión (3). Así mismo, para entender la manera en cómo se oye, se debe tener conocimiento de que los sonidos son vibraciones invisibles que se desplazan por el aire en todas las direcciones, las cuales se denominan ondas sonoras.

En la actualidad, existen gran variedad de factores negativos los cuales afectan a la audición directamente y pueden conllevar a padecer algún tipo de pérdida auditiva, como lo es la exposición a ruidos de alta intensidad en los diferentes ambientes cotidianos de los seres humanos: ambientes laborales, ambientes urbanos y de recreación.(2)

Desde épocas remotas la música ha acompañado a la humanidad como vehículo de expresión, constituyéndose un medio de expansión y una vía de evolución social. Incluso en los últimos años, por comodidad, accesibilidad y/o entretenimiento, los nuevos reproductores de música (MP3, MP4, celulares, y demás dispositivos) han logrado imponerse en la vida cotidiana, permitiendo que la música pueda ser escuchada en todo momento y en cualquier lugar.(3)

Si bien ello puede constituir un hecho positivo, y es cada vez más común ver personas con sus auriculares puestos, también es cierto que esta conducta aumenta el riesgo de adquirir graves e irreversibles problemas auditivos que comenzarán a manifestarse con el transcurso de los años. En efecto, los jóvenes de entre 14 y adulto joven hasta 30 años son los más afectados por el uso de estos dispositivos, ya que esto hace que se adelante la pérdida de sus facultades auditivas.(4)

En los últimos años ha reportado un aumento en la popularidad de los reproductores de música personal como lo son los reproductores MP3, "Ipods" y hasta en los teléfonos móviles. Con esta difusión masiva de la popularidad de estos reproductores portátiles, la exposición a altos niveles de sonido ha incrementado dramáticamente. El desarrollo acelerado de la tecnología digital ha permitido que se crean nuevos y avanzados reproductores de música personal en los cuales la calidad del sonido en volúmenes elevados es mucho mejor. Estos nuevos estilos de reproductores están equipados con auriculares mejorados los cuales no permiten la pérdida del sonido, lo que significa que los reproductores de música se pueden reproducir en volúmenes peligrosos en la mayoría de los entornos sin molestar a otras personas.

Los reproductores de música personal no son la única fuente que puede ocasionar esta pérdida auditiva. Actualmente, los adolescentes y adultos jóvenes se exponen con frecuencia y conscientemente a ruidos fuertes hasta por varias horas, ya sea en el uso personal de estos dispositivos o ante la exposición ruidos excesivos que se encuentran en muchos de los ámbitos sociales (conciertos, teatros y discotecas). 
Diversos organismos internacionales manifiestan su preocupación acerca de los efectos a largo plazo de la exposición a ruido no ocupacional en los jóvenes y advierten el aumento significativo a nivel mundial de "hipoacusias inducidas por ruido" en edades cada vez más tempranas (National Institutes of Health, 2000; Folmer, Griest y Martin., 2002).

Es así como la Organización Mundial de la Salud (OMS) manifiesta en cuanto a los reproductores musicales, que la mejor manera de evitar daños auditivos es evitar escuchar música a niveles altos. Esto fundamenta la idea de que el uso de audífonos a altos niveles no puede ser una buena idea si se desea conservar la audición.

Generalmente la pérdida auditiva secundaria al ruido recreacional es menor que la ocupacional, pero en la actualidad esta pérdida auditiva recreacional está aumentando ya que no existe conciencia pública de su riesgo.(5) Tal es el caso de los jóvenes de la denominada época moderna, que además de exponerse diariamente al ruido ambiental, se exponen también a actividades con música que excedan los límites saludables de la audición. A pesar de que la música desempeña un papel importante en la socialización y la formación de la identidad de una persona, el inconveniente se genera en los altos niveles de intensidad a los que se exponen.(6)

Un reciente estudio hecho entre jóvenes de 18 a 27 años por el centro de Desarrollo Acústico de la escuela de Arquitectura de La Salle, de Barcelona, ha demostrado que hasta un $50 \%$ de los chicos y chicas analizados tiene lesiones auditivas, un $33 \%$ leves y un $17 \%$ graves. Los autores atribuyeron las pérdidas de la audición a la costumbre que tenían los jóvenes de escuchar música a través de reproductores de MP3 con auriculares intracraneales.

De acuerdo a lo anterior, la presente investigación buscar responder el interrogante de cuál es el uso de auriculares musicales y el conocimiento de los efectos en la salud auditiva en estudiantes de la Facultad de Artes y Humanidades (Derecho, Filosofía, Artes Visuales, Comunicación Social, Música), y la Facultad de Ciencias Básicas (matemáticas, Biología, Microbiología Química y Física) de la Universidad de Pamplona Sede Principal. Debido a que la exposición diaria al uso de auriculares a altas intensidades está directamente relacionada con el riesgo de sufrir un daño auditivo, razón por la cual los jóvenes deben conocer en qué momento los auriculares se convierten en una amenaza o en un peligro para su salud.

\section{MÉTODOS}

\section{Tipo de investigación}

El presente estudio corresponde a una investigación con enfoque cuantitativo y un análisis de tipo descriptivo, analítico, correlacional. El enfoque cuantitativo se debe a que las variables tenidas en cuenta se medirán numéricamente, al igual que utiliza la recolección de datos para verificar las hipótesis y un análisis estadístico de relación entre el uso de auriculares musicales y el conocimiento sobre los efectos en la salud; así mismo se utilizan elementos de tipo descriptivo al buscar identificar características de las variables en estudio, analítico ya que se pretende analizar las variables de estudio y correlacional debido a la naturaleza del mismo.

\section{Población y muestra}

La población de la presente investigación corresponde a 1.523 estudiantes de los programas Artes Visuales, Derecho, Filosofía, Música y Comunicación Social de la Facultad de Artes y Humanidades, y 754 estudiantes de los programas Biología, Matemáticas, Física, Microbiología y Química de la Facultad de Ciencias Básicas de la Universidad de Pamplona sede principal Colombia para un total de la población de 2.277. La selección de la muestra se realizó mediante muestreo aleatorio simple respecto del número total de estudiantes de los programas mencionados anteriormente, así como el cumplimiento de los criterios de inclusión y exclusión.

La fórmula aplicada fue la siguiente:

En donde, $\mathrm{N}$ representa la población total 2.277 estudiantes de la Facultad de Artes y Humanidades y Facultad de Ciencias Básicas para la sede principal; $p=65 \%$; $q=35 \% ; Z=1,88$, con una confiabilidad del $94 \% ; e=6 \%$ Error; Muestra $=n$, siendo la muestra de 870 sujetos conformados por 470 estudiantes para la Facultad de Artes y Humanidades y 400 estudiantes para la Facultad de Ciencias Básicas.

Revista Científica Signos Fónicos, 2019,5(2): 97-150. ISNN 2422-1716. 
Jaimes V Z; Arevalo S L; Pinto M A; Ramos Y P; Romero, M F; Sierra E Y; Vega, M G. Revista Científica Signos Fónicos, 2019,5(2): 97-150.

Al dividir la muestra resultante entre el número de programas, el valor corresponde a 80 estudiantes para cada uno de los programas de la dos Facultades mencionadas a diferencias del programa de derecho debido a la población, la muestra fue de 150 estudiantes.

\section{Criterios de inclusión}

Q Estudiante de la Facultad de Artes y Humanidades de la Universidad de Pamplona sede principal modalidad presencial.

\ Estudiante de la Facultad de Ciencias Básicas de la Universidad de Pamplona sede principal modalidad presencial.

\ Participación voluntaria en el estudio previo consentimiento informado.

\section{Criterios de exclusión}

$\otimes \quad$ Estudiante de la otras Facultades de la Universidad de Pamplona que estén cursando sus estudios en otras sedes y cuya modalidad sea diferente a la presencial.

घ Estudiantes que no deseen participar en el estudio.

$\bigotimes \quad$ Estudiantes que tengan patologías auditivas evidentes (disgenesias auditivas).

Hipótesis

Hipótesis general

El uso de auriculares musicales es inadecuado y no se evidencia conocimiento sobre los efectos en la salud en los estudiantes de la Facultad de Artes y Humanidades y Facultad de Ciencias Básicas de la Universidad de Pamplona Sede Principal.

\section{Hipótesis derivadas}

- El uso de auriculares musicales en estudiantes de la Facultad de Artes y Humanidades y Facultad de Ciencias Básicas es inadecuado de acuerdo al tiempo y tipo de auriculares.

- Los estudiantes de la Facultad de Artes y Humanidades y Facultad de Ciencias Básicas no conocen sobre los efectos en la salud generados por el uso de auriculares según efectos físicos, psicológicos y sociales.

- Los estudiantes de la Facultad de Salud tienen mayor conocimiento de los efectos en la salud generados por el uso de auriculares según efectos físicos, psicológicos y sociales con relación a los estudiantes de la Facultad de Artes y Humanidades y Facultad de Ciencias Básicas.

Variables

- Uso de auriculares musicales

- Conocimiento sobre los efectos de los auriculares en la salud.

\section{Técnicas e instrumentos de recolección de información}

Para la recolección de la información se utilizó el instrumento presentado por Ana Negrón de la Universidad Privada de San Juan Bautista en su tesis denominada "USO DE AURICULARES MUSICALES Y EL CONOCIMIENTO DE LOS EFECTOS EN LA SALUD EN ESTUDIANTES DE ENFERMERÍA DE II Y III CICLO DE LA UNIVERSIDAD PRIVADA SAN JUAN BAUTISTA CHORRILLOS NOVIEMBRE - 2017"

Revista Científica Signos Fónicos, 2019,5(2): 97-150. ISNN 2422-1716. 
Este instrumento consta de una encuesta, donde se realiza un cuestionario con una respuesta dicotómica, dos valores, sí o no en su mayor parte. También contiene una presentación, instrucciones, datos generales y contenido propiamente, el cual se constituye de 19 ítems. Es de destacar que el instrumento posee una prueba de confiabilidad valorada por 8 expertos profesionales de salud entre ellos dos licenciadas especialistas en otorrinolaringología y profesoras de investigación, los cuales hicieron las calificaciones para ser modificadas de acuerdo a las observaciones dadas durante su revisión a fin de establecer la validez del instrumento que fue medido con la tabla de prueba cuyo valor fue de 0.0226 .

Para la prueba de confiabilidad la autora del instrumento llevó acabo la prueba piloto en una muestra de 20 estudiantes de enfermería del II y III ciclo del 2017 II con similares características de las requeridas para el estudio para calcular el K-Richardson 20 a fin de establecer la confiabilidad, cuyo valor fue de 0.9884 resultado que indica que es altamente confiable.

\section{Diseño de recolección de datos}

Para la recolección de datos se llevó a cabo trámites administrativos, a fin de obtener las facilidades para realizar el estudio. Se indagó con los directores de cada programa el número de estudiantes que cursaban sus asignaturas en la sede principal, motivo por el cual se excluyó el programa de Geología de la Facultad de Ciencias Básicas y el programa de Licenciatura en Educación Artística de la Facultad de Artes y Humanidades, ya que solo se ofertan en la Sede Villa del Rosario. Posteriormente, se gestionaron los espacios con los docentes encargado de impartir las asignaturas en los diferentes programas, a fin de definir el proceso para la recolección de datos, considerando un tiempo de 20 minutos máximo para su aplicación, previa presentación y explicación.

Anterior a la aplicación del instrumento se explicó a los estudiantes en qué consistía el objeto de estudio y la importancia de la información brindada, para luego entregarles el consentimiento informado que garantiza la autonomía del estudiante en determinar su participación, voluntaria. De igual manera se cumplieron los principios de justicia, beneficencia y no maleficencia, al no tener actitudes discriminatorias y no producir daño alguno en los estudiantes.

\section{Procesamiento y análisis de datos}

En cuanto al procesamiento y análisis de datos, se realizó el levantamiento de la información, los datos, se tabularon manualmente proporcionando un valor a cada respuesta en relación con la escala de valoración. Fueron tabulados y procesados por medio del programa de computación Microsoft Office Excel 2016. Los resultados se presentados se describen a continuación:

- Datos generales (sexo y edad) análisis descriptivo porcentual.

- Variables Uso de auriculares y Conocimiento de los efectos del uso de auriculares análisis descriptivo porcentual y diagrama de dispersión.

- Respuesta a hipótesis planteadas en contraste con los resultados encontrados.

\section{RESULTADOS}

FACULTAD DE ARTES Y HUMANIDADES

DERECHO 
Gráfica 1. Género estudiantes del Programa de Derecho.

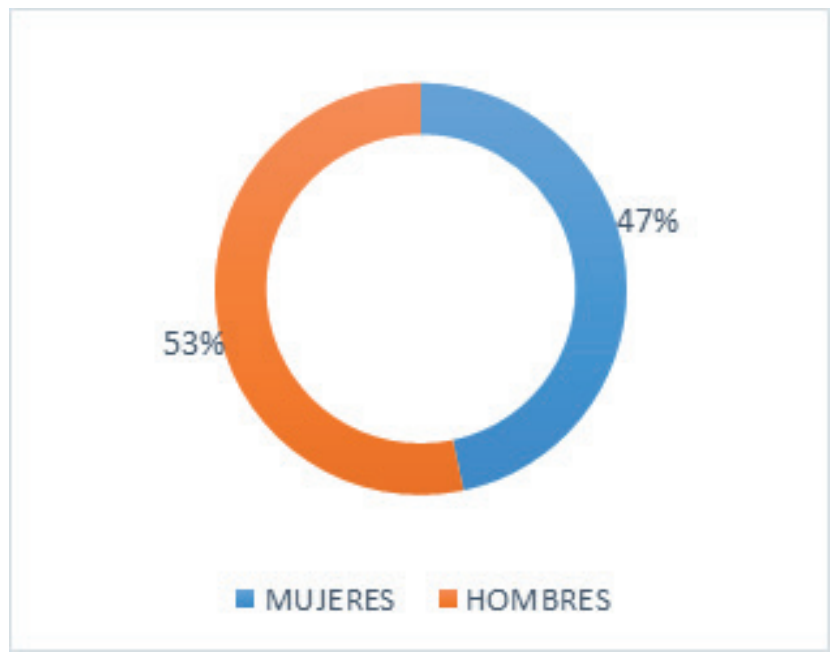

Fuente: Los Autores

Para una muestra de 150 estudiantes pertenecientes al programa de Derecho en donde se encontró que el $53 \%$ son hombres y un $47 \%$ son mujeres, obteniendo resultados similares para los dos géneros.

Gráfica 2. Edades de estudiantes de Derecho.

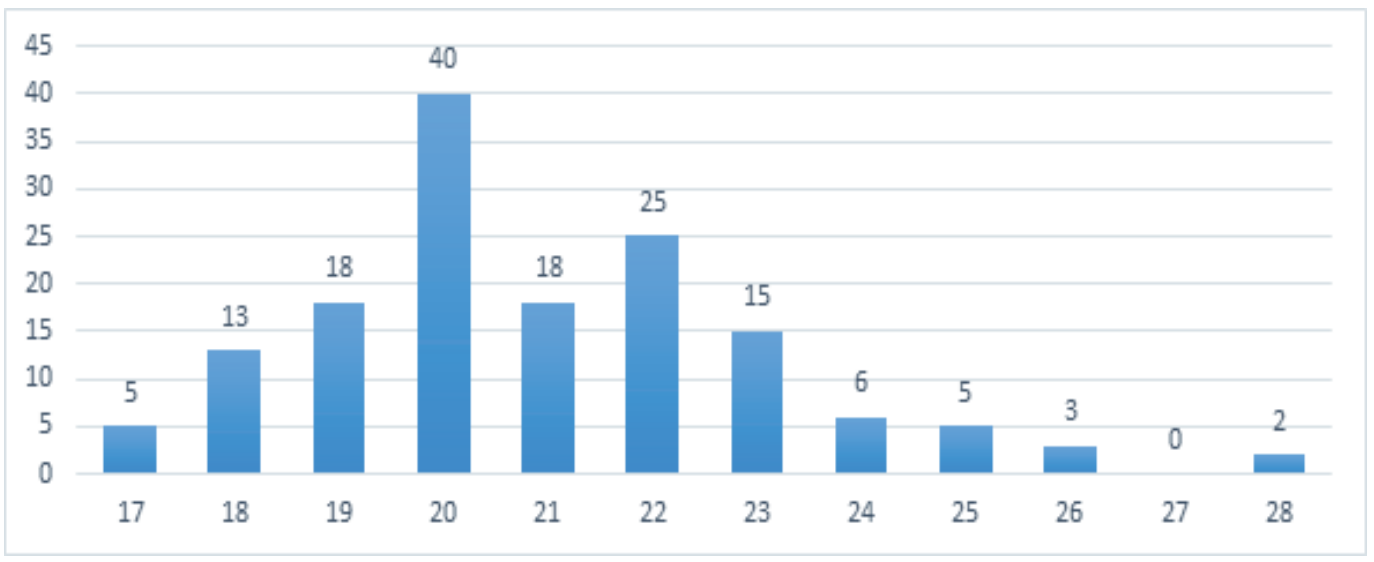

Fuente: Los Autores.

Las edades que predominan en la carrera de Derecho de la Universidad de Pamplona sede Principal están entre los 17 a 28 años, en donde el mayor número de estudiantes se encuentra en una edad de 20 años, representado por 40 estudiantes que reflejan el 50\% de la muestra, seguido se encuentran aquellos estudiantes cuya edad está entre los 22 años ( 25 estudiantes) en porcentaje representa el $31,25 \%$, y la edad de 19 y 21 años cuentan con el mismo porcentaje $22,5 \%$. 
Gráfica 3. Uso de auriculares en los estudiantes de Derecho.

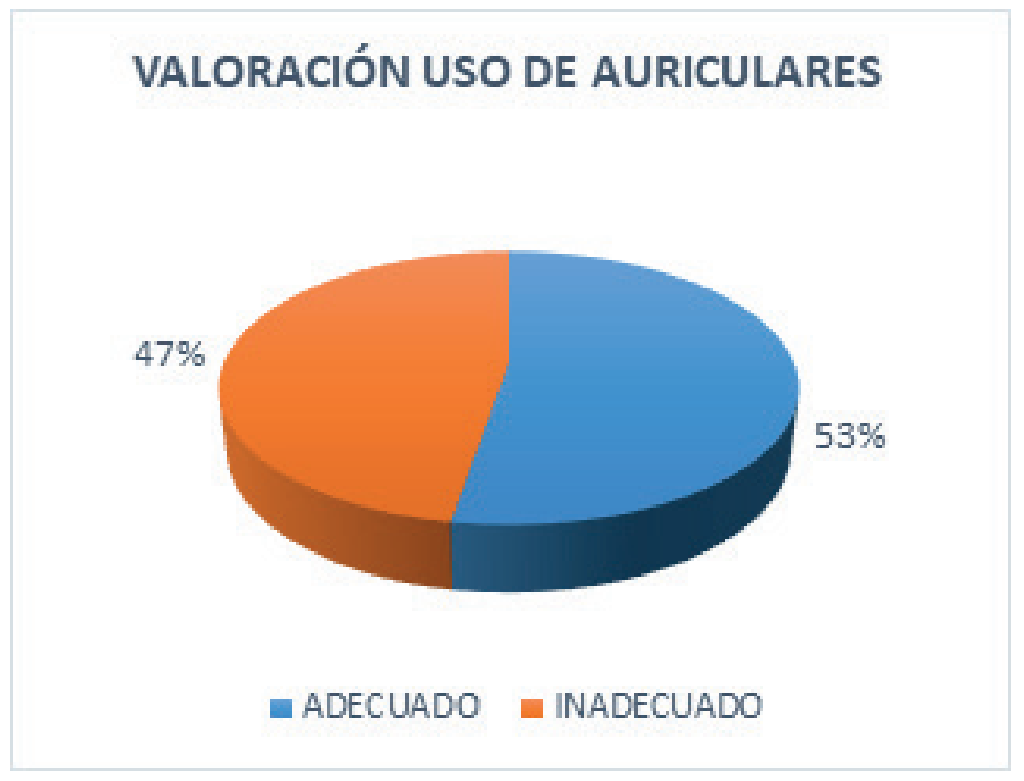

Fuente: Los Autores.

El 53\% de los estudiantes de Derecho de la Universidad de Pamplona sede principal hacen uso adecuado de los auriculares y el $47 \%$ de los estudiantes hacen uso inadecuado de los auriculares.

Gráfica 4. Tipo de auriculares que utilizan los estudiantes de Derecho.

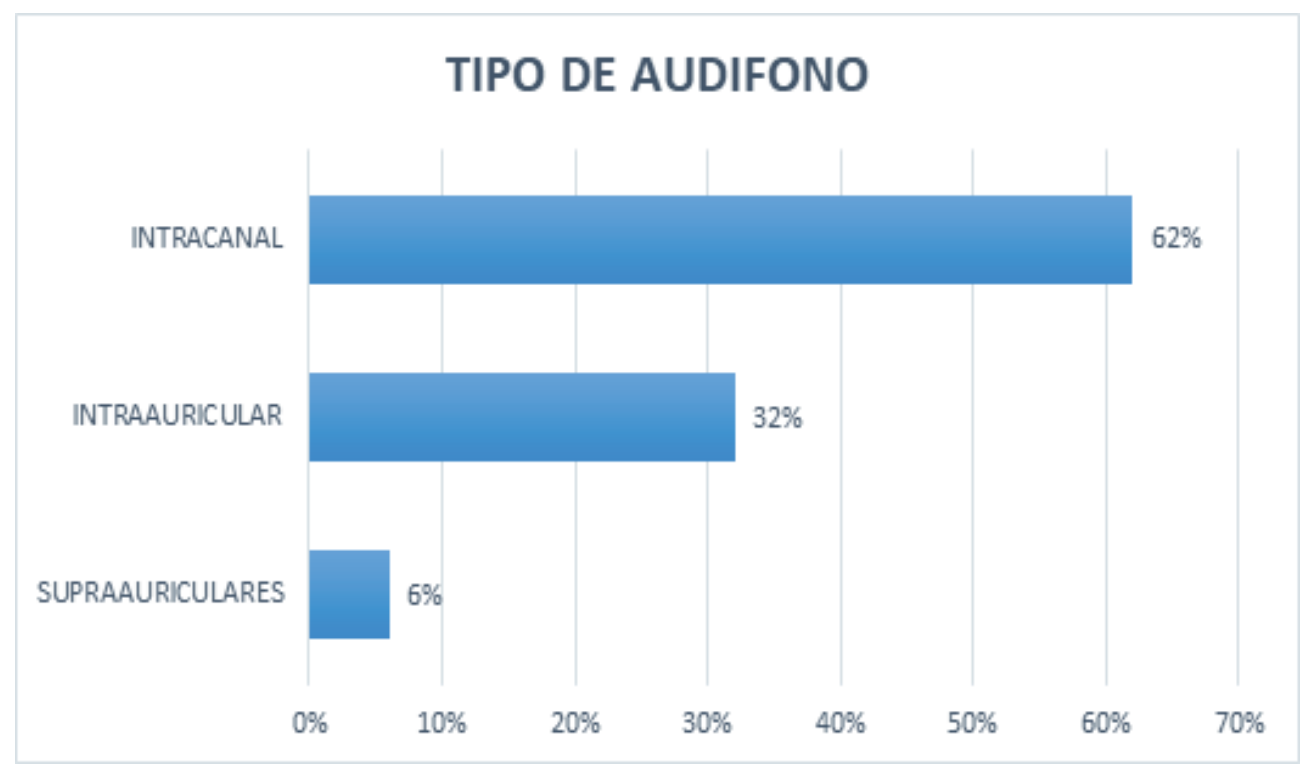

Fuente: Los Autores.

Así mismo, los estudiantes del programa de Derecho en mayor medida hacen uso de los auriculares de tipo intracanal en un $62 \%$, luego se encuentran aquellos que usan los auriculares de tipo intraauricular 
representado por un 32\% y por último se encuentran aquellos estudiantes que usan los supra auriculares representados con un $6 \%$.

Gráfica 5. Horas diarias de uso de auriculares en estudiantes de Derecho.

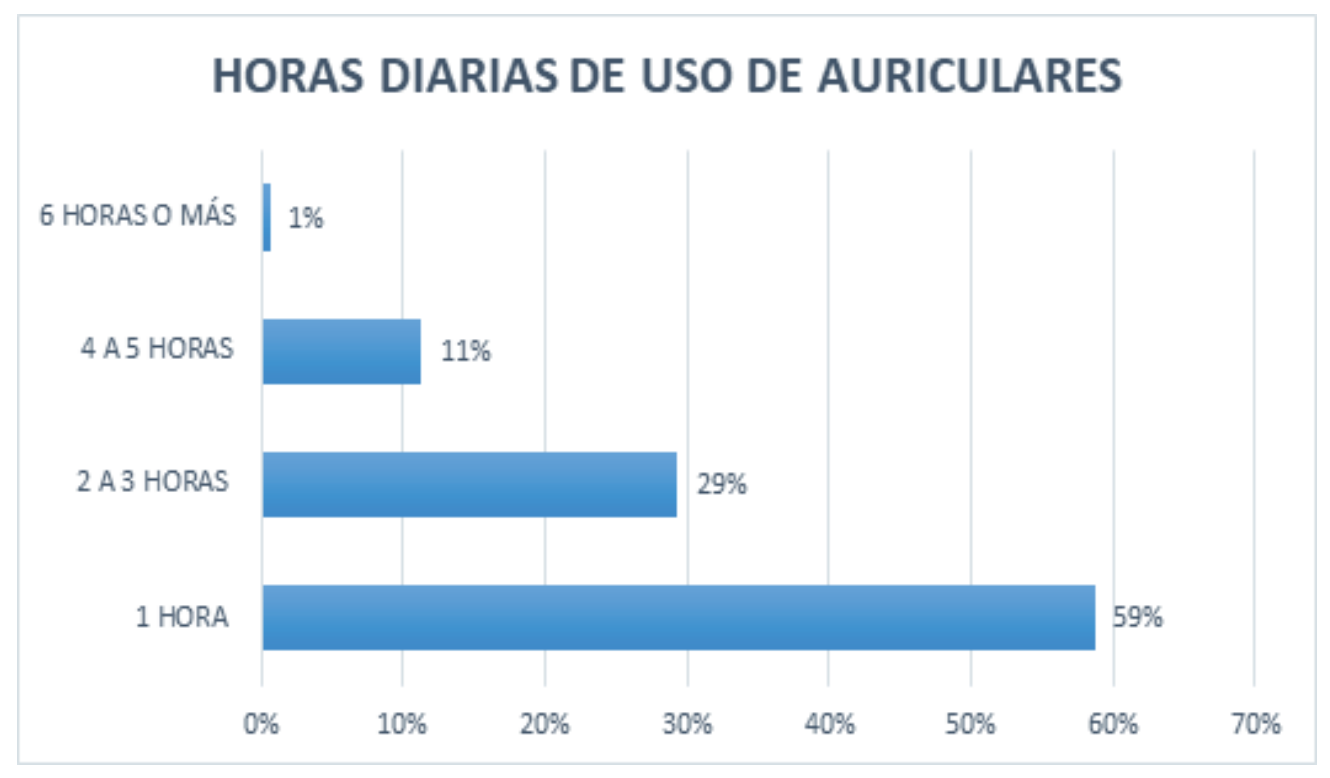

Fuente: Los Autores.

Los estudiantes de Derecho de la Universidad de Pamplona en su mayoría utilizan los audífonos 1 hora diaria representados por un 59\%, después se encuentran aquellos estudiantes que los utilizan de 2-3 horas diarias con un $29 \%$, por otro lado, aquellos que los utilizan de 4-5 horas están representados por un $11 \%$, y por último, según la muestra los estudiantes que utilizan los auriculares 6 o más horas al día están representados por el $1 \%$.

Gráfica 6. Conocimiento de los efectos del uso de auriculares en estudiantes de Derecho.

\section{VALORACIÓN SOBRE LOS EFECTOS EN EL USO DE AURICULARES}

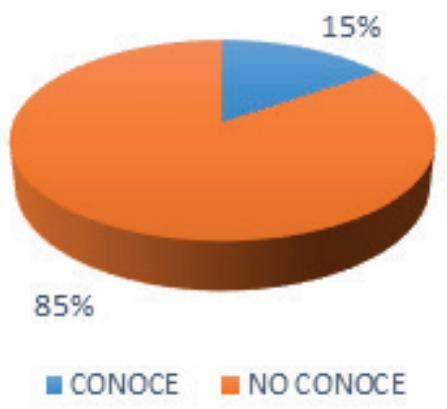

Fuente: Los Autores. 
Los estudiantes de Derecho de la Universidad de Pamplona sede principal desconocen sobre los efectos que tiene el uso de auriculares con un porcentaje del $85 \%$, por otro lado, los estudiantes que conocen sobre los efectos en la salud que genera el uso de auriculares representa el $15 \%$.

Gráfica 7. Conocimiento sobre los efectos del uso de auriculares en estudiantes de Derecho.

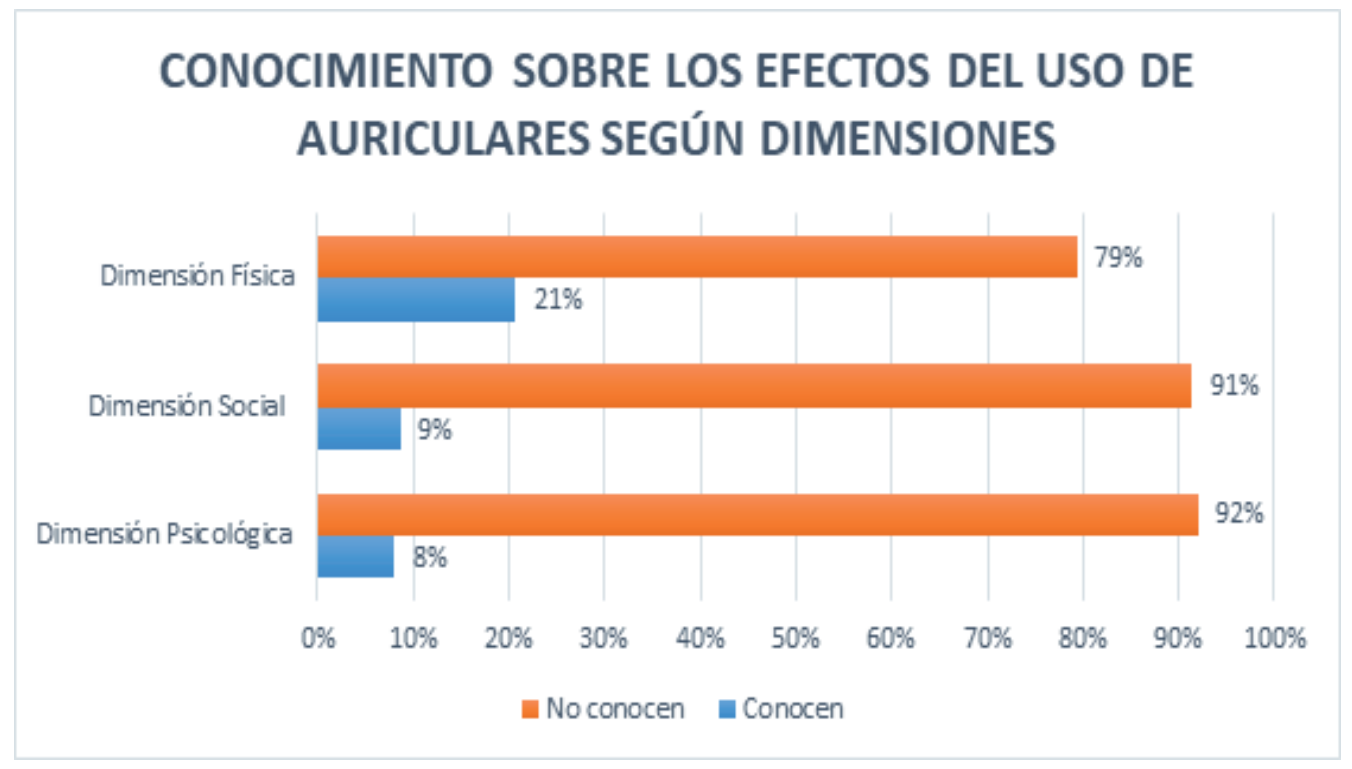

Fuente: Los Autores.

Los estudiantes de Derecho de la Universidad de Pamplona sede Principal no conocen los efectos del uso de auriculares en la dimensión física, social y psicológica con un porcentaje de 79\%, 91\% y 92\%, en contraste con un $21 \% 9 \%$ y $8 \%$ que conocen los efectos que trae el uso de auriculares en cada área.

Gráfica 8. Uso de auriculares y conocimiento de los efectos en la salud en estudiantes de Derecho.

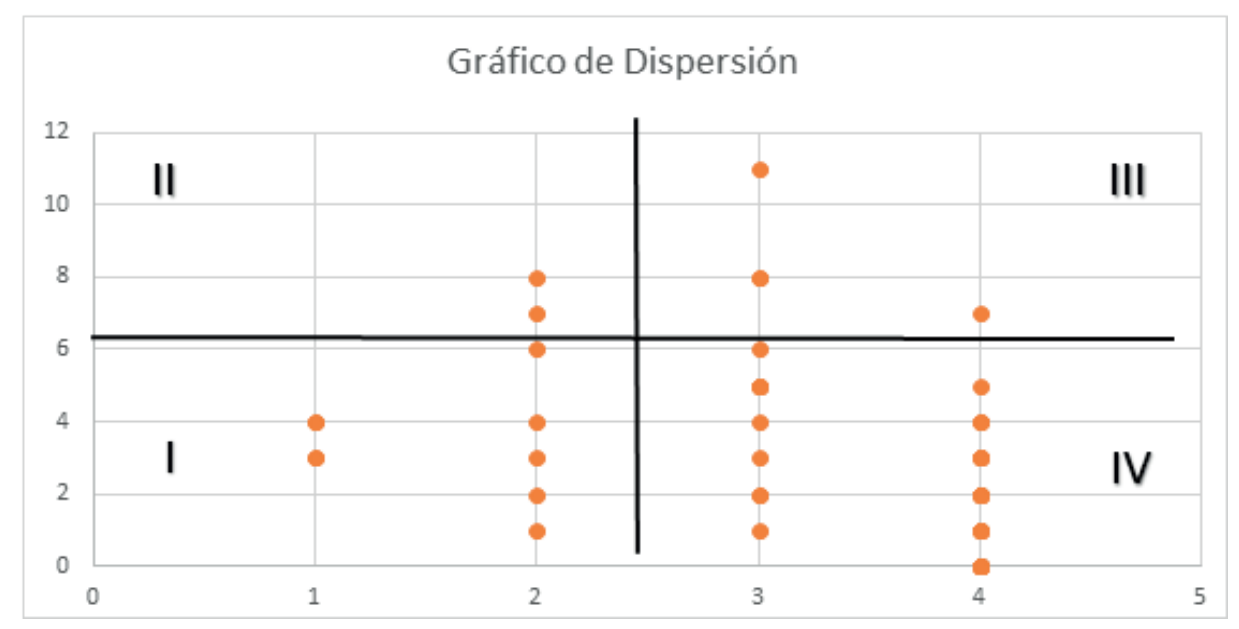

Fuente: Los Autores.

Los estudiantes de Derecho de la Universidad de Pamplona sede Principal el 37\%, hacen uso inadeRevista Científica Signos Fónicos, 2019,5(2): 97-150. ISNN 2422-1716. 
cuado y no conocen los efectos que causan el uso de los auriculares, el $11 \%$ hacen uso inadecuado, pero conocen los efectos de los auriculares, el $5 \%$ hacen un uso adecuado, pero conocen los efectos que estos causan y por último el $48 \%$ de los estudiantes hacen un uso adecuado, pero no conocen los efectos que estos dispositivos pueden llegar a causar.

\section{ARTES VISUALES}

Gráfica 9. Género en estudiantes de Artes Visuales.

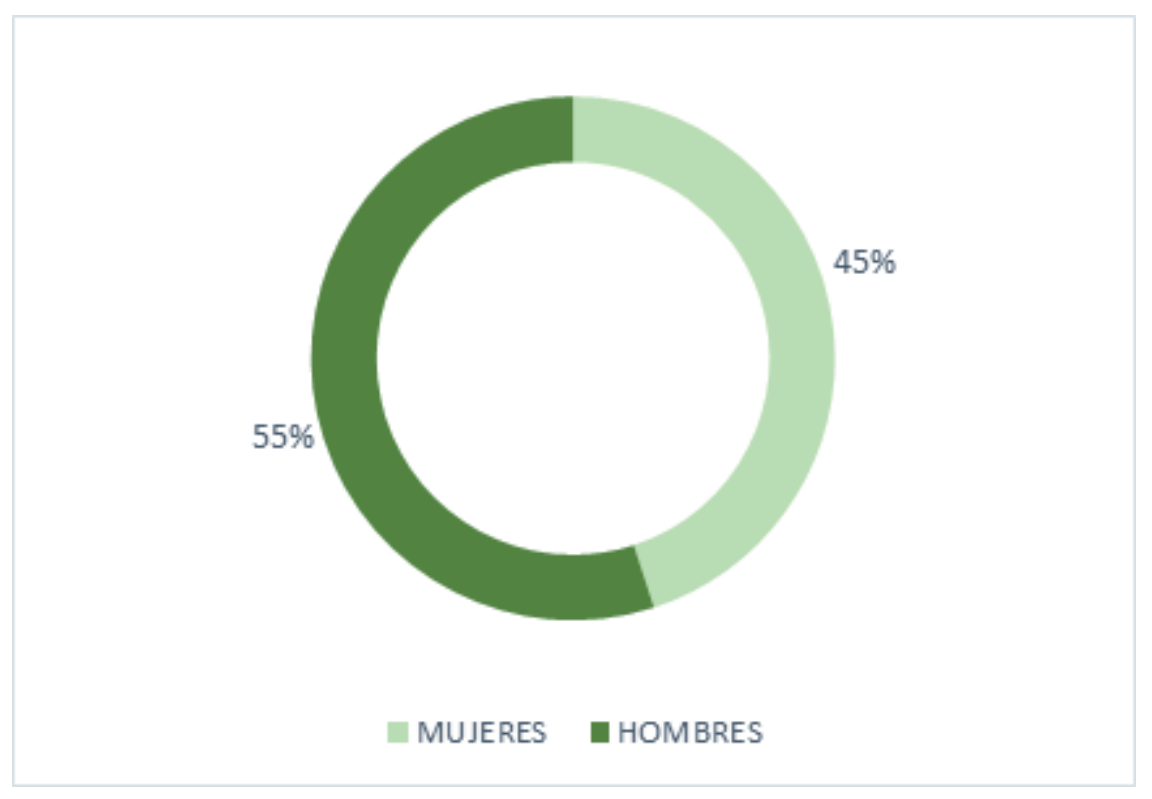

Fuente: Los Autores.

Para una muestra de 80 estudiantes pertenecientes al programa de Artes Visuales se encontró que el $55 \%$ son hombres y un $45 \%$ son mujeres, estos datos permiten afirmar que se encuentran en una proporción de género similar.

Gráfica 10. Edades de estudiantes de Artes Visuales.

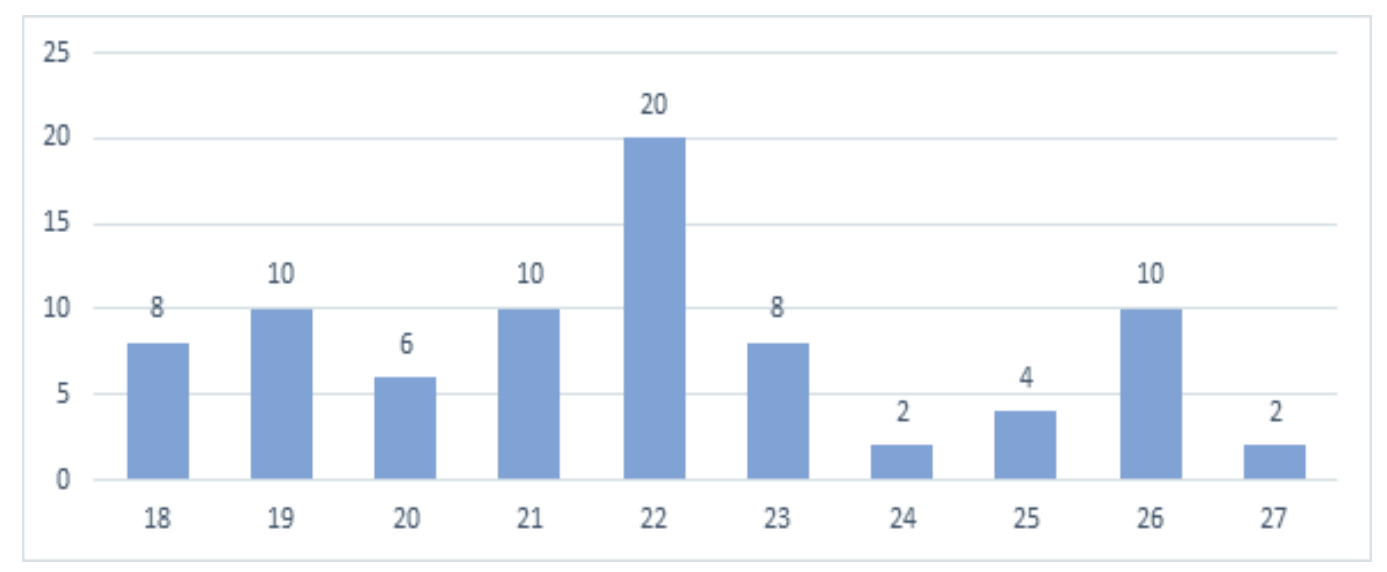

Fuente: Los Autores.

Revista Científica Signos Fónicos, 2019,5(2): 97-150. ISNN 2422-1716. 
Las edades que predominan en la carrera de Artes Visuales de la Universidad de Pamplona sede Principal están entre los 18 a 27 años, en donde el mayor número de estudiantes se encuentra en una edad de 22 años, representado por 20 estudiantes que en porcentaje representa el $25 \%$, seguido de los 21 años con 10 estudiantes representado por (12,5\%).

Gráfica 11. Uso de auriculares en estudiantes de Artes Visuales.

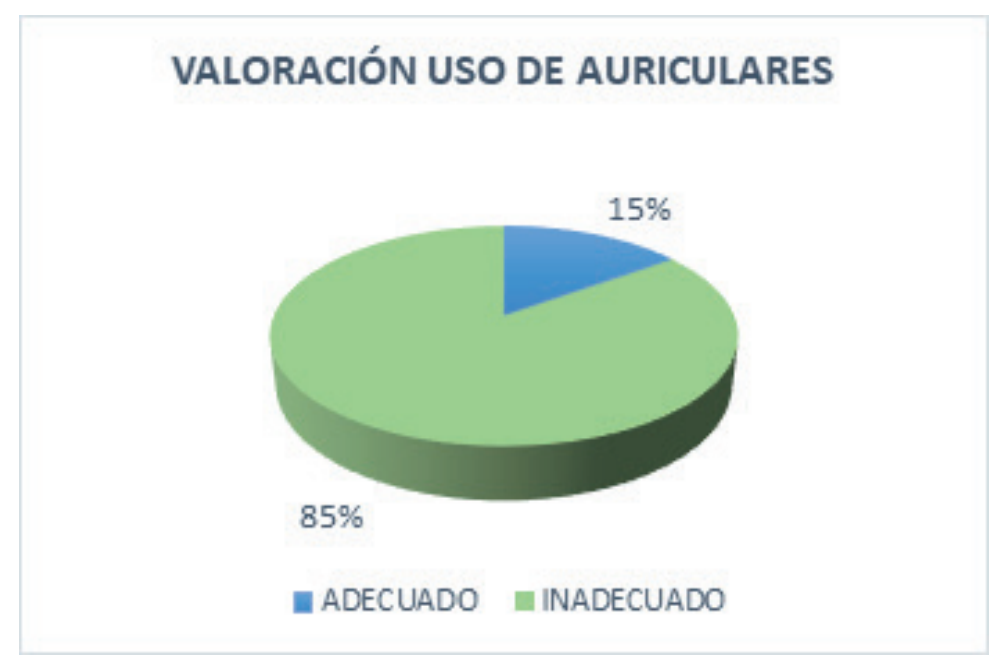

Fuente: Los Autores.

El $85 \%$ de los estudiantes de Artes Visuales de la Universidad de Pamplona sede principal hacen uso inadecuado de los auriculares, y el $15 \%$ hace uso adecuado de los auriculares.

Gráfica 12. Tipo de auriculares que utilizan los estudiantes de Artes Visuales.

\section{TIPO DE AUDIFONO}

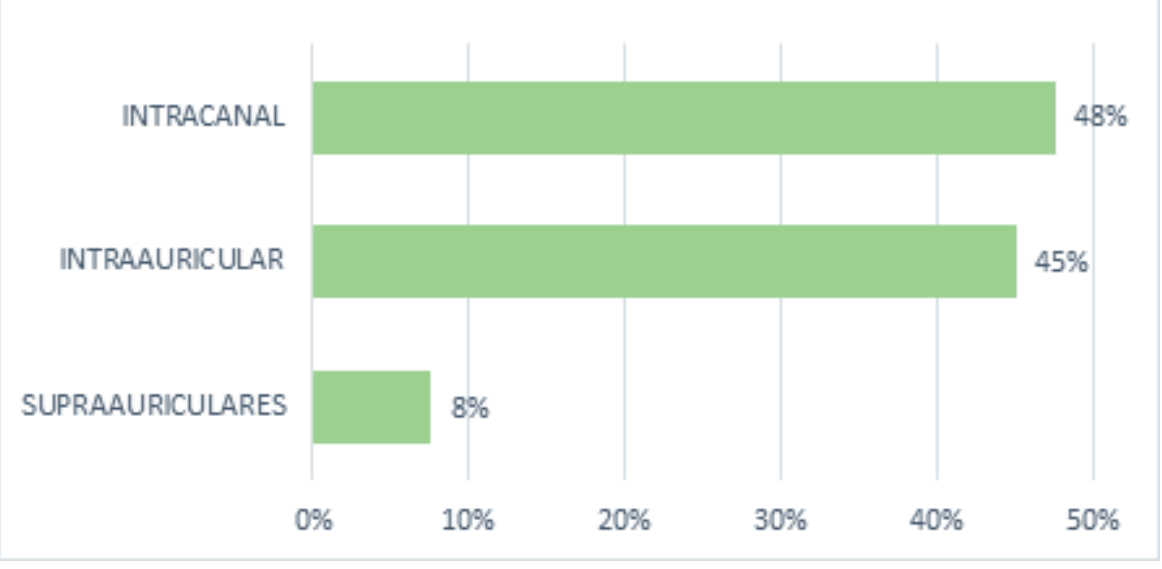

Fuente: Los Autores.

Los estudiantes de Artes Visuales de la Universidad de Pamplona sede principal hacen uso de los auriculares de tipo intracanal en un $48 \%$ seguido de aquellos estudiantes que hacen uso del tipo intrauricular con un 45\%; por otra parte, el $8 \%$ hacen uso de los tipos supraauricular. 
Gráfica 13. Horas diarias de uso de auriculares en estudiantes de Artes Visuales.

\section{HORAS DIARIAS DE USO DE AURICULARES}

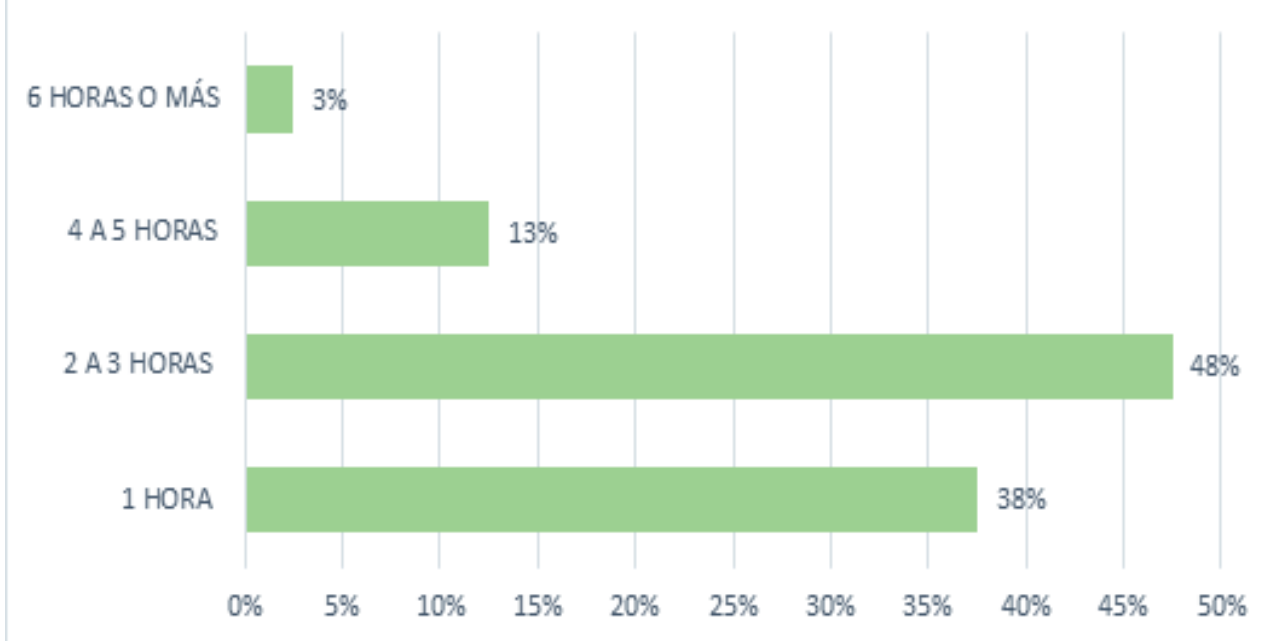

Fuente: Los Autores.

Los estudiantes de Artes Visuales de la Universidad de Pamplona sede principal en su mayoría utilizan los audífonos 2-3 horas diarias (46\%), seguido de aquellos que hacen uso de 1 hora diaria (38\%) después se encuentran aquellos que los utilizan 4 a 5 horas con un (13\%) y tan solo de un $3 \%$ de la muestra los utiliza 6 horas o más.

Gráfica 14. Conocimiento de los efectos del uso de auriculares en estudiantes de Artes Visuales.

\section{VALORACIÓN SOBRE LOS EFECTOS EN EL USO DE AURICULARES}

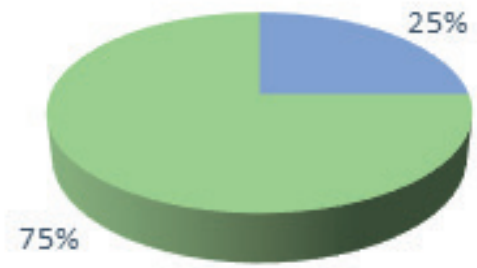

$\because$ CONOCE $\quad$ NOCONOCE

Fuente: Los Autores.

Los estudiantes de Artes visuales de la Universidad de Pamplona sede principal desconocen los efectos que tiene el uso de auriculares en la salud, ya que el $75 \%$ no conocen los efectos, y el $25 \%$ conocen los efectos que causan en la salud. 
Gráfica 15. Conocimiento sobre los efectos del uso de auriculares en estudiantes de Artes Visuales.

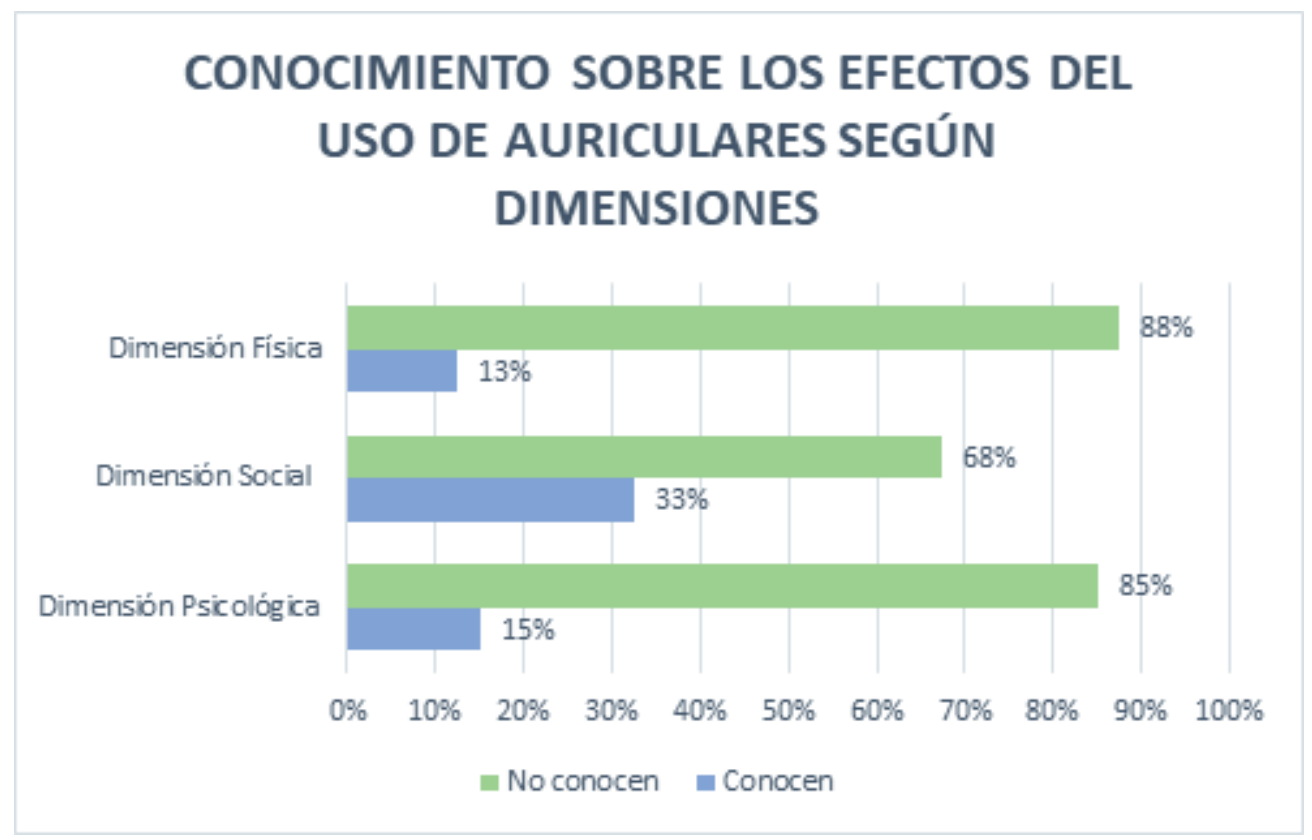

Fuente: Los Autores.

Los estudiantes de Artes Visuales de la Universidad de Pamplona sede Principal el 88\% no conocen los efectos del uso de auriculares, en la dimensión física, y así mismo en la dimensión social (85\%), sin embargo, el $68 \%$ de los estudiantes conocen los efectos psicológicos.

Gráfica 16. Uso de auriculares y conocimiento de los efectos en la salud en estudiantes de Artes Visuales.

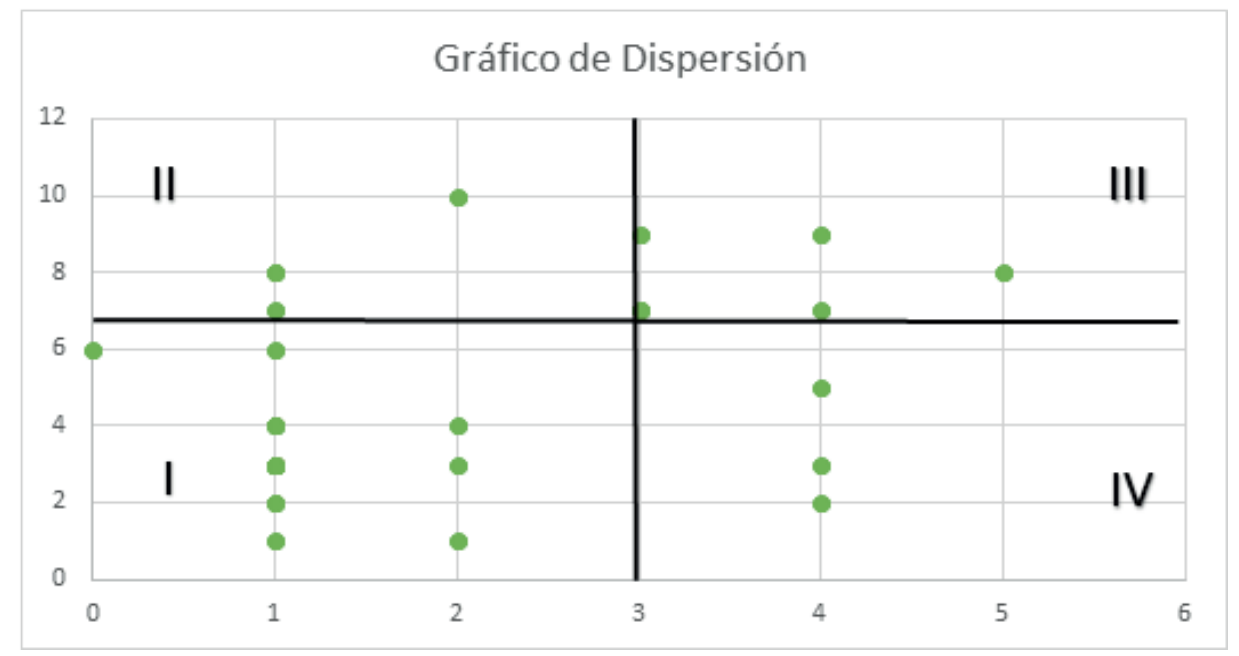

Los estudiantes de Artes Visuales de la Universidad de Pamplona sede Principal el 68\%, hacen uso inadecuado y no conocen los efectos que causan el uso de los auriculares, el $18 \%$ hacen uso inade- 
cuado, pero conocen los efectos de los auriculares, el $8 \%$ hacen un uso adecuado, pero conocen los efectos que estos causan y por último el $8 \%$ de los estudiantes hacen un uso adecuado, pero no conocen los efectos que estos dispositivos pueden llegar a causar.

\section{FILOSOFÍA}

Gráfica 17. Género estudiantes del programa Filosofía

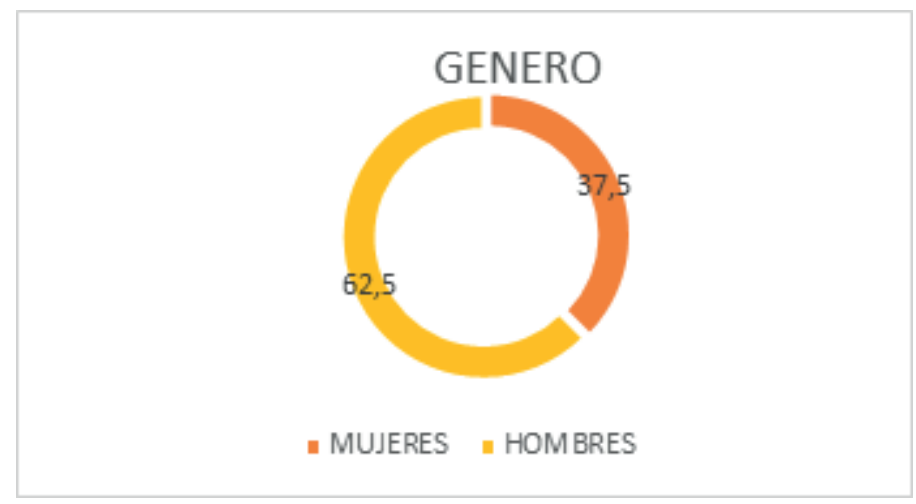

Fuente: Los Autores.

Para una muestra de 80 estudiantes pertenecientes al programa de Filosofía donde se encontró que el $62,5 \%$ son hombres y un $37,5 \%$ son mujeres, se observa que una proporción mayor de la población está representada por hombres y en menor medida por mujeres. por otro lado, las edades de la muestra están representadas de manera porcentual en el gráfico a continuación.

Gráfica 18. Edades en estudiantes de Filosofía.

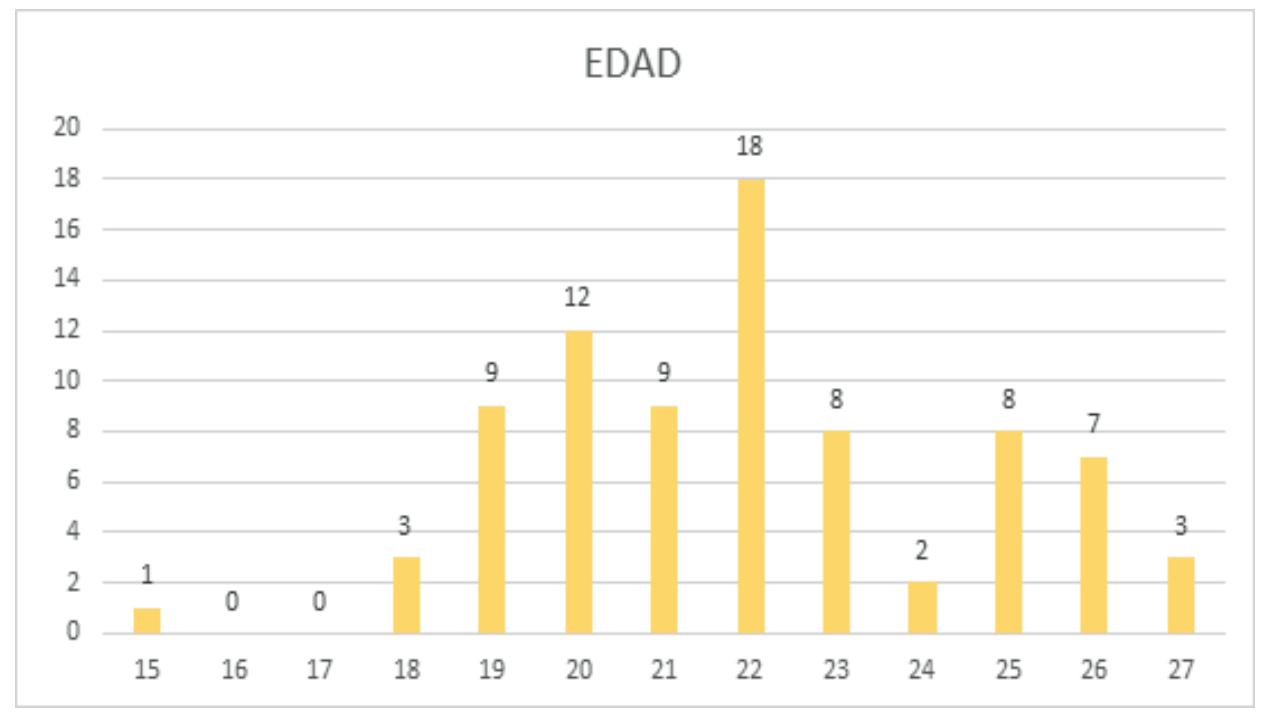

Fuente: Los Autores.

Las edades que predominan en la carrera de Filosofía de la Universidad de Pamplona sede Principal están entre los 15 a 27 años, en donde el mayor número de estudiantes se encuentra en una edad de 22 años, representado por el 27,5\%, seguido de los 20 años 15\%, y los 21 con un 11,25\%; en menor medida se encuentra un rango de 15-17 años.

Revista Científica Signos Fónicos, 2019,5(2): 97-150. ISNN 2422-1716. 
Gráfica 19. Uso de auriculares en estudiantes de Filosofía.

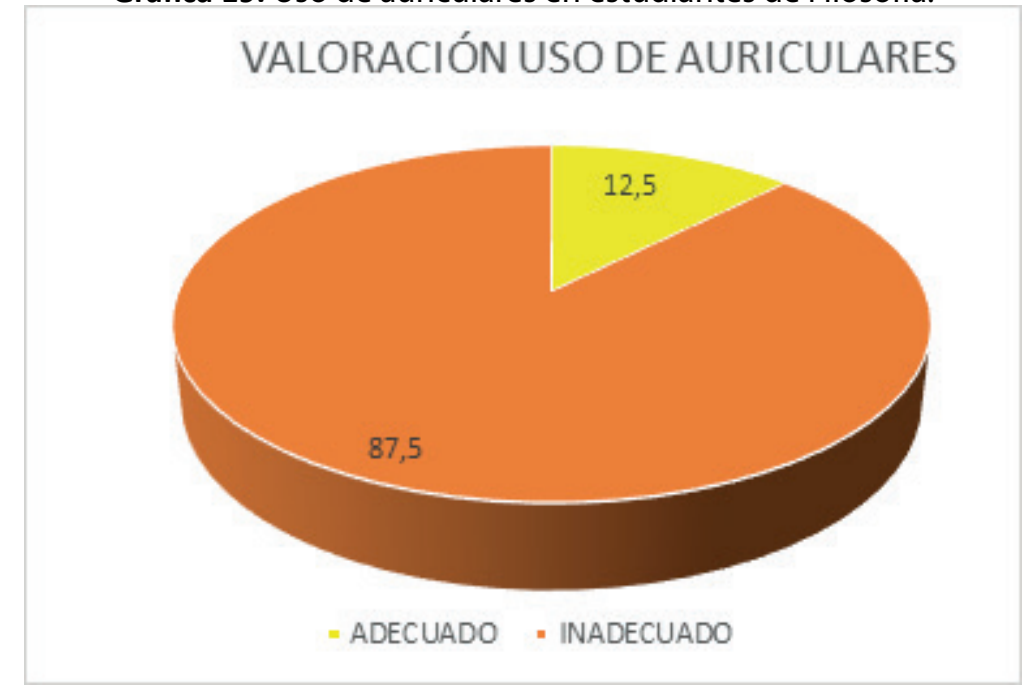

Fuente: Los Autores.

Los estudiantes de Filosofía de la Universidad de Pamplona sede principal hacen uso inadecuado de los auriculares, representado por un $87,5 \%$ de la muestra total tomada para el estudio; en contraste, solo el $12,5 \%$ de los estudiantes de este programa hacen un uso adecuado.

Gráfica 20. Tipo de auriculares que utilizan los estudiantes de Filosofía.

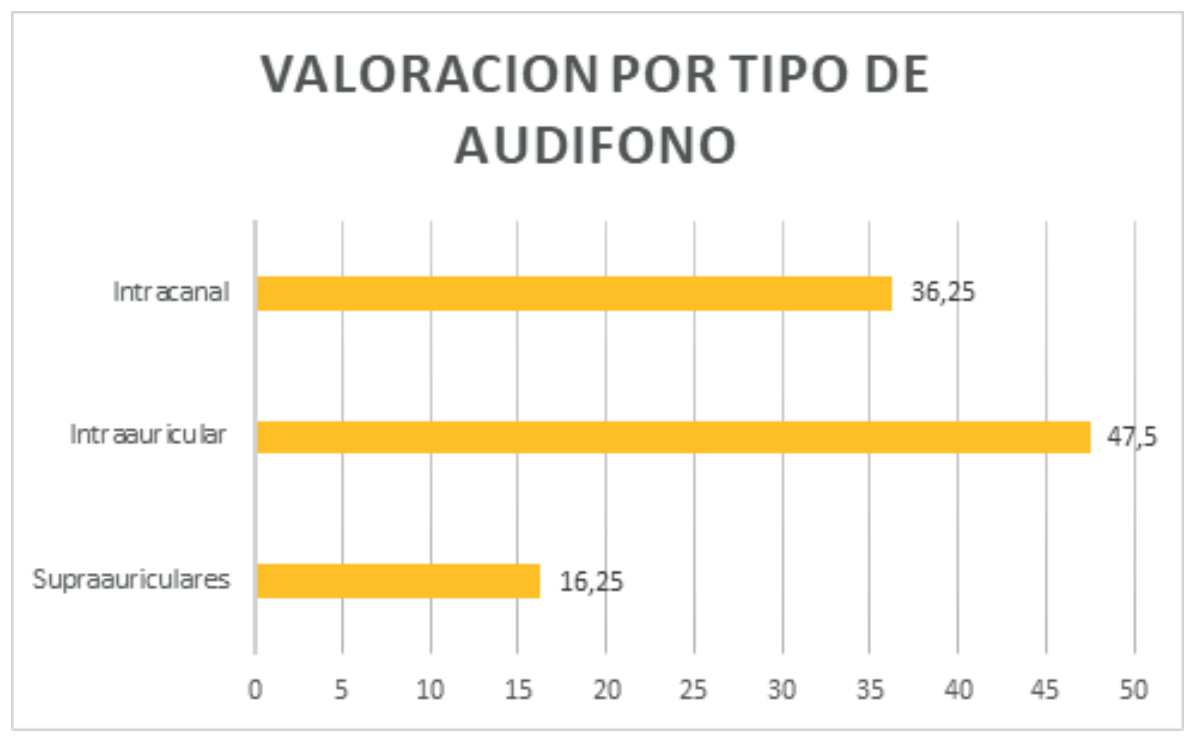

Fuente: Los Autores.

Así mismo, los estudiantes del programa de Filosofía en mayor medida hacen uso de los auriculares de tipo intraauricular en un 47,5\% seguido de aquellos estudiantes que hacen uso del tipo intracanal con un $36,25 \%$; luego se encuentran aquellos que hacen uso del tipo supraauriculares representado por un $16,25 \%$. 
Gráfica 21. Horas de uso diarias de uso de auriculares en estudiantes de Filosofía.

\section{Horas diarias de uso de auriculares}

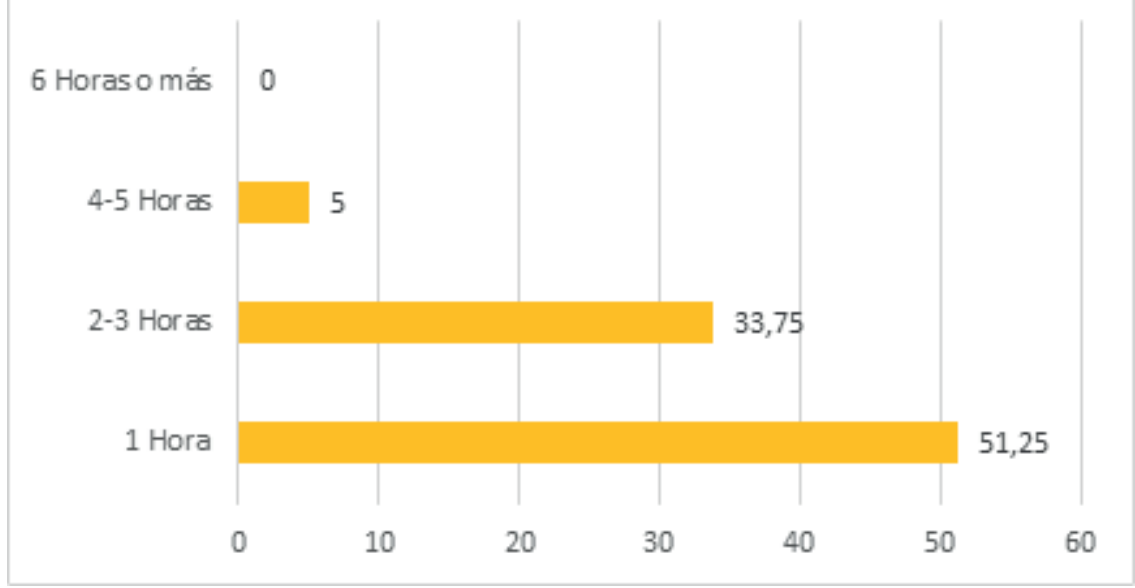

Fuente: Los Autores.

Los estudiantes de Filosofía de la Universidad de Pamplona sede principal en su mayoría utilizan los audífonos 1 hora diaria con un $51,25 \%$, seguido de aquellos que hacen uso de 2 a 3 horas diarias con un $33,75 \%$ y por últimos se encuentran aquellos que los utilizan de $4-5$ horas con un 5 . Según la muestra, no hay estudiantes que utilicen los auriculares 6 o más horas al día.

Gráfica 22. Efectos en el uso de auriculares en estudiantes de Filosofía.

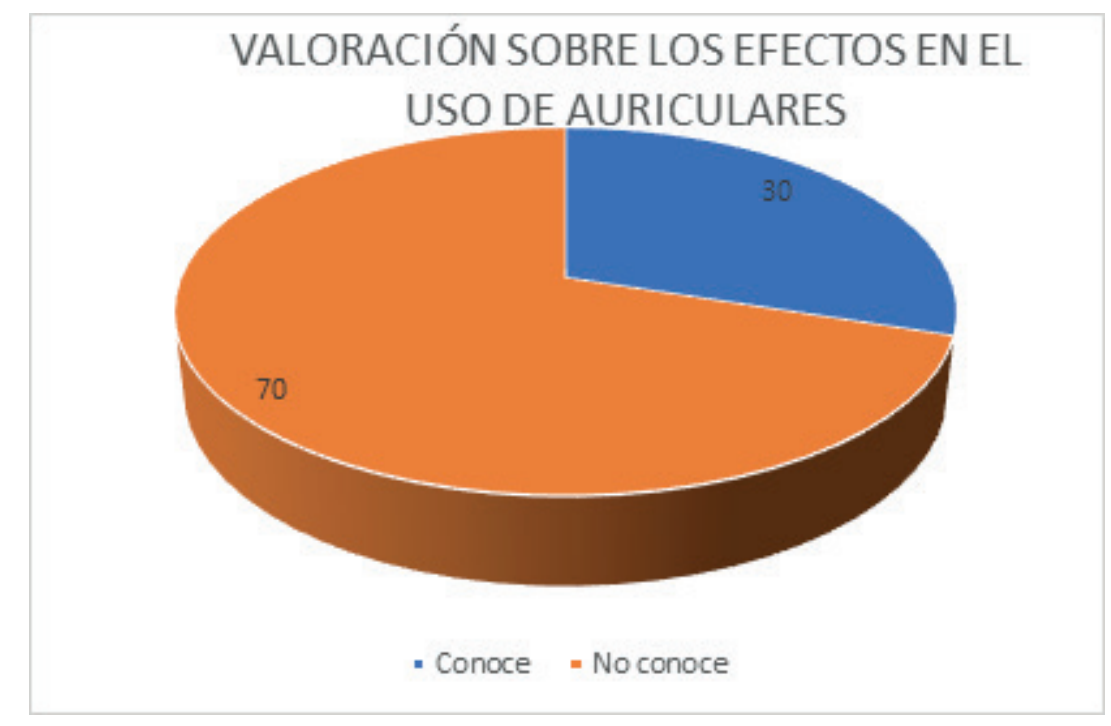

Fuente: Los Autores.

Los estudiantes de Filosofía de la Universidad de Pamplona sede principal desconocen sobre los efectos que tiene el uso de auriculares en la salud, con un porcentaje de $70 \%$, por otro lado, los estudiantes que conocen sobre los efectos en la salud generan el uso de auriculares repercute al $30 \%$. 
Gráfica 23. Conocimiento sobre los efectos del uso de auriculares en estudiantes de Filosofía.

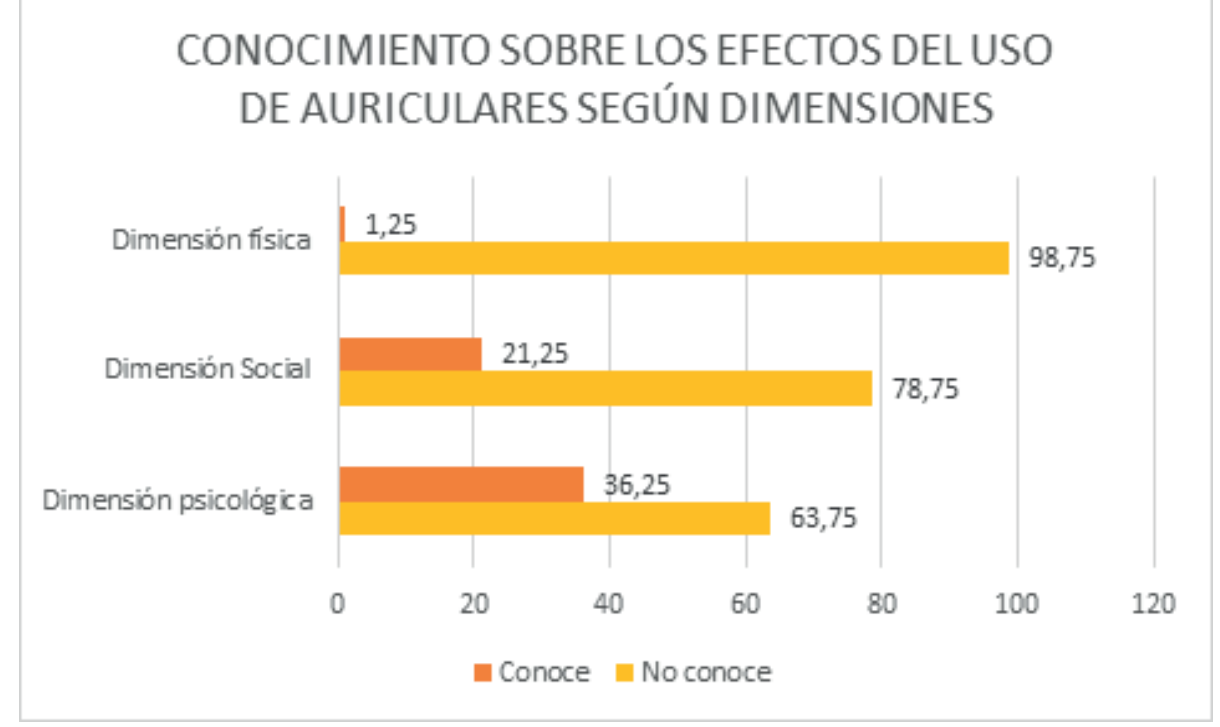

Fuente: Los Autores.

Los estudiantes de Filosofía de la Universidad de Pamplona sede Principal no conocen los efectos que generan en la salud el uso excesivo de auriculares, en la dimensión física se da un resultado del 98,75\%, en esta dimensión física con un resultado del 1,25\% conoce los efectos, en la dimensión social un resultado $78,75 \%$ y referentes a la dimensión psicológica con un 63,75\%.

Gráfica 24. Uso de auriculares y conocimiento de los efectos en la salud en estudiantes de Filosofía.

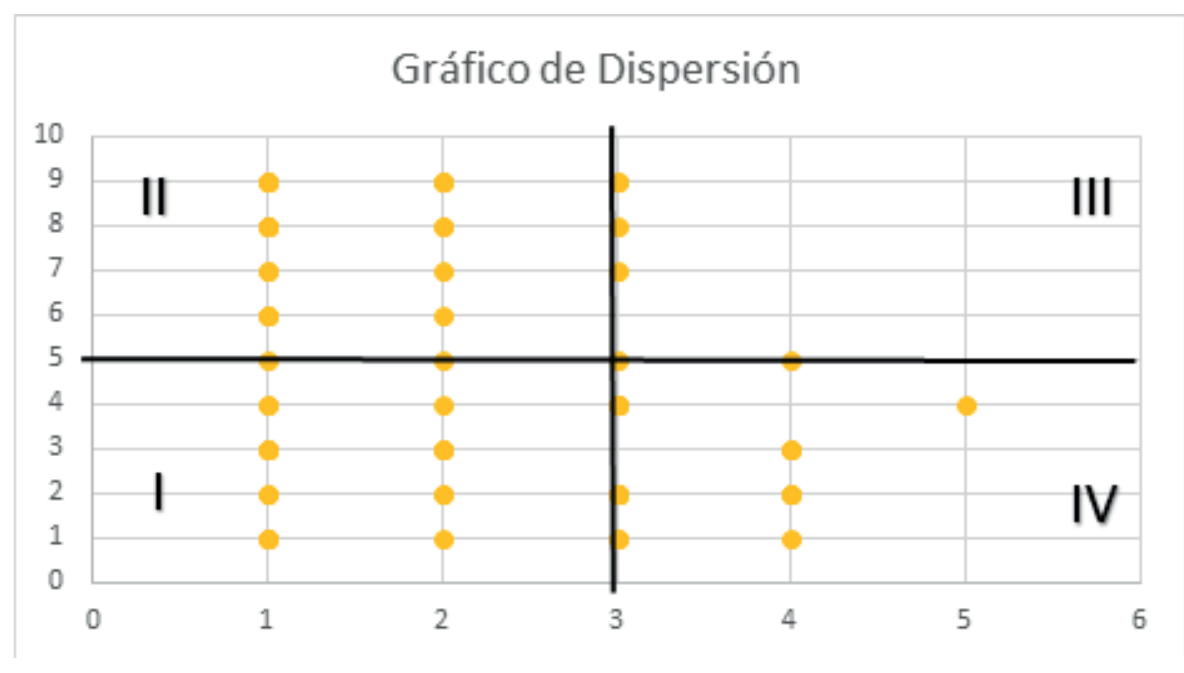

Fuente: Los Autores.

Los estudiantes de Filosofía de la Universidad de Pamplona sede Principal el $58 \%$, hacen uso inadecuado y no conocen los efectos que causan el uso de los auriculares, el 30\% hacen uso inadecuado, pero

Revista Científica Signos Fónicos, 2019,5(2): 97-150. ISNN 2422-1716. 
conocen los efectos de los auriculares, por otra parte, no hay estudiantes que hagan un uso adecuado y conozcan los efectos de su uso y por último el $48 \%$ de los estudiantes hacen un uso adecuado, pero no conocen los efectos que estos dispositivos pueden llegar a causar.

\section{COMUNICACIÓN SOCIAL}

Gráfica 25. Género estudiantes del programa de Comunicación Social.

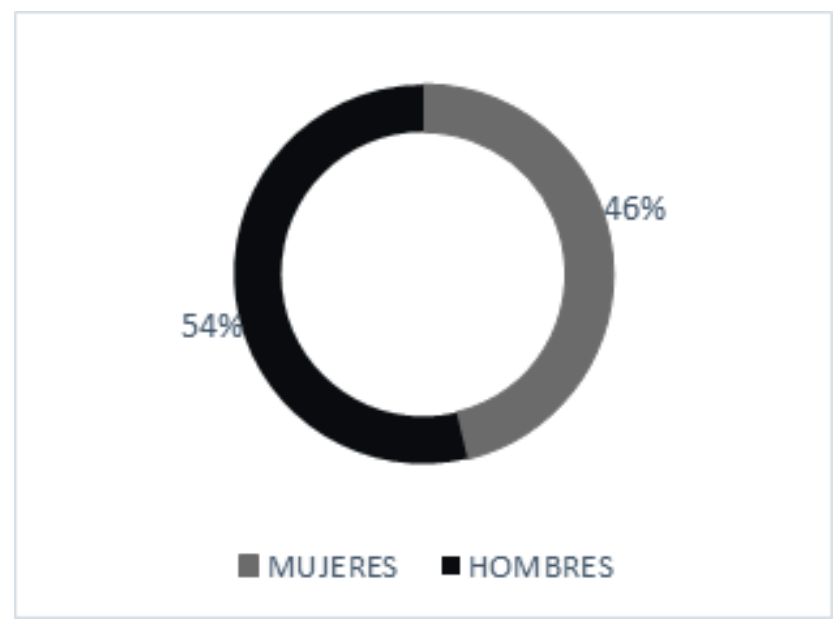

Fuente: Los Autores.

Para una muestra de 80 estudiantes pertenecientes al programa de Comunicación Social se evidencio que el $54 \%$ son hombres y un $46 \%$ son mujeres, se observa que una porción mayor de la población está representada por hombres y en menor medida por mujeres.

Gráfico 26. Edades de estudiantes en Comunicación Social.

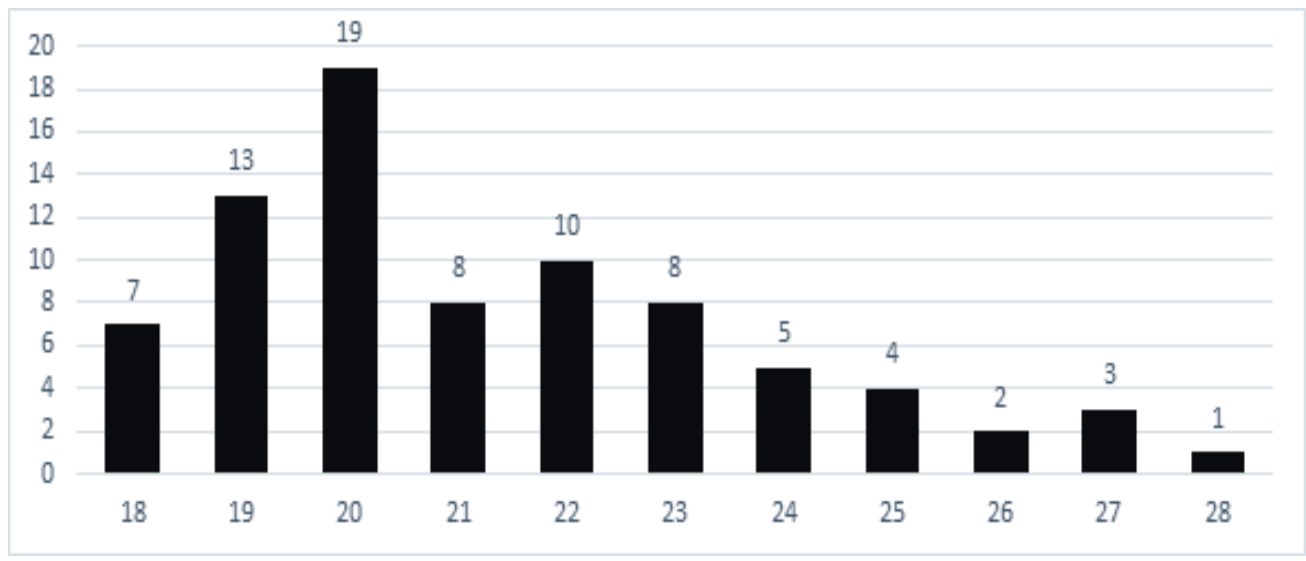

Fuente: Los Autores.

Las edades que predominan en el programa de Comunicación Social están entre los 18 a 28 años, en donde el mayor número de estudiantes se encuentra en una edad de 20 años, representado por $23,75 \%$, seguido de los 19 años (16,25\%); y los 21 y 23 años con un porcentaje de $10-12,5$ y $10 \%$ respectivamente. y en menor medida se encuentran un rango de 18 años y de 24 a 28 años. 
Gráfico 27. Uso de auriculares en estudiantes de Comunicación Social.

\section{VALORACIÓN USO DE AURICULARES}

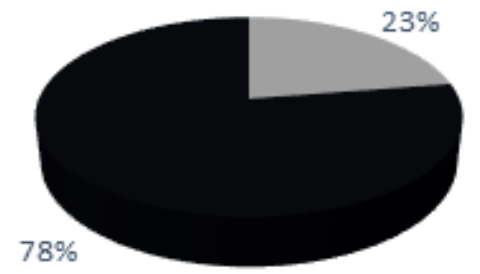

aDECUADO $\boldsymbol{\square}$ INADECUADO

Fuente: Los Autores.

Los estudiantes de Comunicación Social, hacen uso inadecuado de los auriculares, representado por un $78 \%$ de la muestra total tomada para el estudio; en contraste solo el $23 \%$ de los estudiantes hacen uso adecuado de los auriculares

Gráfica 28.Tipo de auriculares que utilizan los estudiantes de Comunicación Social.

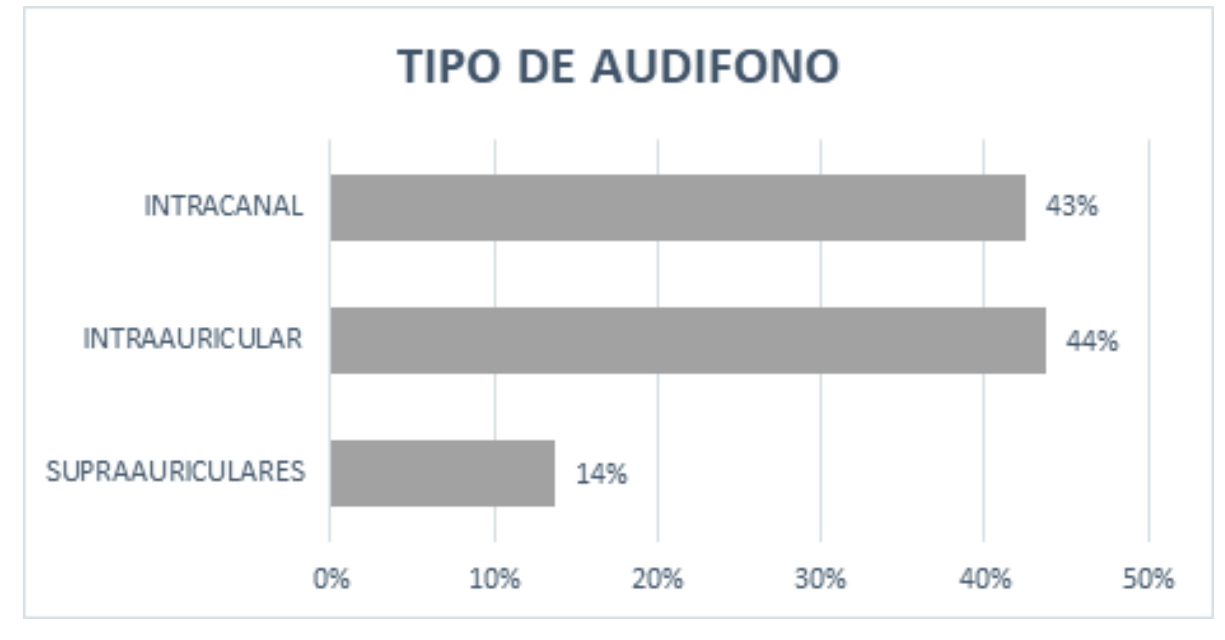

Fuente: Los Autores.

Los estudiantes de Comunicación Social en mayor medida hacen uso de los auriculares de tipo intraauricular e intracanal en la misma proporción de $44 \%$ y $43 \%$ respectivamente; luego se encuentran aquellos que hacen uso de supraauricular en menor medida con un $14 \%$. 
Gráfica 29. Efectos en el uso de auriculares en estudiantes de Comunicación Social.

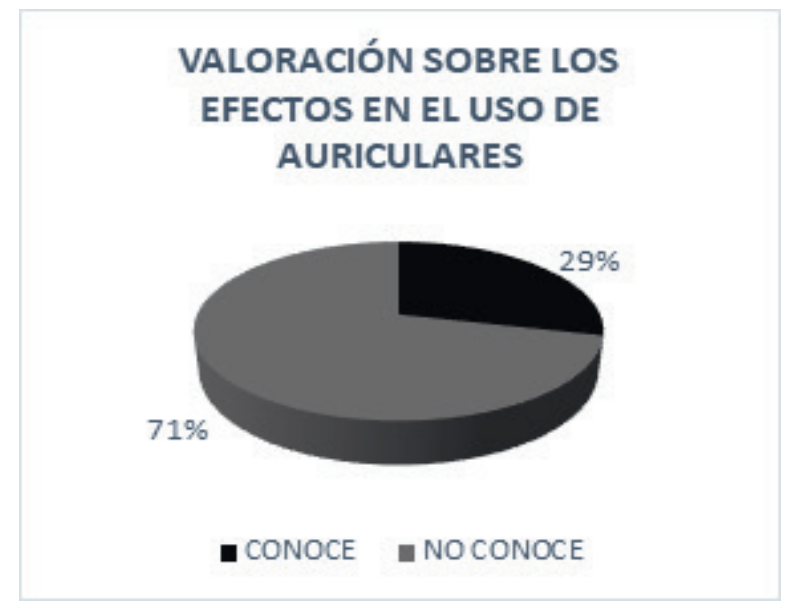

Fuente: Los Autores.

Los estudiantes de Comunicación Social desconocen los efectos que causan en la salud, ya que el $71 \%$ no conocen los efectos, en contraste que el $29 \%$ si conocen los efectos que causan estos dispositivos en la salud.

Gráfica 30.Valoración sobre los efectos en el uso de auriculares en estudiantes de Comunicación Social.

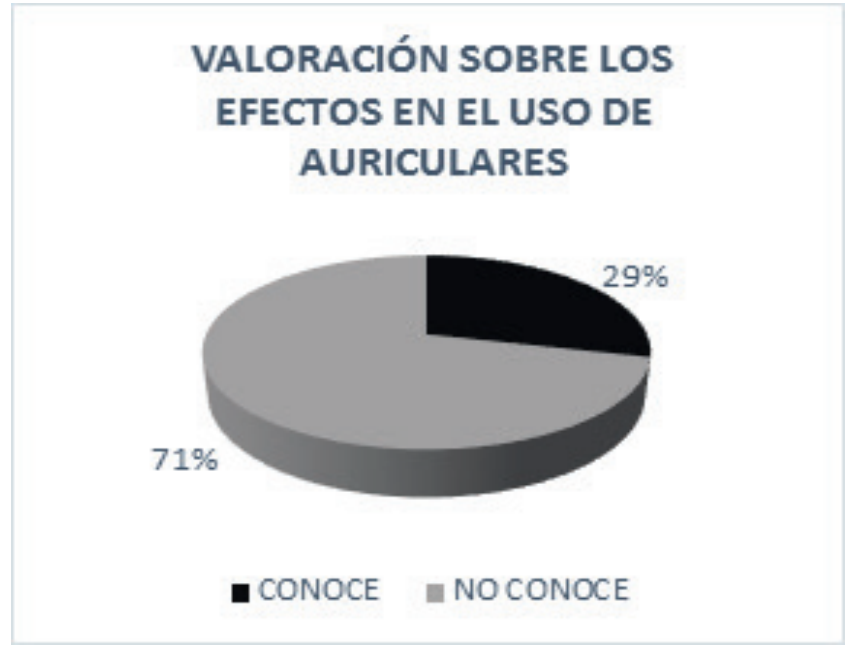

Fuente: Los Autores.

Los estudiantes de Comunicación Social desconocen los efectos que ocasionan en la salud, ya que el $71 \%$ no conocen los efectos, en contraste que el $29 \%$ si conocen los efectos que causan estos dispositivos en la salud. 
Gráfica 31. Conocimiento sobre los efectos del uso de auriculares en estudiantes de Comunicación Social

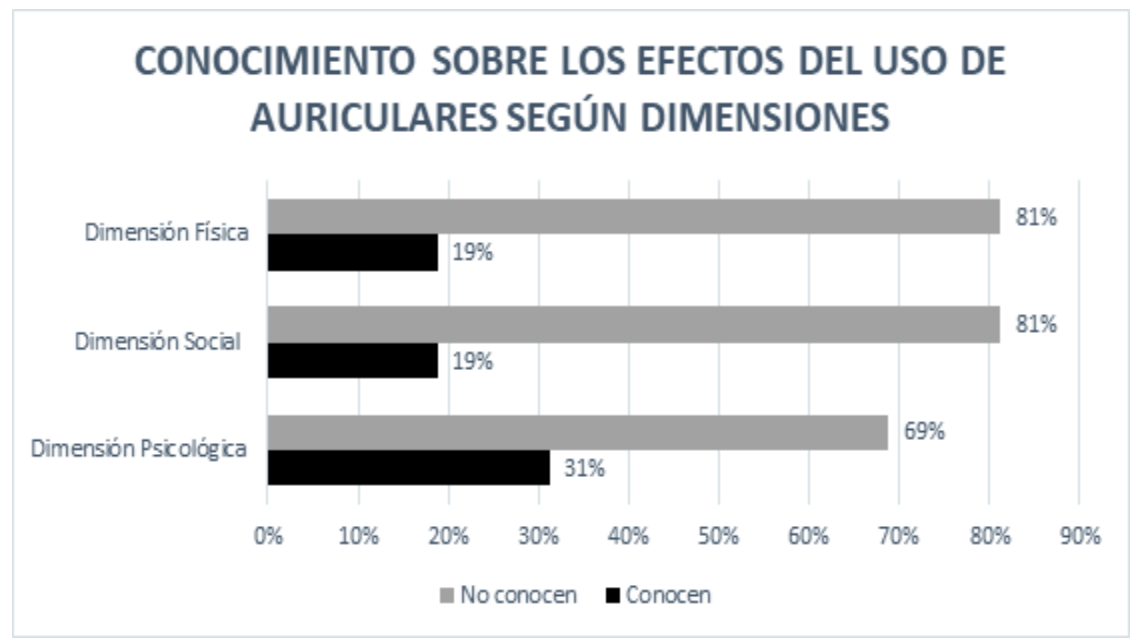

Fuente: Los Autores.

Los estudiantes de Comunicación Social el $81 \%$ no conocen los efectos del uso de auriculares en la dimensión física, así mismo en la dimensión social $81 \%$ y el $69 \%$ en la dimensión psicológica.

Gráfica 32. Uso de auriculares y conocimiento de los efectos en la salud en estudiantes de Comunicación Social.

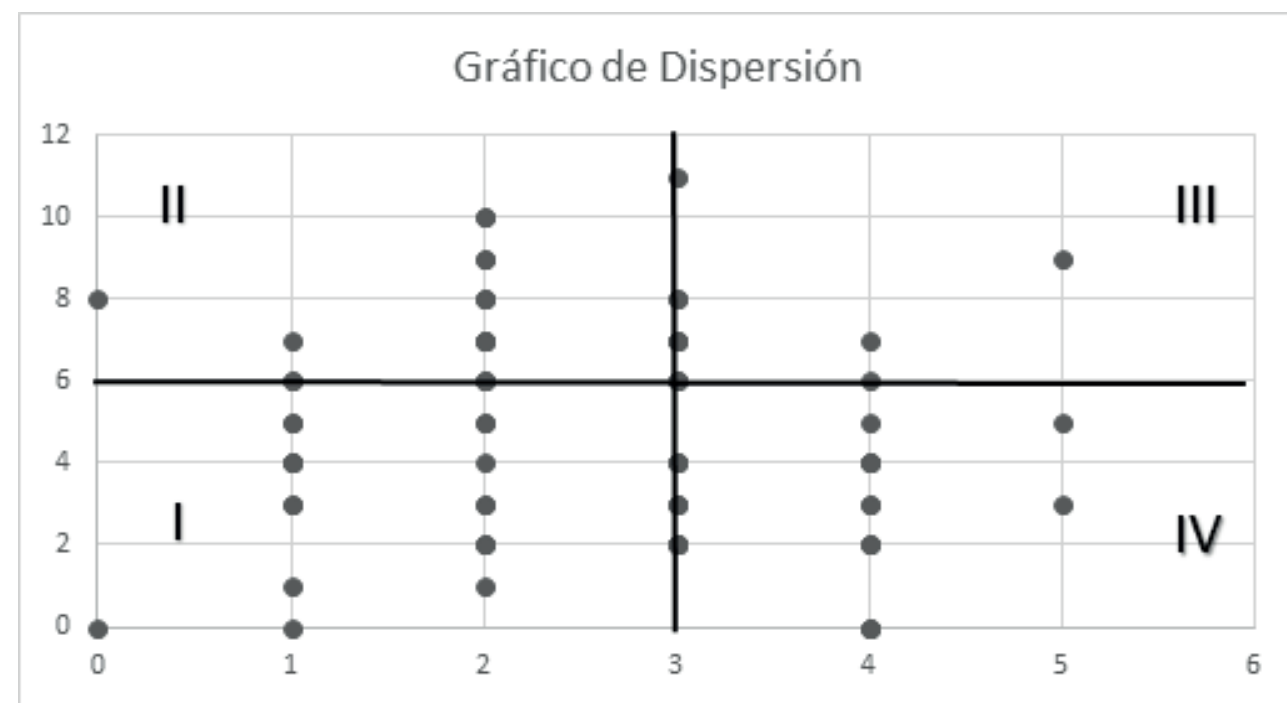

Fuente: Los Autores.

Los estudiantes de Comunicación Social de la Universidad de Pamplona sede Principal el 51\%, hacen uso inadecuado y no conocen los efectos que causan el uso de los auriculares, el $26 \%$ hacen uso inadecuado, pero conocen los efectos de los auriculares, el $3 \%$ hacen un uso adecuado, pero conocen los efectos que estos causan y por último el $20 \%$ de los estudiantes hacen un uso adecuado, pero no conocen los efectos que estos dispositivos pueden llegar a causar. 


\section{MÚSICA}

Gráfica 33. Género estudiantes del programa de Música.

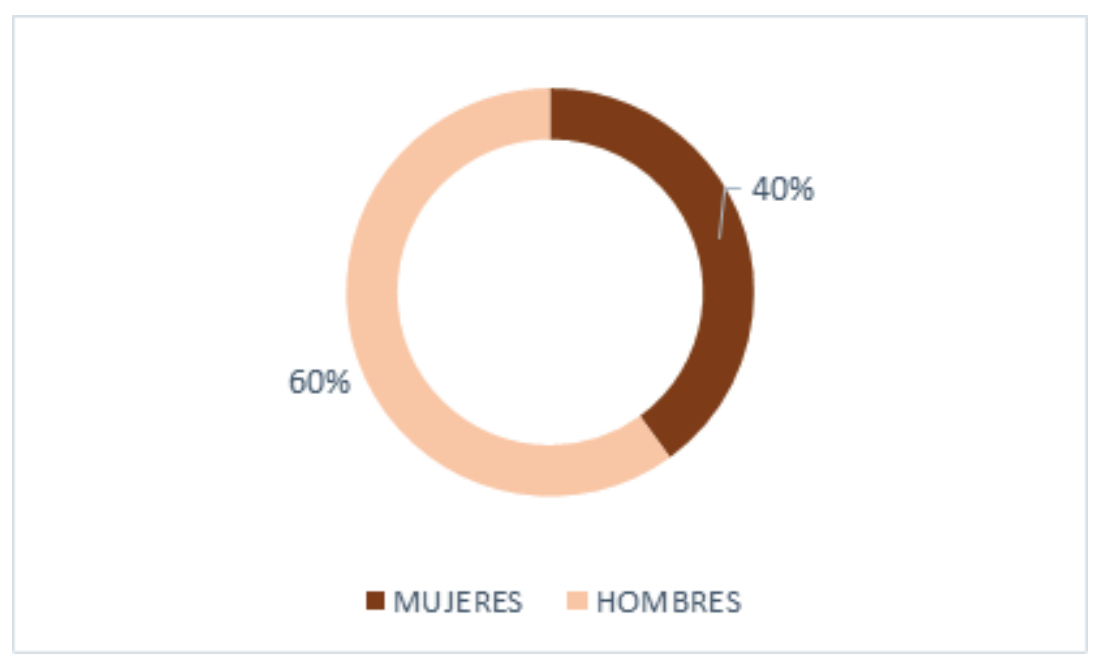

Fuente: Los Autores.

Para una muestra de 80 estudiantes pertenecientes al programa de Música se encontró que el $60 \%$ son hombres y un $40 \%$ son mujeres, siendo más representativa la muestra poblacional masculina.

Gráfica 34. Edades en estudiantes de Música.

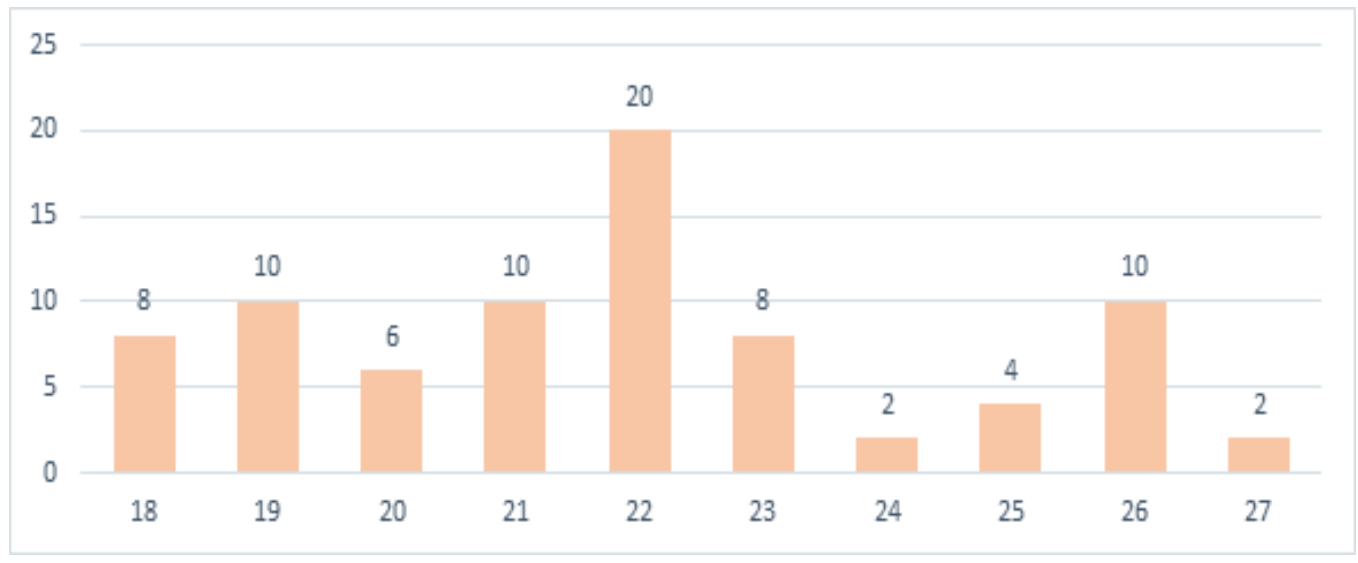

Fuente: Los Autores.

Las edades que predominan en la carrera de Música de la Universidad de Pamplona sede Principal están entre los 18 a 27 años, en donde el mayor número de estudiantes se encuentra en una edad de 20 años, representado por 20 estudiantes que en porcentaje reflejan el 25\%, seguido de los 19 y 21 años con 10 estudiantes representado por (12,5\%) cada edad. Cabe resaltar que en la edad de 18 a 21 años existe una frecuencia similar de la edad. 
Gráfica 35. Valoración uso de auriculares en estudiantes de Música.

\section{VALORACIÓN USO DE AURICULARES}

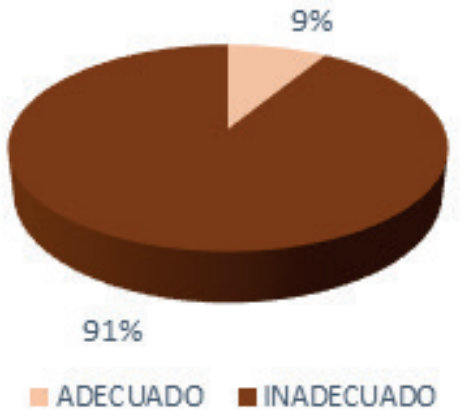

Fuente: Los Autores.

Los estudiantes de Música de la Universidad de Pamplona sede principal hacen uso inadecuado de los auriculares en mayor proporción, en porcentaje está dado por $91 \%$ por otra parte el uso inadecuado de los auriculares solo se representa por un $9 \%$.

Gráfica 36. Valoración por tipo de audífono en estudiantes de Música.

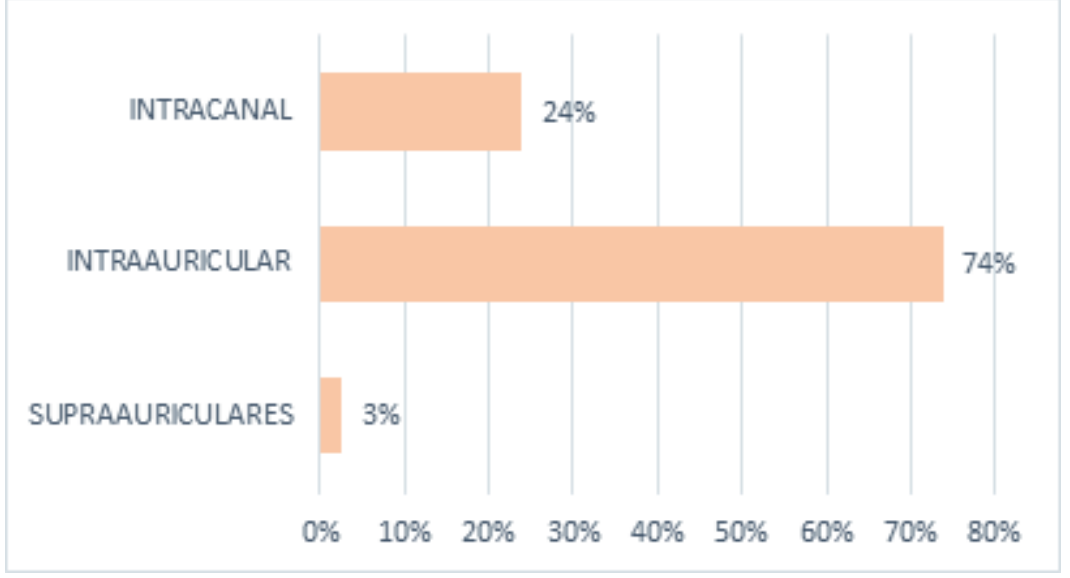

Fuente: Los Autores.

Así mismo, los estudiantes de Música de la Universidad de Pamplona sede principal hacen uso de los auriculares de tipo intraauricular en una proporción mayor, representada por $74 \%$, seguido se encuentra que el auricular de tipo intracanal el cual es el segundo más usado en este programa, aunque existe una gran diferencia entre intraauricular e intracanal del 50\%; por último, se encuentran los supraauriculares que solo están representados por un 3\% de la muestra poblacional. 
Gráfica 37. Horas de uso diarias de uso de auriculares en estudiantes de Música.

\section{HORAS DIARIAS DE USO DE AURICULARES}

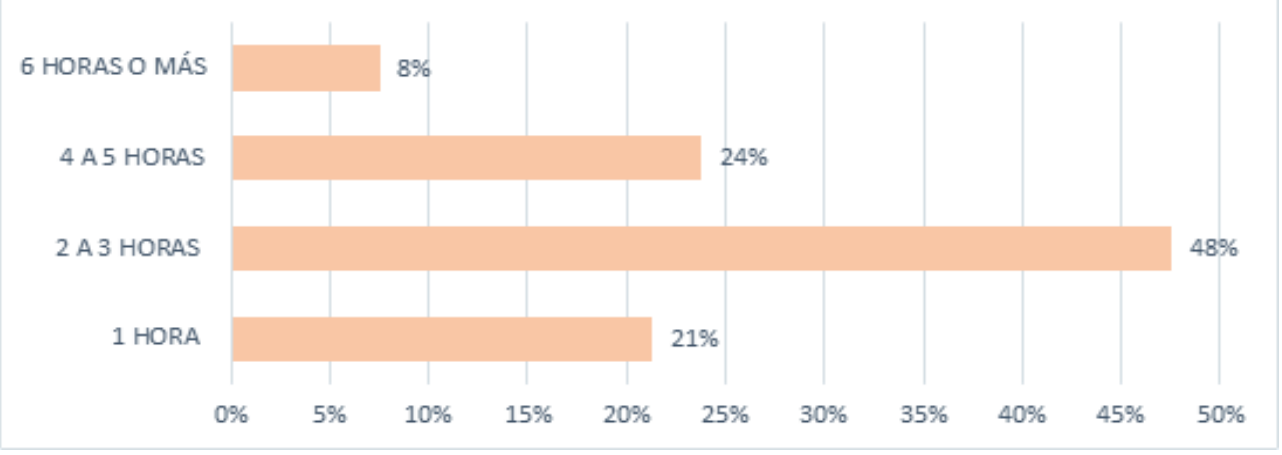

Fuente: Los Autores.

Los estudiantes de Música de la Universidad de Pamplona sede principal en su mayoría utilizan los audífonos 2-3 horas diarias (48\%), luego se encuentran aquellos que usan los auriculares alrededor de 4 a 5 horas representado con un (24\%) seguido de los estudiantes que utilizan por una hora diaria (21\%), y por último se encuentran aquellos que los utilizan 6 horas o más, que están representados por un $8 \%$.

Gráfica 38. Valoración sobre el efecto de uso de auriculares en estudiantes de Música.

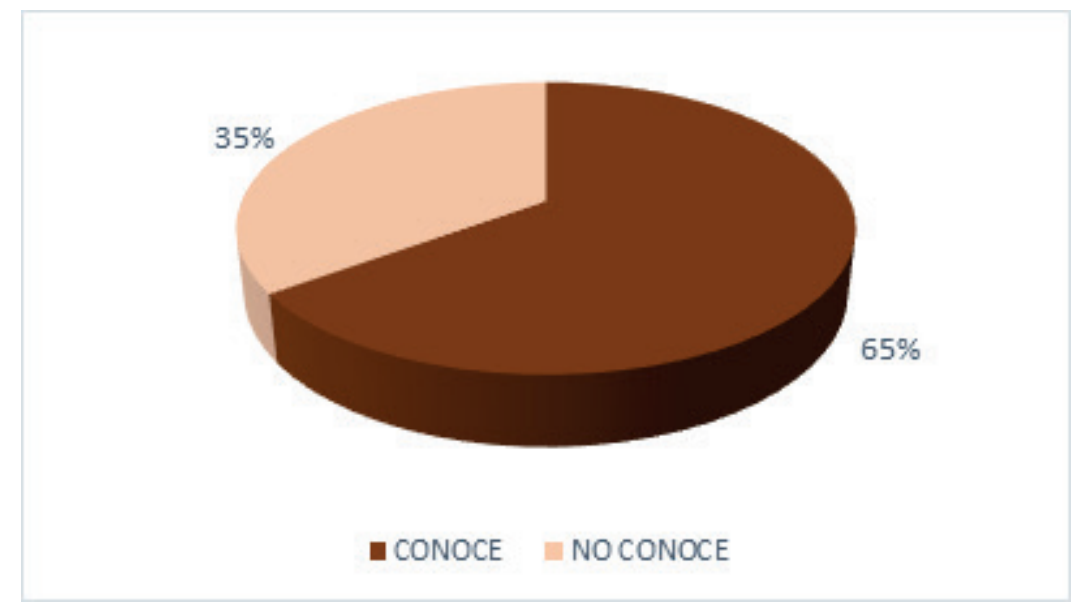

Fuente: Los Autores.

Los estudiantes de Música de la Universidad de Pamplona sede principal conocen sobre los efectos que tiene el uso de auriculares en la salud con un porcentaje de $65 \%$, por otro lado, los estudiantes que desconocen repercuten en un $35 \%$ sus efectos. 
Gráfica 39. Conocimiento sobre los efectos del uso de auriculares en estudiantes de Música.

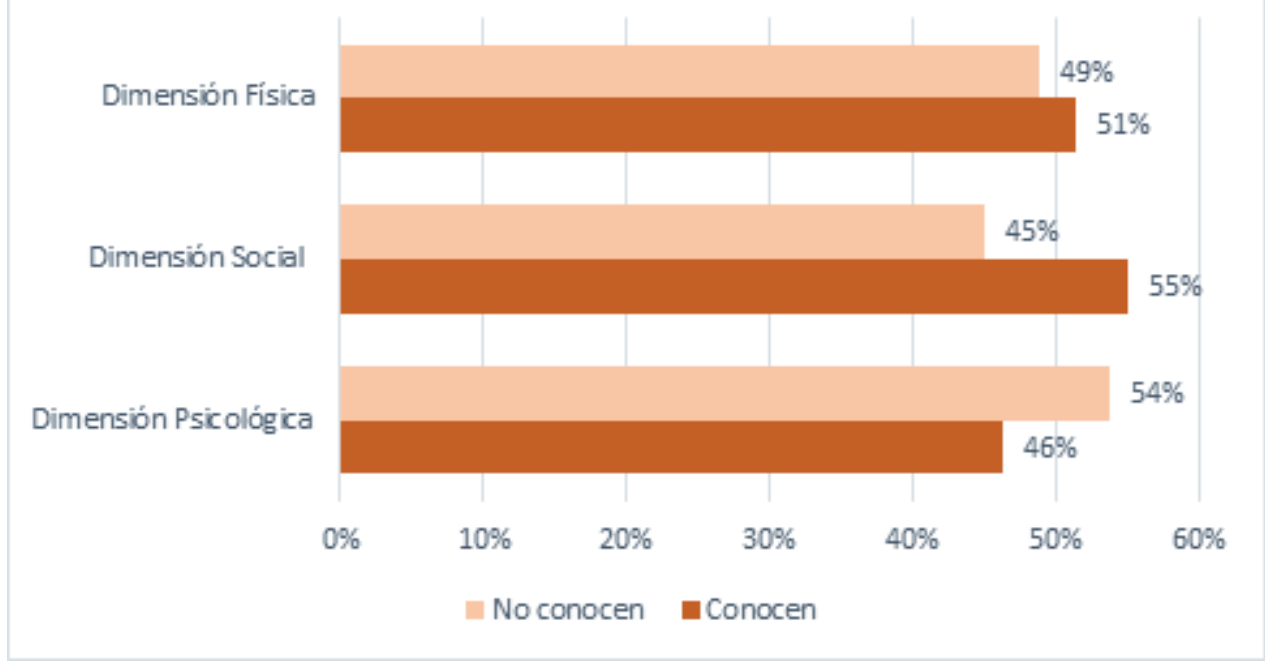

Fuente: Los Autores.

Los estudiantes de Música de la Universidad de Pamplona sede Principal conocen los efectos del uso de auriculares en la dimensión física y social con porcentajes de $51 \%$ y $55 \%$ respectivamente; por otra parte, en la dimensión psicológica los estudiantes de música no conocen los efectos que trae el uso de auriculares, del total de la muestra el $54 \%$. Todo esto permite afirmar que los resultados de la muestra poblacional de los estudiantes de música están divididos en proporciones similares entre conocer o no los efectos que trae el uso de auriculares.

Gráfica 40. Uso de auriculares y conocimiento de los efectos en la salud en estudiantes de Música.

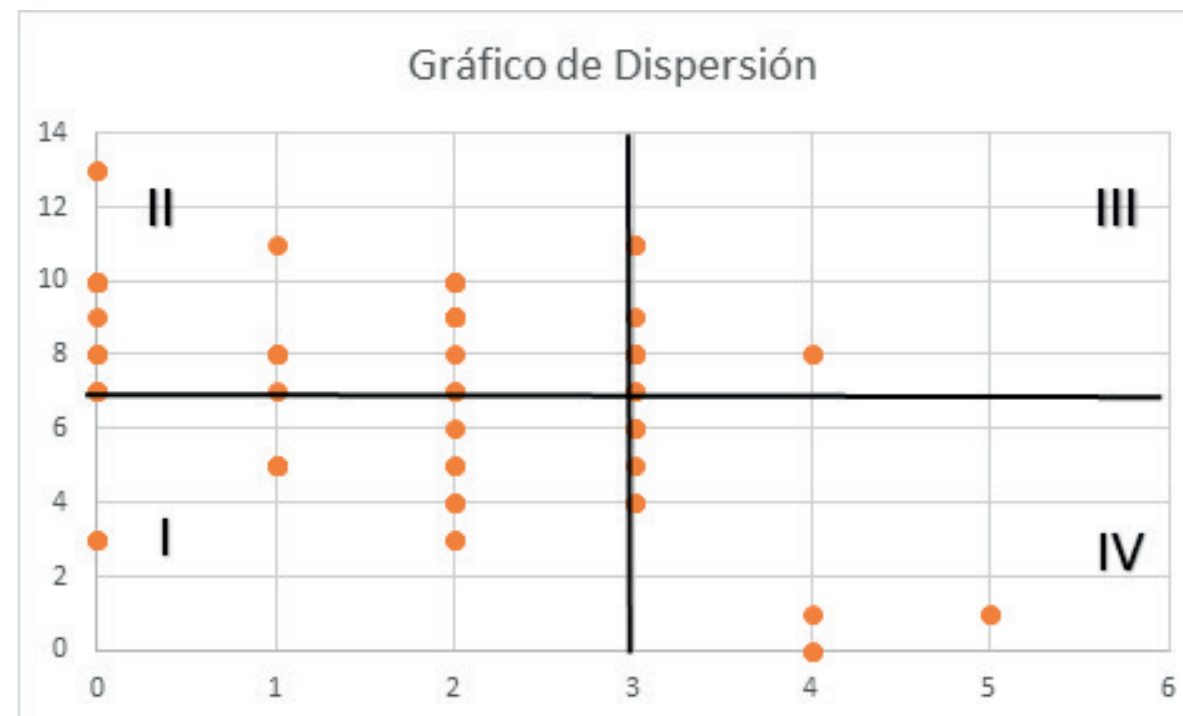

Fuente: Los Autores.

Los estudiantes de Música de la Universidad de Pamplona sede Principal el 29\%, hacen uso inadecuado y no conocen los efectos que causan el uso de los auriculares, el $63 \%$ hacen uso inadecuado, pero conocen los efectos de los auriculares, el $3 \%$ hacen un uso adecuado, pero conocen los efectos que estos causan y por último el $6 \%$ de los estudiantes hacen un uso adecuado, pero no conocen los efectos que estos dispositivos pueden llegar a causar. 


\section{FACULTAD DE CIENCIAS BÁSICAS}

MATEMÁTICAS

Gráfica 41. Géneros estudiantes del programa de Matemáticas.

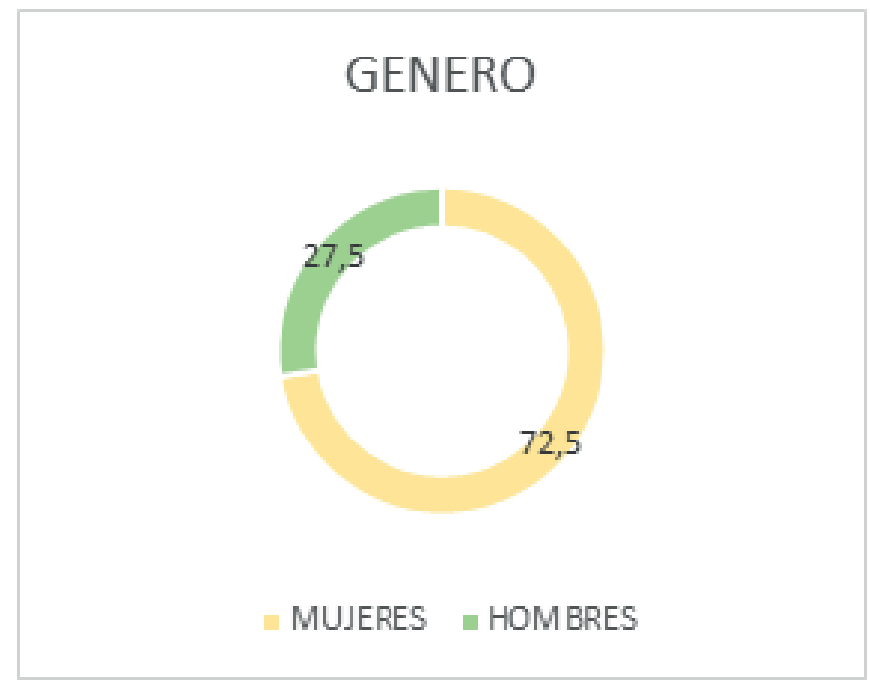

Fuente: Los Autores.

Para una muestra de 80 estudiantes pertenecientes al programa de Matemática se encontró que el $72,5 \%$ son mujeres y un $27,5 \%$ son hombres, estos datos permiten afirmar que una proporción mayor de la población está representada por mujeres y en menor medida por hombres.

Gráfica 42. Edad en estudiantes de Matemáticas.

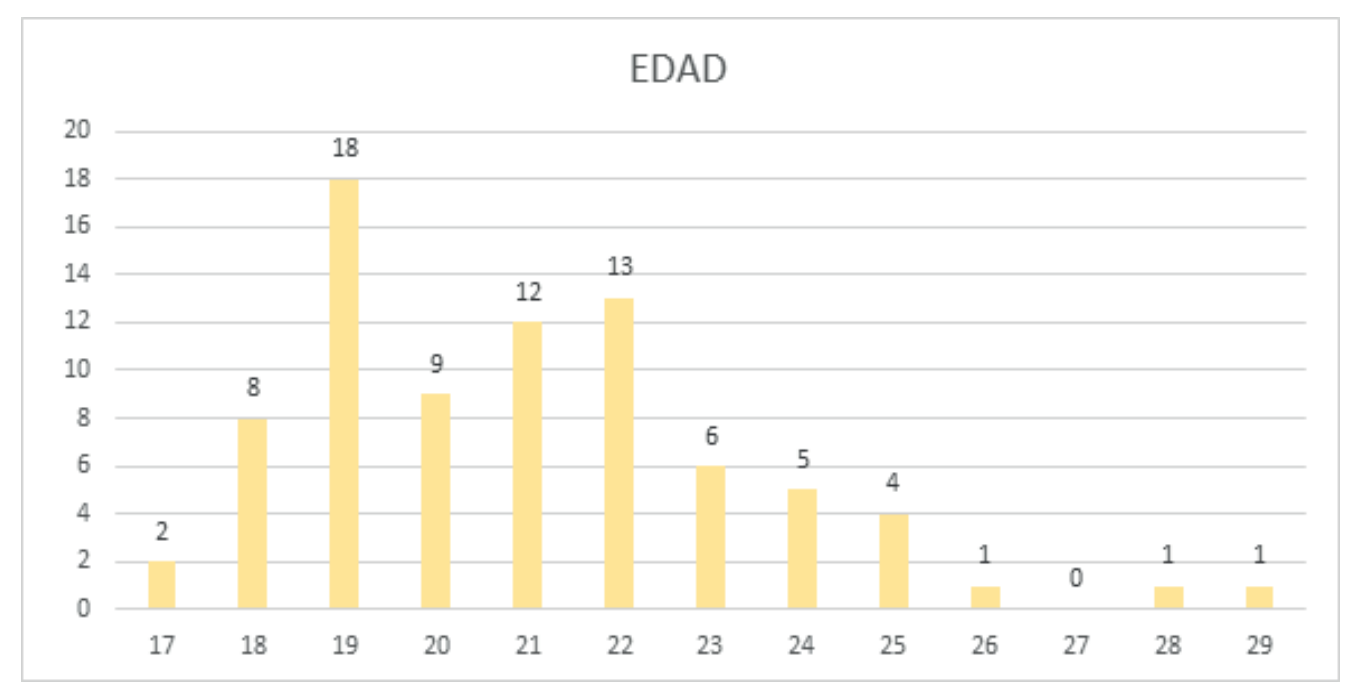

Fuente: Los Autores.

Las edades que predominan en el programa de Matemática están entre los 17 a 29 años, en donde el mayor número de estudiantes se encuentra en una edad de 19 años, representado por 18 estudiantes que reflejan el 22,5\%, seguido de los 22 años con 13 estudiantes representado por (16,25\%); también aquellos estudiantes con 21 y 20 años con un porcentaje de $15 \%$ y $11,25 \%$ respectivamente. 
Gráfica 43. Uso de auriculares en estudiantes de Matemática.

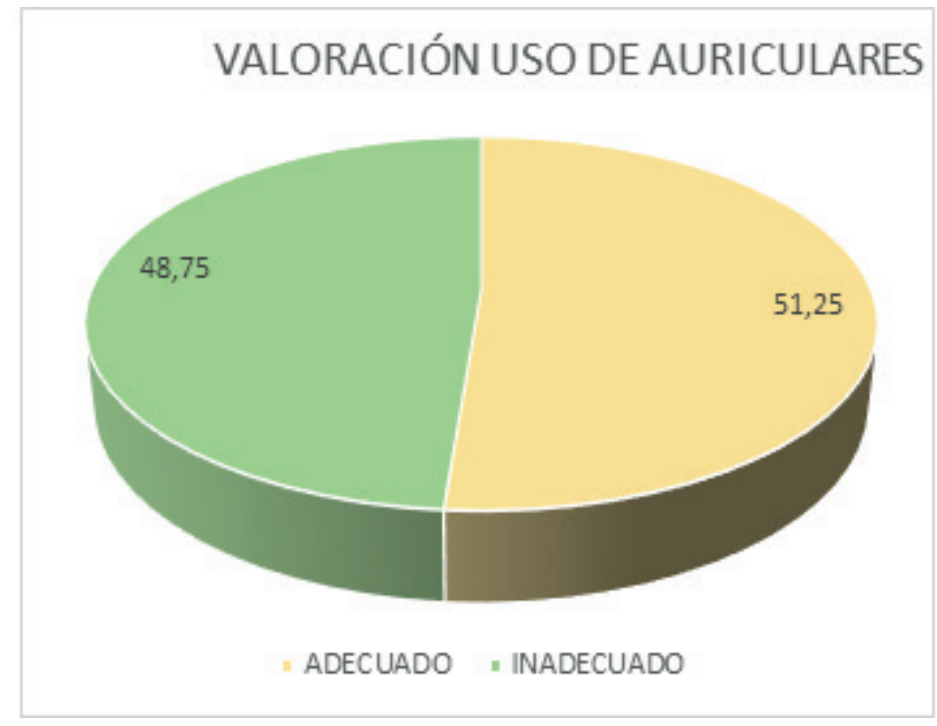

Fuente: Los Autores.

Los estudiantes de Matemática hacen uso adecuado e inadecuado de los auriculares en forma similar, aquellos que lo hacen de forma adecuada están representados por el $48,75 \%$ del total de la muestra y aquellos que lo hacen de forma inadecuada están representados por el $51,25 \%$.

Grafica 44. Tipo de auriculares que utilizan los estudiantes de matemática.

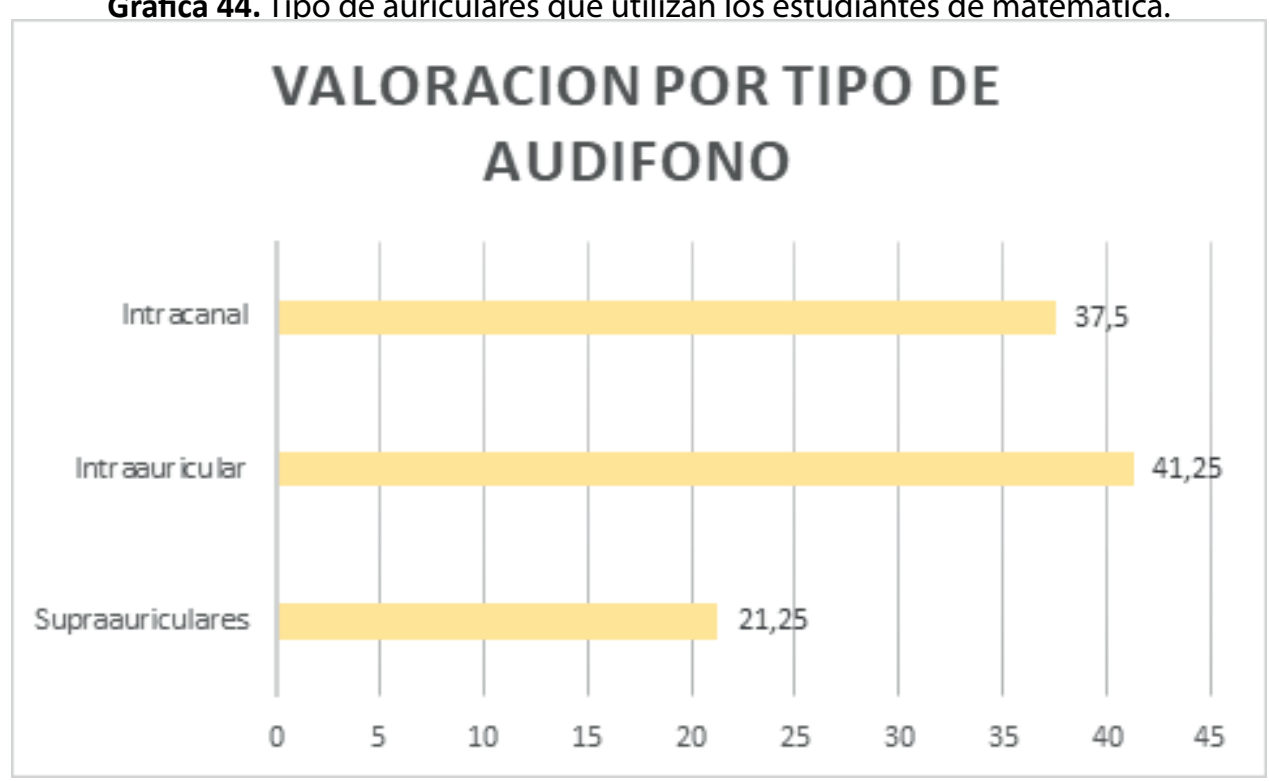

Fuente: Los Autores.

Los estudiantes de Matemática en mayor medida hacen uso de los auriculares de tipo intraauricular en un $41,25 \%$; guido de aquellos estudiantes que utilizan auriculares tipo intracanal son usados por un $37,5 \%$ y los supraauriculares utilizados por un $21,25 \%$ 
Gráfica 45. Efectos del uso de auriculares en estudiantes de Matemáticas.

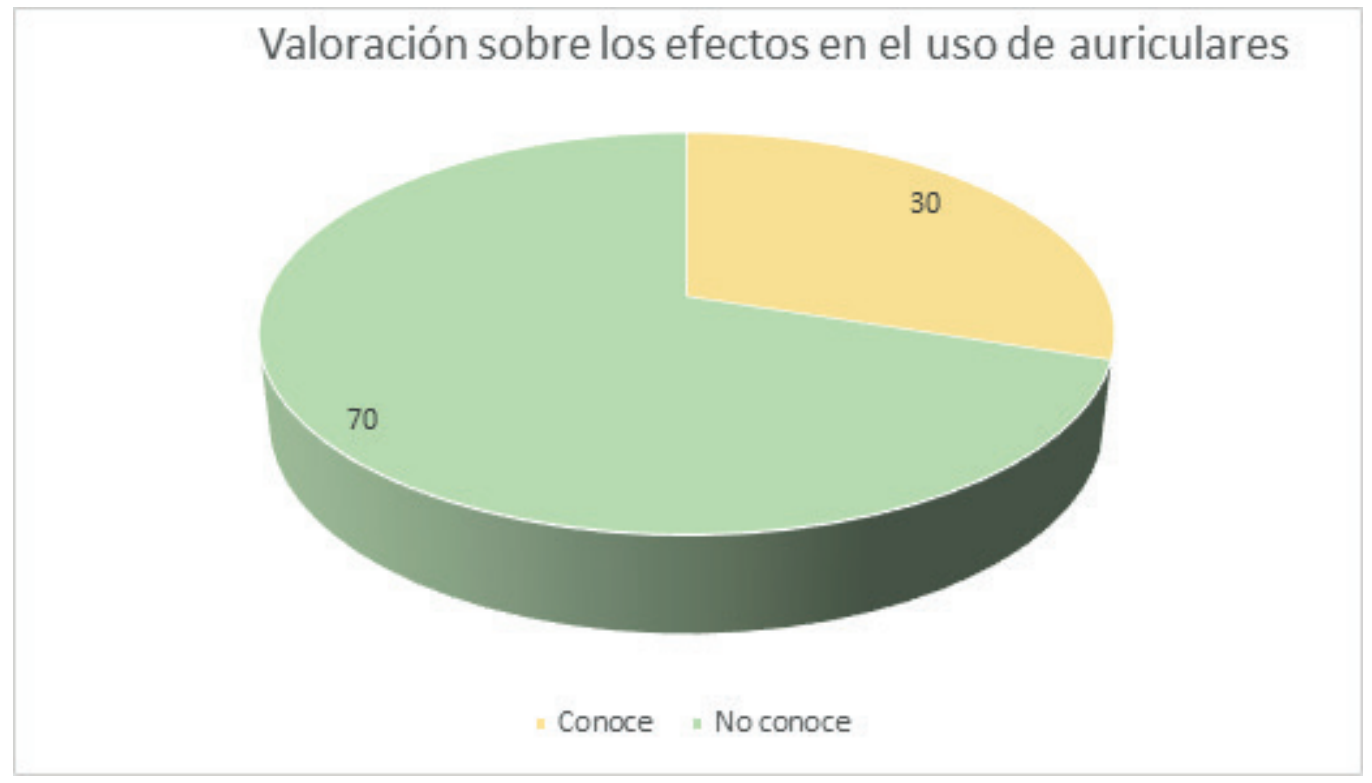

Fuente: Los Autores.

Los estudiantes de Matemática no conocen sobre los efectos que tiene el uso de auriculares en la salud, puesto que según la muestra el $70 \%$ los desconocen y el 30\% conocen los efectos que trae el uso de estos.

Gráfica 46. Valoración sobre los efectos en el uso de auriculares en estudiantes de Matemáticas.

\section{Valoración sobre los efectos en el uso de auriculares}

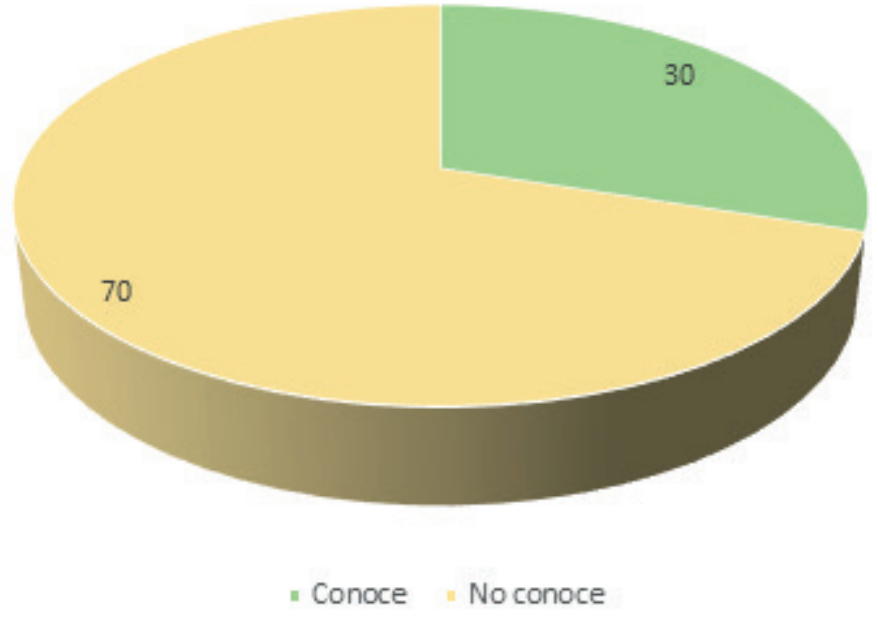

Fuente: Los Autores.

Los estudiantes de Matemática no conocen sobre los efectos que tiene el uso de auriculares en la salud, puesto que según la muestra el $70 \%$ los desconocen y el 30\% conocen los efectos que trae el uso de estos. 
Gráfica 47. Conocimiento sobre los efectos del uso de auriculares en estudiantes de Matemáticas.

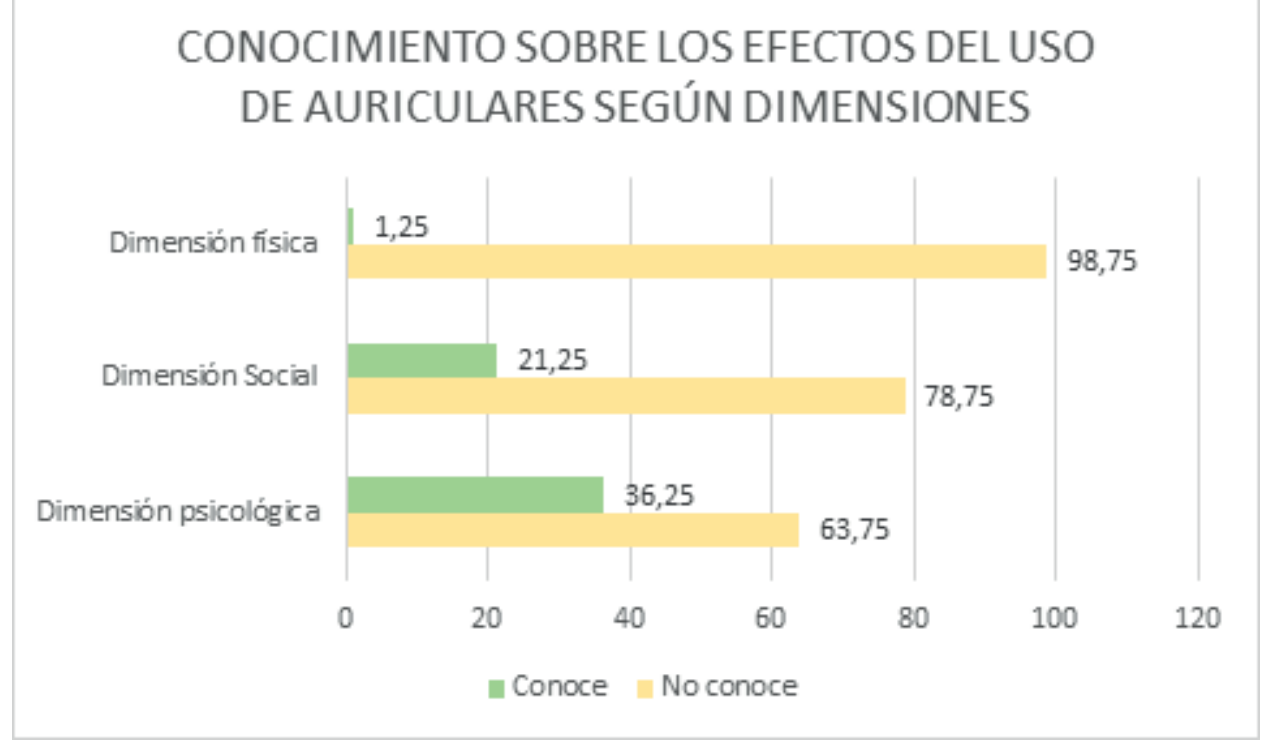

Fuente: Los Autores.

Los estudiantes de Matemática no conocen los efectos del uso de auriculares en las tres dimensiones física social y psicológica con porcentajes del $98,75 \% 78,75 \%$ y $63,75 \%$ respectivamente, física el 1,25\% conoce los efectos físicos que trae el uso de audífonos, en las dimensiones social y psicológica las proporciones de conocimiento son mayores.

Gráfica 48. Uso de auriculares y conocimiento de los efectos en la salud en estudiantes de Matemáticas.

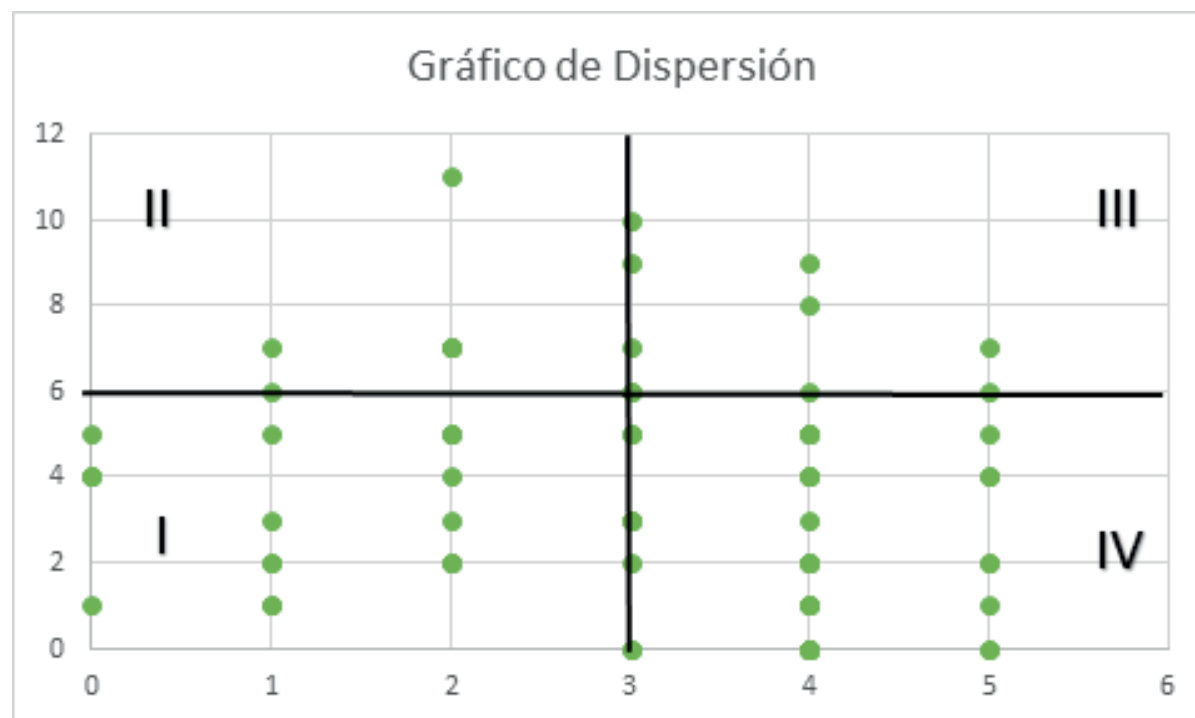

Fuente: Los Autores.

Los estudiantes de Matemáticas de la Universidad de Pamplona sede Principal que hacen uso inadecuado y no conocen los efectos que tienen el uso de los auriculares son el $38 \%$, aquellos estudiantes que hacen uso inadecuado pero conocen los efectos de los auriculares están representados por tan solo el $11 \%$, los estudiantes que hacen un uso adecuado y conocen los efectos están representados por el $4 \%$ y por último están los estudiantes que hacen un uso adecuado pero no conocen los efectos

Revista Científica Signos Fónicos, 2019,5(2): 97-150. ISNN 2422-1716. 
que tienen, están representados por un porcentaje elevado, el $48 \%$.

\section{BIOLOGÍA}

Gráfica 49. Género estudiantes del programa de Biología.

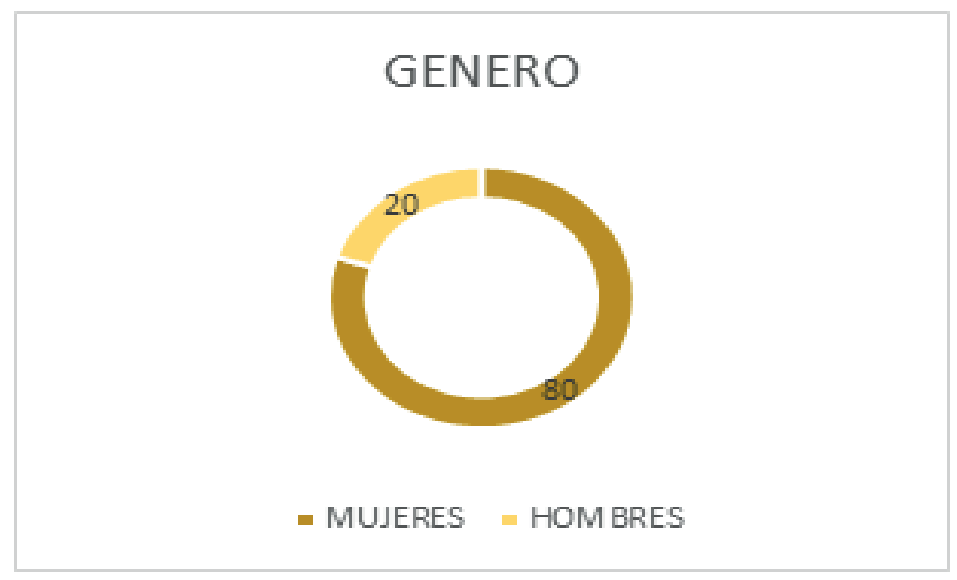

Fuente: Los Autores.

Para una muestra de 80 estudiantes pertenecientes al programa de Biología en donde se encontró que el $80 \%$ son mujeres y un $20 \%$ son hombres, se observa que una proporción mayor de la población está representada por mujeres y en menor medida por hombres. por otro lado, las edades de la muestra están representadas de manera porcentual en el gráfico a continuación.

Gráfica 50. Edad en estudiantes de Bioloqía.

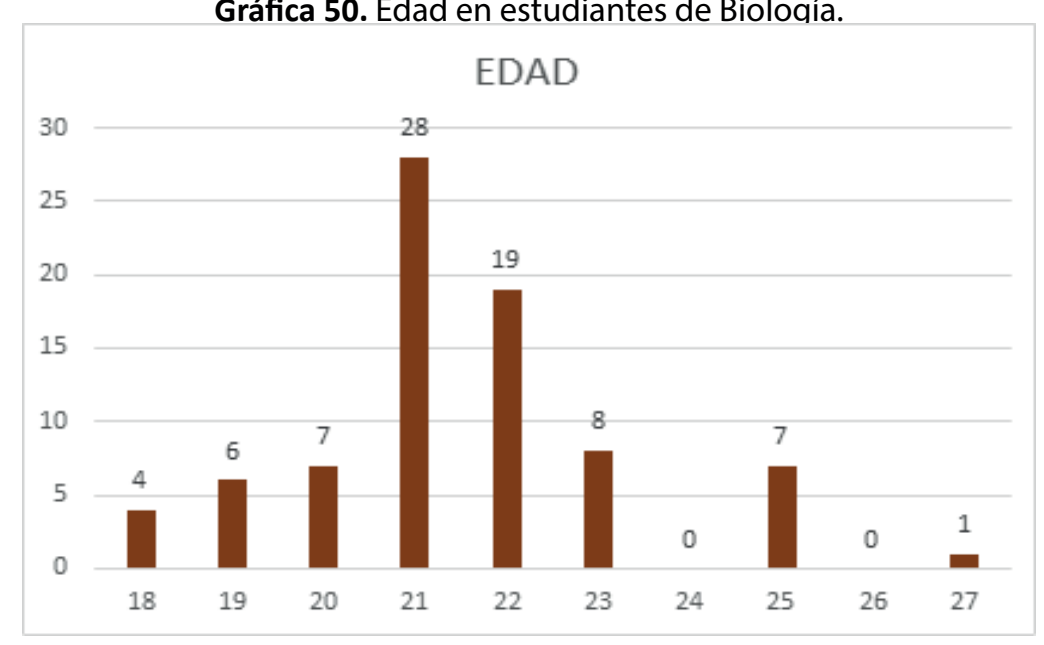

Fuente: Los Autores.

Las edades que predominan la carrera de Biología de la Universidad de Pamplona sede principal están entre los 18 a 27 años de edad, el mayor número de estudiantes se encuentra en una edad de 21 años, representado por el 35\%, seguido de los 22 años representado por un 23,75\%; estas dos edades son las que más representan estudiantes en la muestra, pues las otras edades están dadas por un número menor de estudiantes. 
Gráfica 51. Uso de auriculares en estudiantes de Bioloqía.

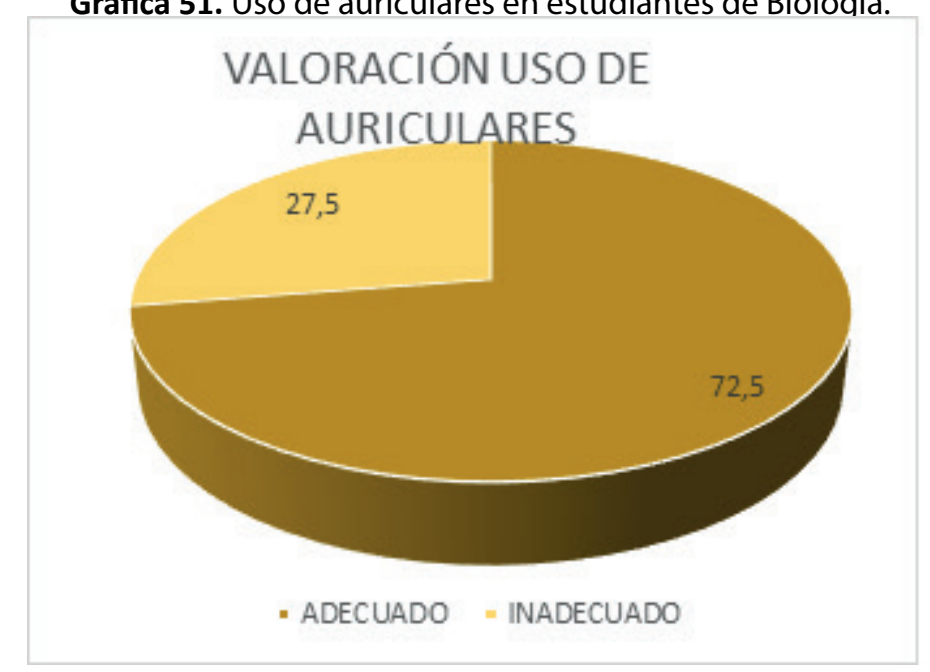

Fuente: Los Autores.

Los estudiantes de Biología de la Universidad de Pamplona sede principal hacen uso adecuado de los auriculares, representado por un $72,5 \%$ de la muestra total tomada para el estudio; en contraste solo el $27,5 \%$ de los estudiantes de este programa hacen un uso inadecuado.

Gráfica 52. Valoración por tipo de audífonos.

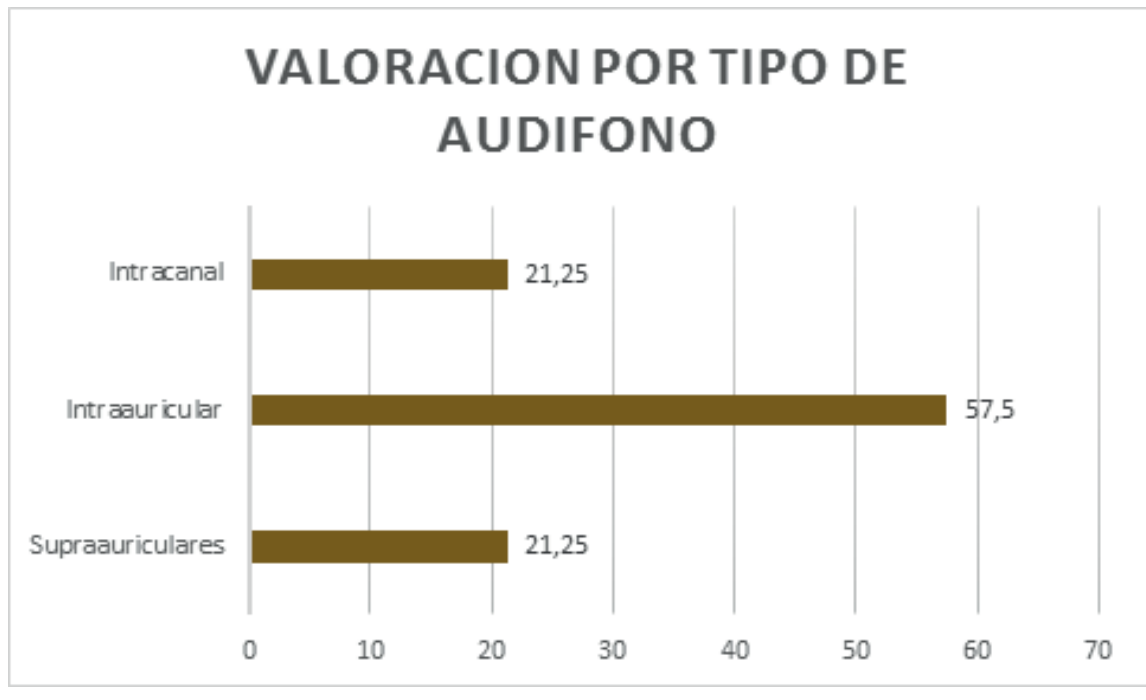

Fuente: Los Autores.

Así mismo, los estudiantes del programa de Biología en mayor medida hacen uso de los auriculares de tipo intraauricular en un 57,5\%; seguido aquellos que usan tipo intracanal con un $21,25 \%$ y por último se encuentran aquellos estudiantes que usan supraauriculares en una proporción de $21,25 \%$. 
Gráfica 53. Horas de uso diarias de uso de auriculares en estudiantes de Bioloqía.

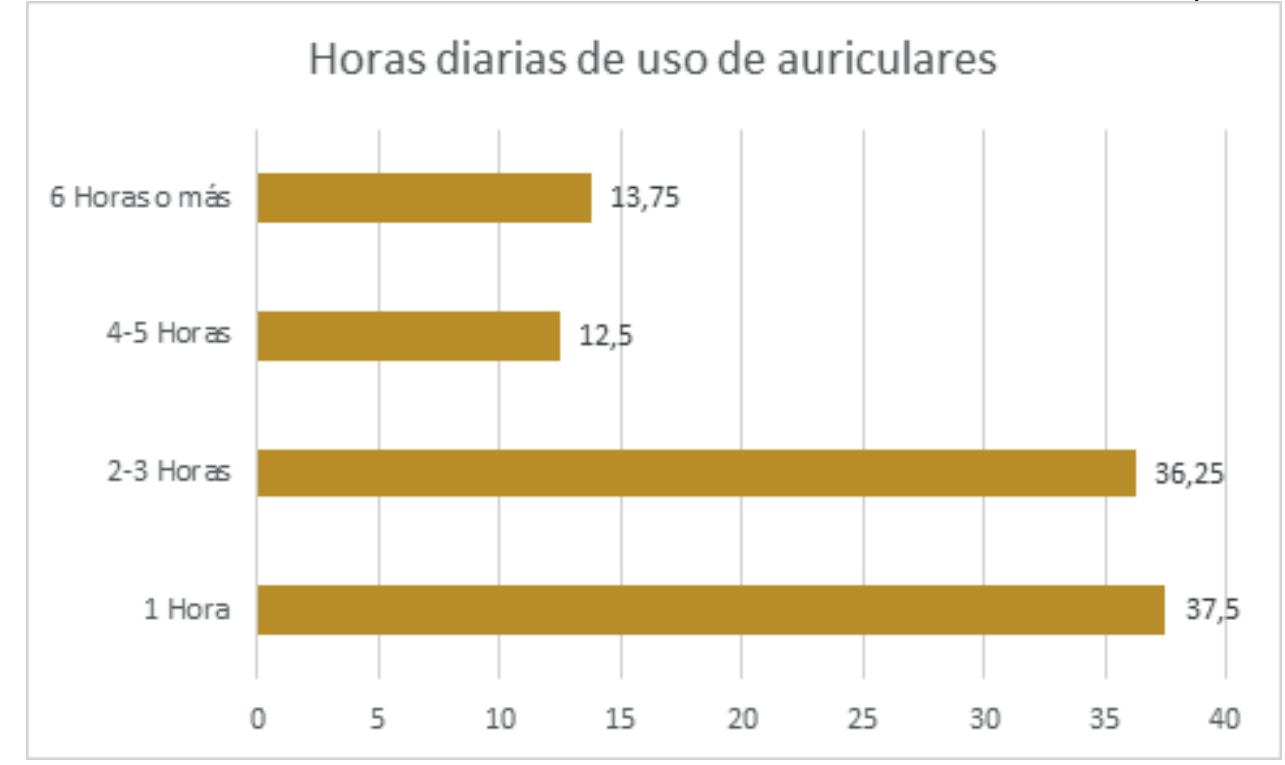

Fuente: Los Autores.

Los estudiantes de Biología de la Universidad de Pamplona en su mayoría utilizan los audífonos 1 hora con un $37,5 \%$ seguido de aquellos que usan $2-3$ horas diarias con un $36,25 \%$; por otro lado, aquellos que hacen uso de 6 horas o más diarias con un porcentaje del 13,75\% y por último se encuentran aquellos estudiantes que los utilizan de $4-5$ horas con un $12,5 \%$.

Gráfica 54. Conocimiento de los efectos del uso de auriculares en estudiantes de Biología.

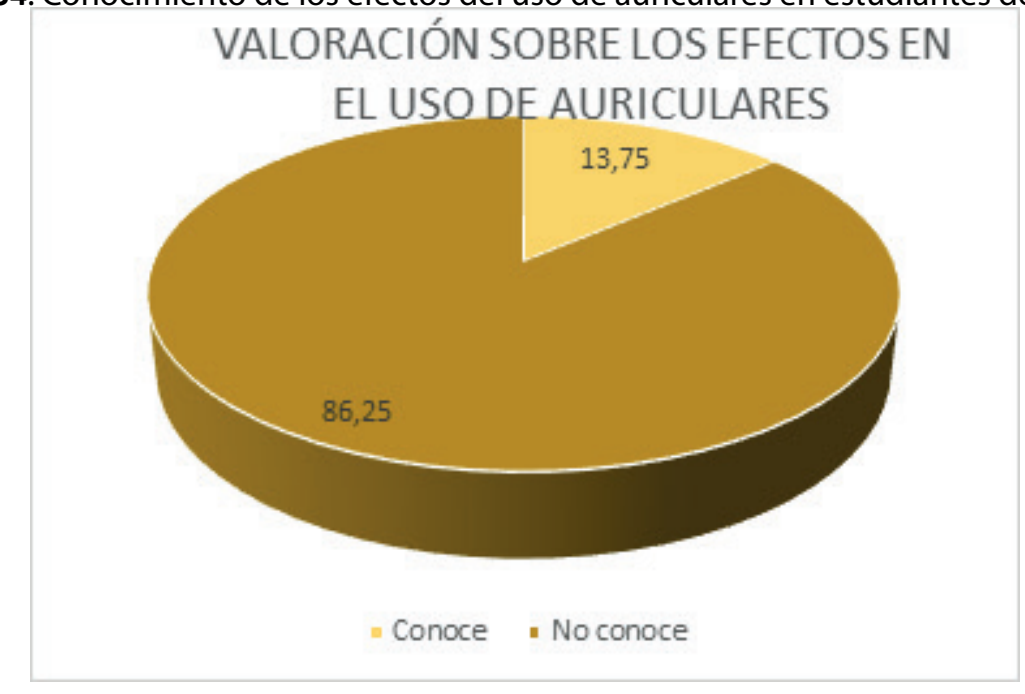

Fuente: Los Autores.

Los estudiantes de Biología de la Universidad de Pamplona sede principal no conocen sobre los efectos que tiene el uso de auriculares en la salud con un porcentaje de $86,25 \%$ y tan solo el $13,75 \%$ conocen los efectos que trae el uso de estos. 
Gráfica 55. Conocimiento sobre los efectos del uso de auriculares en estudiantes de Biología.

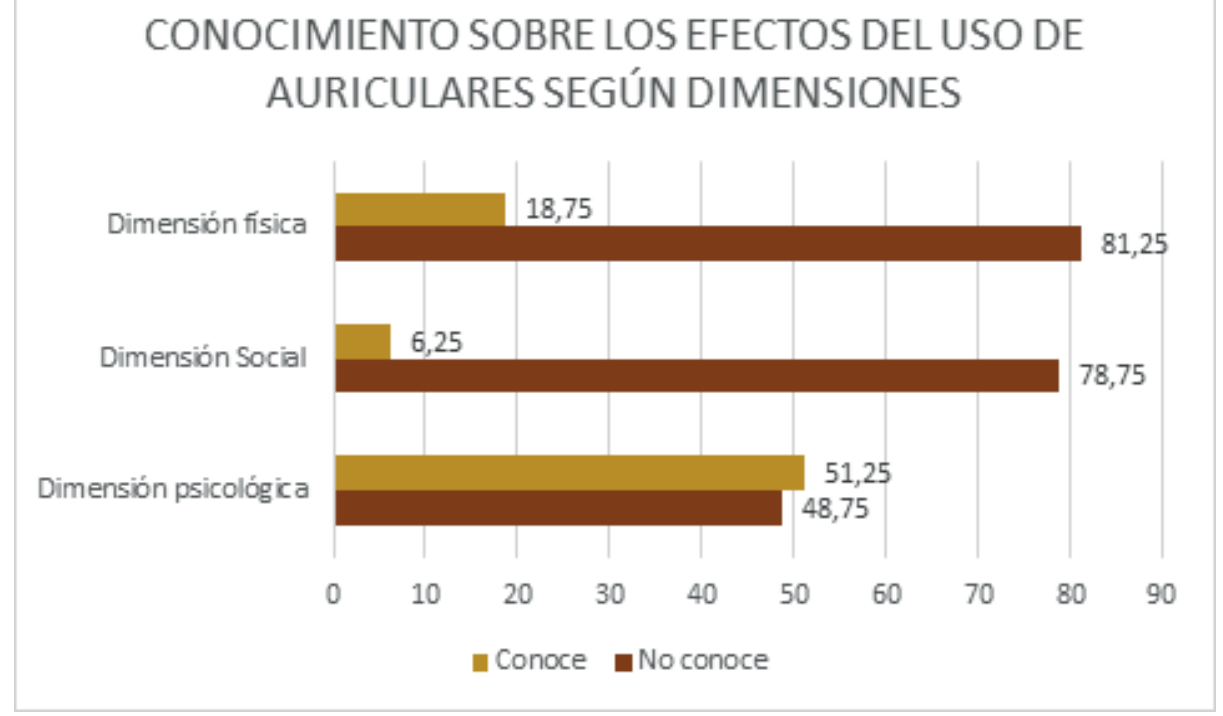

Fuente: Los Autores.

Los estudiantes de Biología de la Universidad de Pamplona sede Principal conocen los efectos que generan en la salud el uso excesivo de auriculares en la dimensión psicológica con un resultado del $51,25 \%$, por otra parte, en la dimensión social no conocen los efectos en un $78,75 \%$ y finalmente en la física no conocen los efectos que trae el uso de auriculares en un $81,25 \%$.

Gráfica 56. Uso de auriculares y conocimiento de los efectos en la salud en estudiantes de Biología.

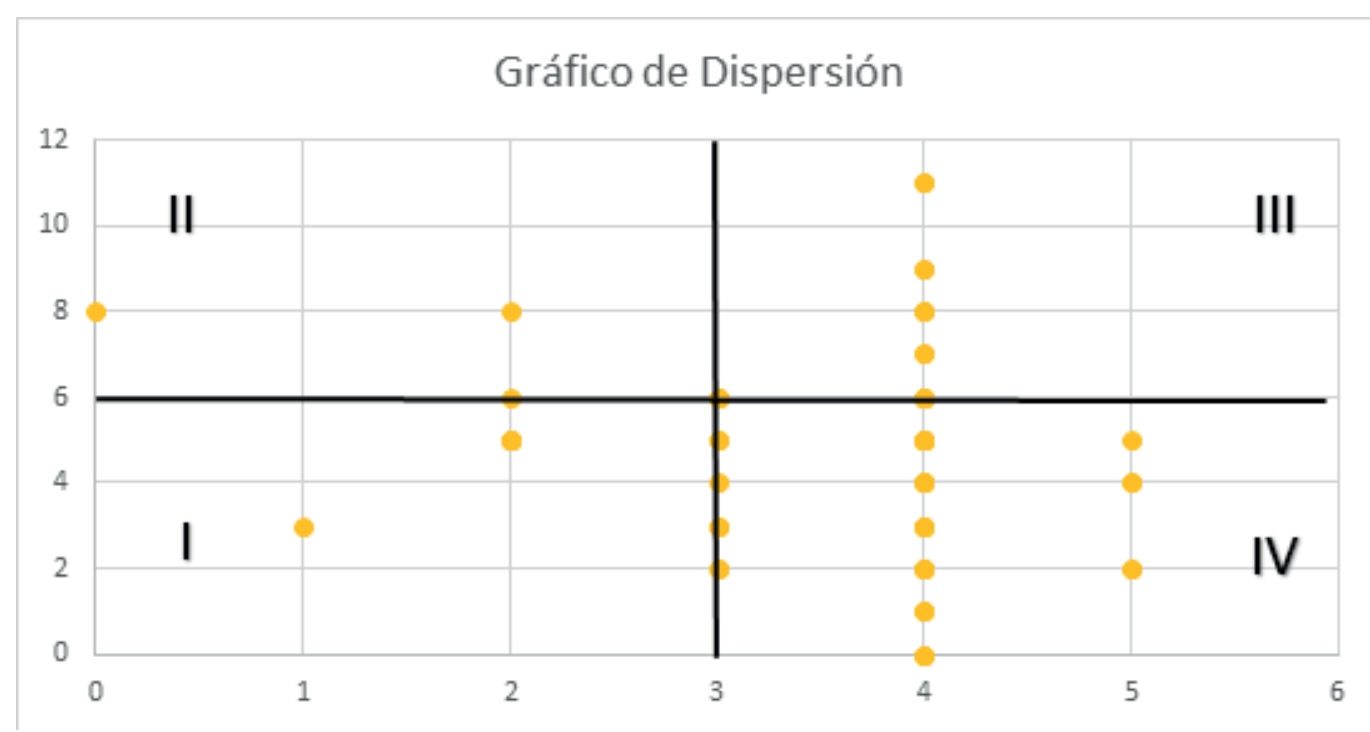

Fuente: Los Autores.

Los estudiantes de Biología de la Universidad de Pamplona sede Principal el $25 \%$, hacen uso inadecuado y no conocen los efectos que causan el uso de los auriculares, el $3 \%$ hacen uso inadecuado, pero conocen los efectos de los auriculares, el $11 \%$ hacen un uso adecuado, pero conocen los efectos que estos causan y por último el $61 \%$ de los estudiantes hacen un uso adecuado, pero no conocen los efectos que estos dispositivos pueden llegar a causar. 
Gráfica 57. Género estudiantes del programa de Microbiología.

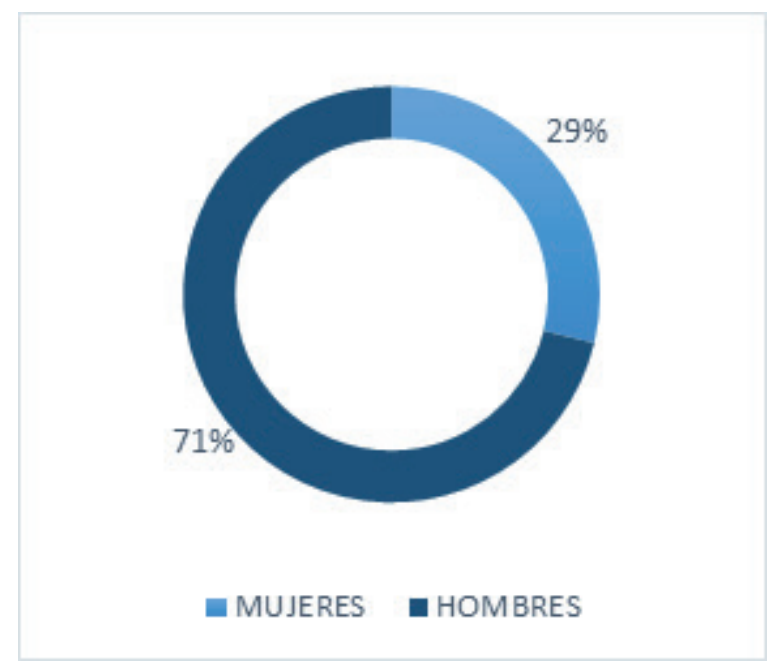

Fuente: Los Autores.

Para una muestra de 80 estudiantes pertenecientes al programa de Microbiología se encontró que el $71 \%$ son hombres y un $29 \%$ son mujeres, siendo más representativa la muestra poblacional masculina.

Gráfica 58. Edad en estudiantes de Microbiología.

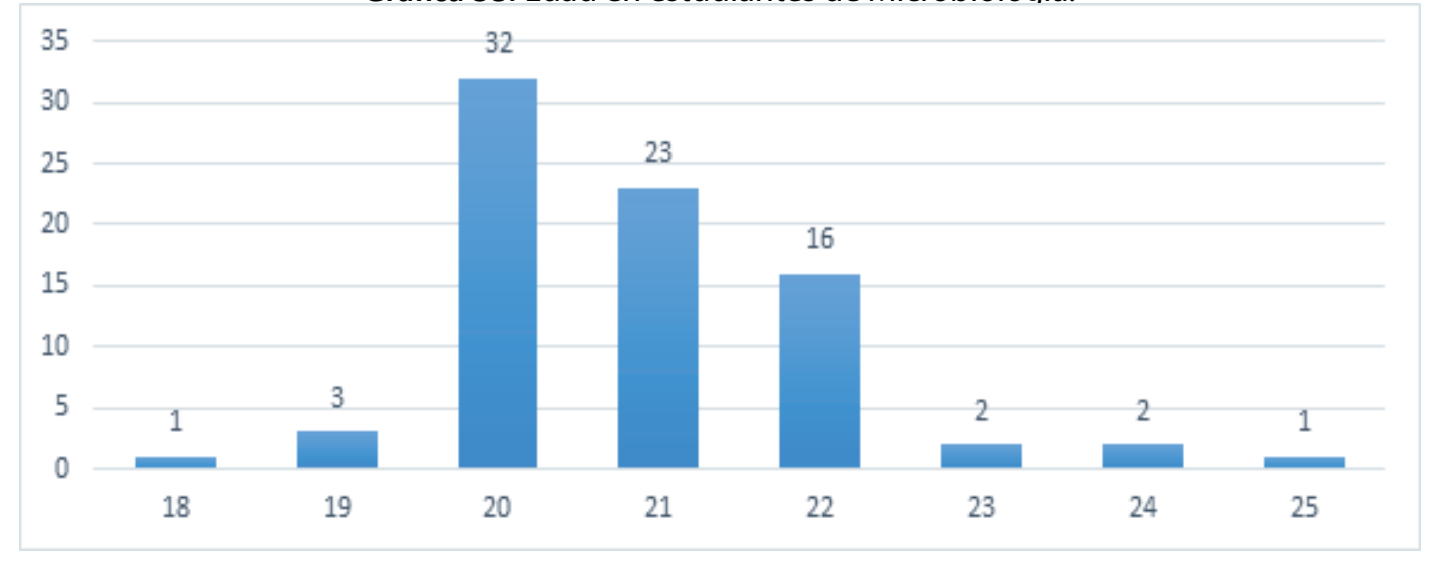

Fuente: Los Autores.

Las edades que predominan en la carrera de Microbiología de la Universidad de Pamplona sede Principal están entre los 20 a 22 años de edad, el mayor número de estudiantes se encuentra en una edad de 20 años, representado por el $32 \%$ seguido de los 21 años $23 \%$, y los de 22 años con un porcentaje de $16 \%$. 
Gráfica 59. Uso de auriculares en estudiantes de Microbiología.

\section{VALORACIÓN USO DE AURICULARES}

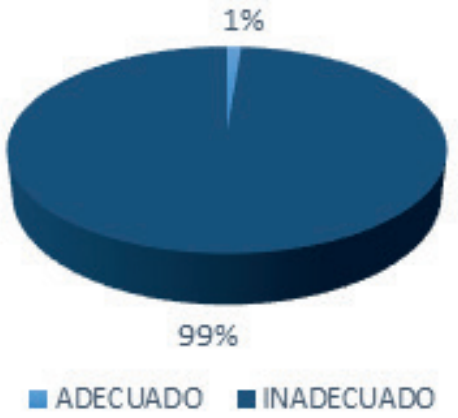

Fuente: Los Autores.

Los estudiantes de microbiología de la Universidad de Pamplona sede principal hacen uso inadecuado de los auriculares, representado por un $99 \%$ de la muestra total tomada para el estudio; en contraste solo el $1 \%$ de los estudiantes de estas carreras hacen un uso adecuado.

Gráfica 60. Tipo de auriculares que utilizan los estudiantes de Microbioloqía.

\section{TIPO DE AUDIFONO}

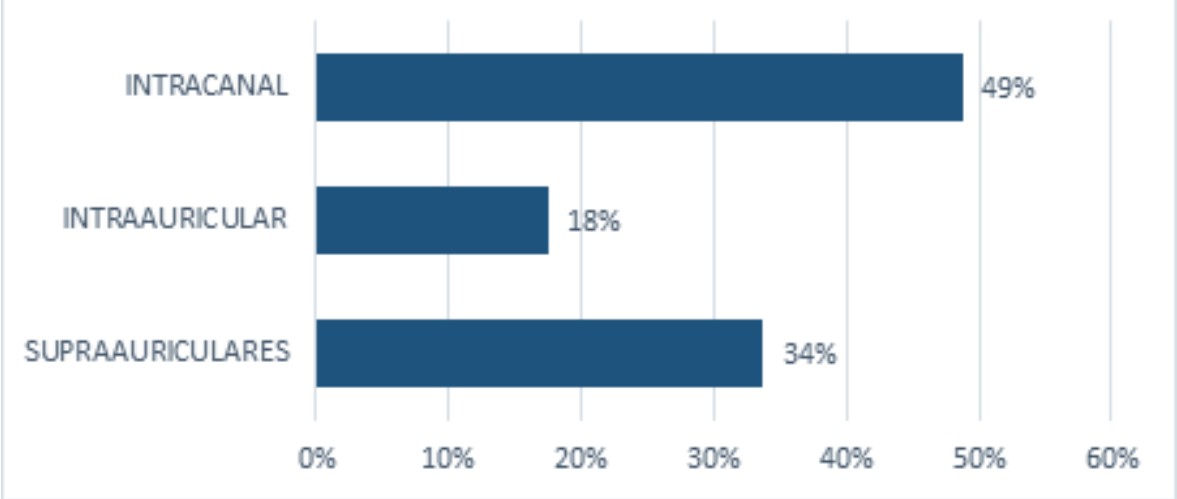

Fuente: Los Autores.

Los estudiantes de Microbiología de la Universidad de Pamplona sede principal hacen uso de los auriculares de tipo intracanal en una proporción mayor, representada por $49 \%$, seguido se encuentra el uso de supraauriculares con un $34 \%$ y por último y menos usado por los estudiantes de microbiología está el intraauricular. 
Gráfica 61. Horas diarias de uso de auriculares en estudiantes de Microbiología.

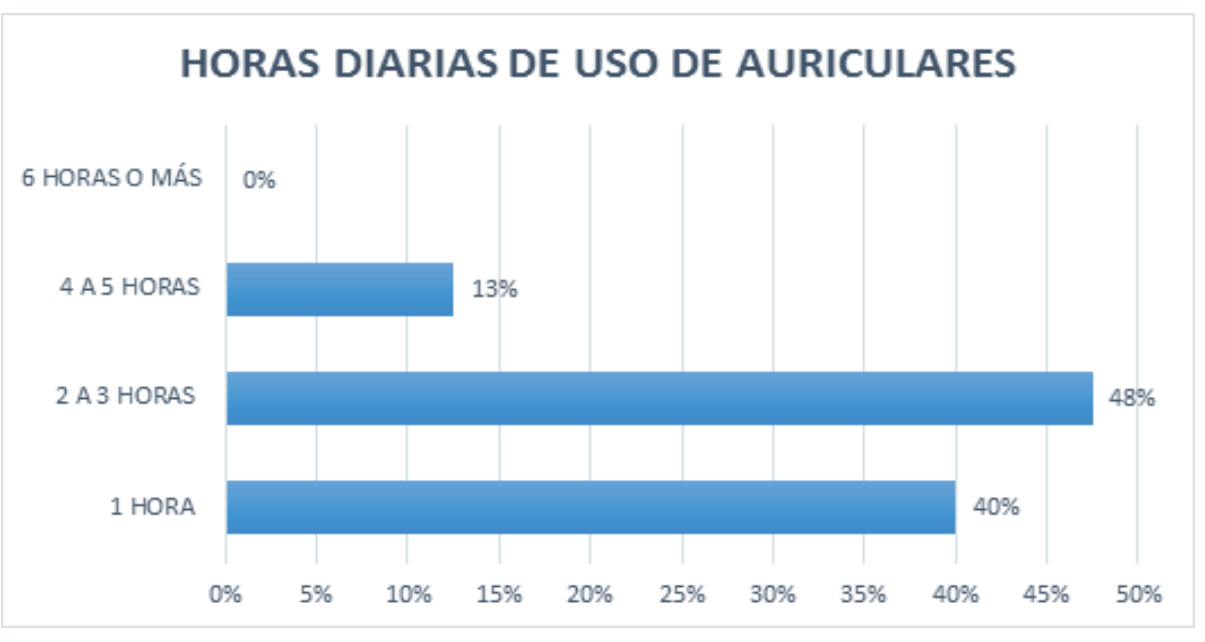

Fuente: Los Autores.

Los estudiantes de Microbiología de la Universidad de Pamplona sede principal en su mayoría utilizan los audífonos 2-3 horas diarias 48\%, seguido de aquellos que hacen uso de 1 hora diaria representando por el $40 \%$ y de 4 a 5 horas con un $13 \%$ dado en porcentajes estos dos últimos presentan un uso similar; además según la muestra nadie hace uso de los auriculares 6 horas o más.

Gráfica 62. Conocimiento de los efectos del uso de auriculares en estudiantes de Microbiología.

\section{VALORACIÓN SOBRE LOS EFECTOS EN EL USO DE AURICULARES}

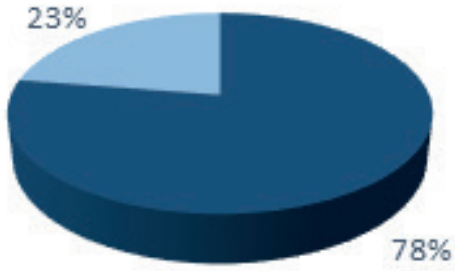

- CONOCE NOCONOCE

Fuente: Los Autores.

Los estudiantes de Microbiología de la Universidad de Pamplona sede principal conocen conoce los efectos que tiene el uso de auriculares en la salud, puesto que según la muestra el $78 \%$ los conocen y el $23 \%$ desconocen sus efectos. 
Gráfica 63. Conocimiento sobre el uso de auriculares en estudiantes de Microbiología.

\section{CONOCIMIENTO SOBRE LOS EFECTOS DEL USO DE AURICULARES SEGÚN DIMENSIONES}

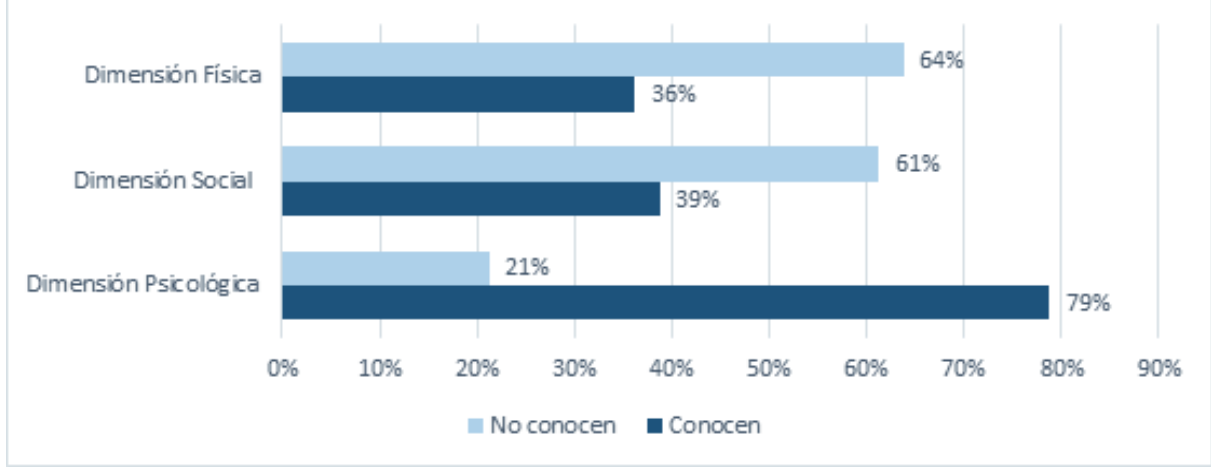

Fuente: Los Autores.

Los estudiantes de Microbiología de la Universidad de Pamplona sede Principal conocen los efectos del uso de auriculares en la dimensión psicológica con un porcentaje de 79\%; por otra parte, en la dimensión física y social los estudiantes de microbiología no conocen los efectos que trae el uso de estos; del total de la muestra el $36 \%$ y $39 \%$ respectivamente desconocen los efectos.

Gráfica 64. Uso y conocimiento de auriculares en estudiantes de Microbiología.

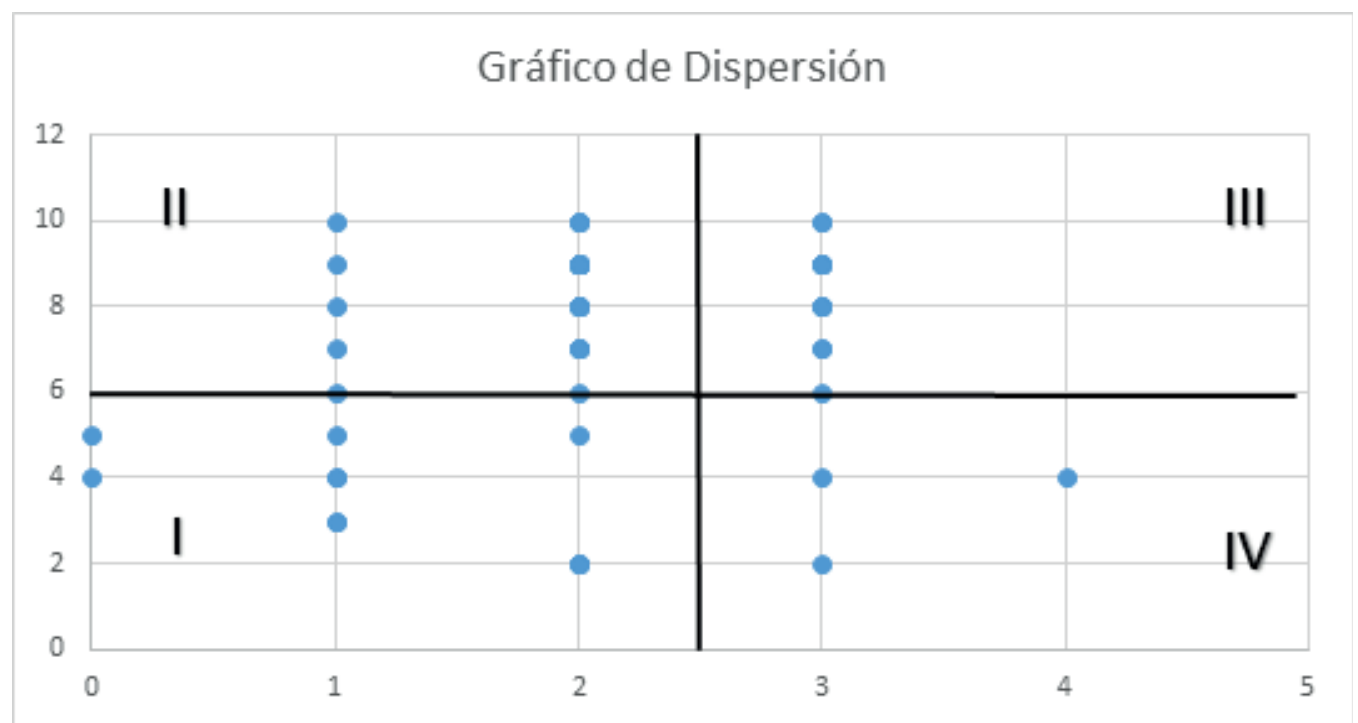

Fuente: Los Autores.

Los estudiantes de Microbiología de la Universidad de Pamplona sede Principal el $21 \%$, hacen uso inadecuado y no conocen los efectos que causan el uso de los auriculares, el $78 \%$ hacen uso inadecuado, pero conocen los efectos de los auriculares, por otro lado, no hay estudiantes que hagan un uso adecuado y conozcan los efectos del uso de auriculares, y por último el $1 \%$ de los estudiantes hacen un uso adecuado, pero no conocen los efectos que estos dispositivos pueden llegar a causar. 


\section{QUÍMICA}

Gráfica 65. Género estudiantes del proqrama de Química.

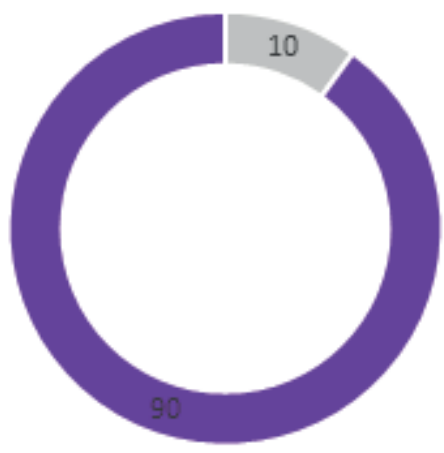

- MUJERES - HOMBRES

Fuente: Los Autores.

Para una muestra de 80 estudiantes pertenecientes al programa de Química en donde se encontró que el $90 \%$ son hombres y un $10 \%$ son mujeres, se observa que una proporción mayor de la población está representada por hombres y en menor medida por mujeres. por otro lado, las edades de la muestra están representadas de manera porcentual en el gráfico a continuación.

Gráfica 66. Edades en estudiantes de Química.

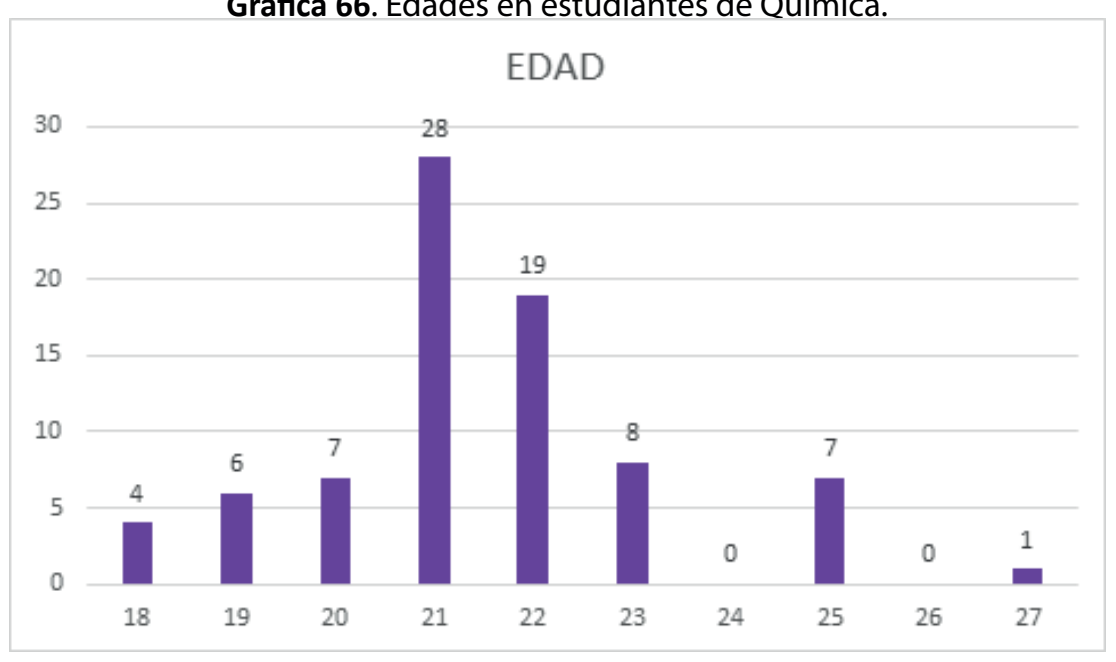

Fuente: Los Autores.

Las edades que predominan en el programa de Química de la Universidad de Pamplona sede Principal están entre los 18 a 25 años, el mayor número de estudiantes se encuentra en una edad de 21 años representado por el $35 \%$, seguido de ellos se encuentran aquellos que están en una edad de 22 años con un porcentaje del $23,7 \%$, las demás edades representan un porcentaje menor dentro de la muestra poblacional del programa mencionado. 
Gráfica 67. Valoración uso de auriculares en estudiantes de Química.

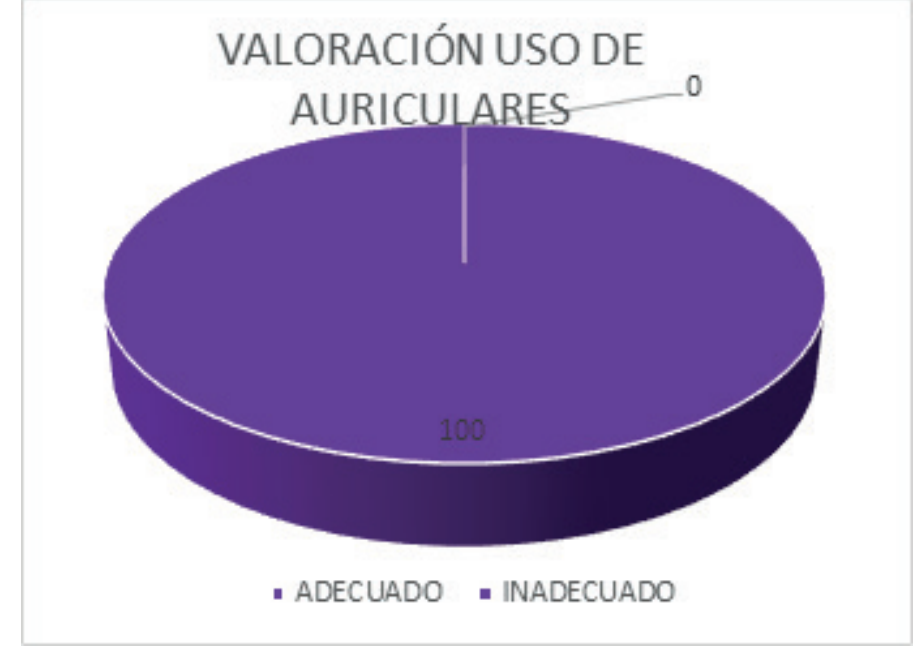

Fuente: Los Autores.

Todos los estudiantes de Química de la Universidad de Pamplona sede principal hacen uso inadecuado de los auriculares en porcentaje está dado por $100 \%$.

Gráfica 68. Tipo de Audífonos en estudiantes de Química.

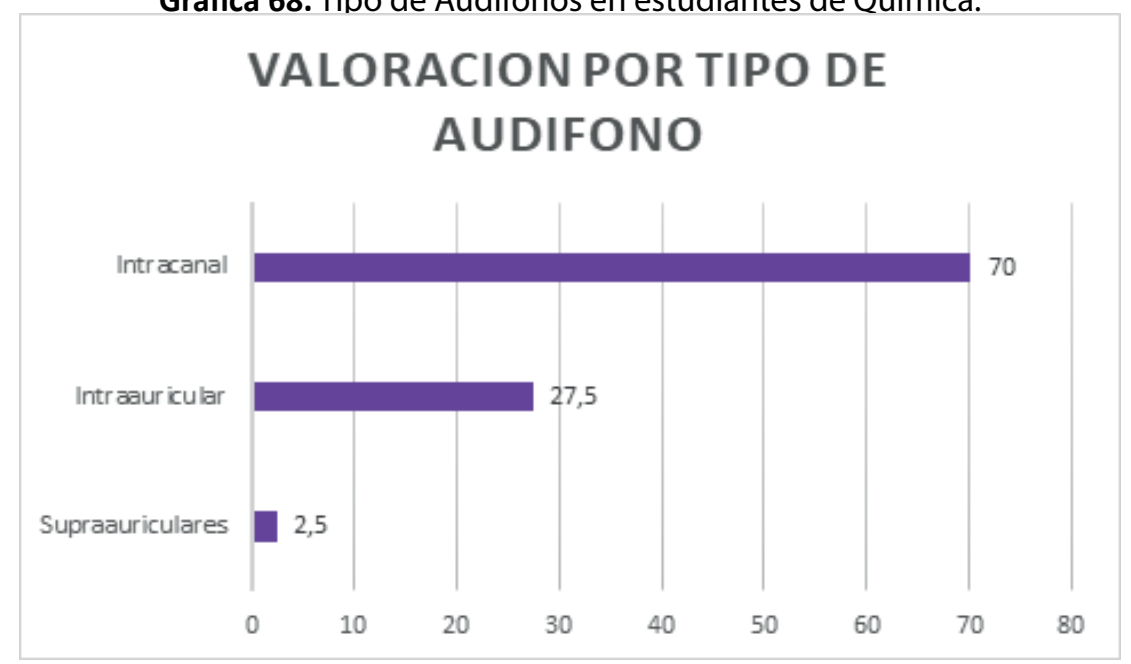

Fuente: Los Autores.

Así mismo, los estudiantes de Química de la Universidad de Pamplona sede principal hacen uso de los auriculares de tipo intracanal en una proporción mayor, representada por un 70\%, seguido de aquellos estudiantes que hacen uso de intra auricular con un $27,5 \%$ y por último se encuentran aquellos estudiantes que usan el supraauricular con un $2,5 \%$. 
Gráfica 69. Horas de uso diarias de uso de auriculares en estudiantes de Química.

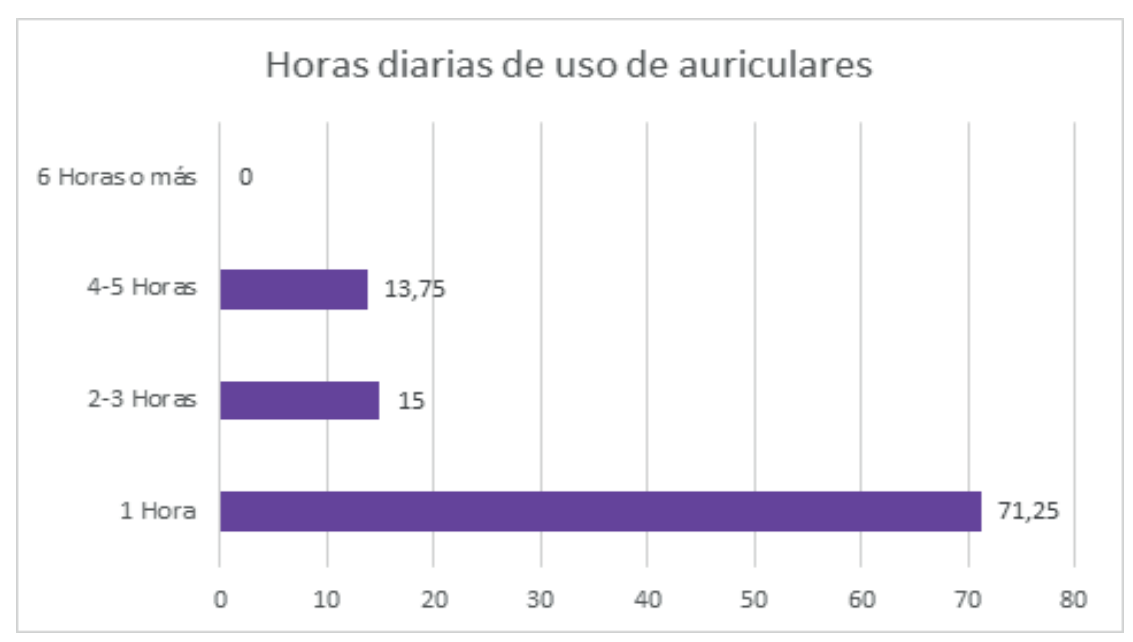

Fuente: Los Autores.

Los estudiantes de Química de la Universidad de Pamplona sede principal en su mayoría utilizan los audífonos 1 horas diaria siendo el 71,25\%, seguido de aquellos que hacen uso 2 a 3 horas con un 15\% y por último aquellos de utilizan de 4 a 5 horas con un 13,75\%; además según la muestra nadie hace uso de los auriculares 6 horas o más.

Gráfica 70. Conocimiento de los efectos del uso de auriculares en estudiantes de Química.

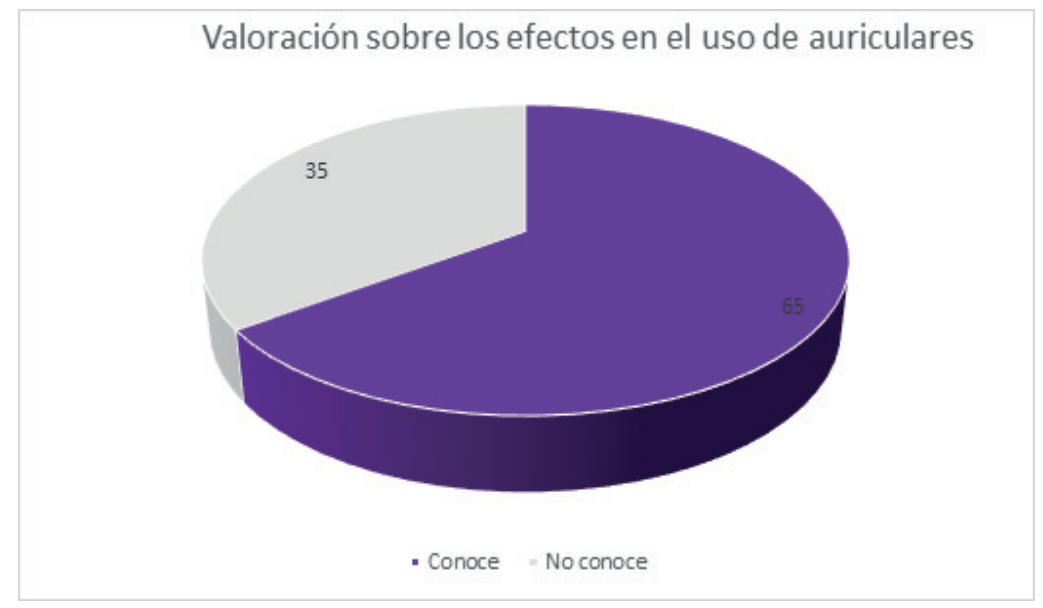

Fuente: Los Autores.

Los estudiantes de Química de la Universidad de Pamplona sede principal conocen los efectos que tiene el uso de auriculares en la salud con un porcentaje del $65 \%$ y por otro lado los estudiantes que desconocen sobre los efectos que tiene el uso de auriculares repercute al 35\%. 
Gráfica 71. Conocimiento sobre los efectos del uso de auriculares en estudiantes de Química.

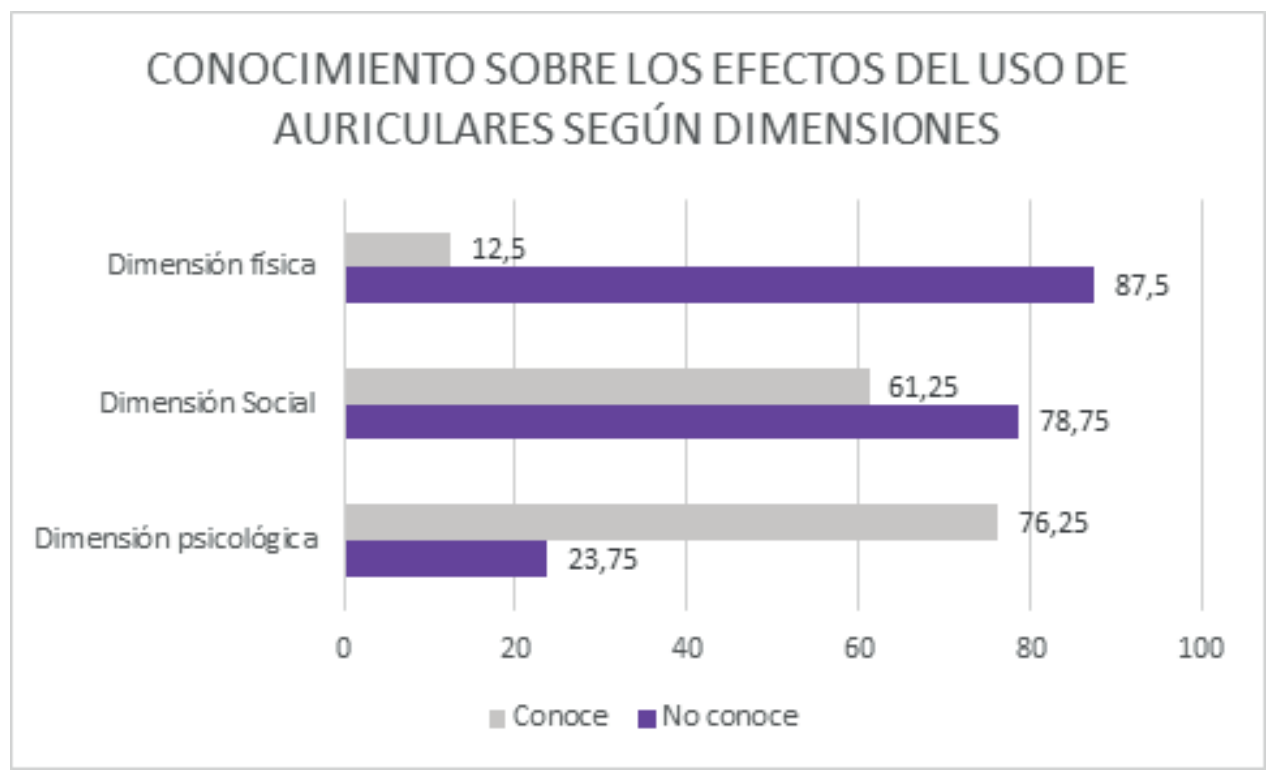

Fuente: Los Autores.

Los estudiantes de Química de la Universidad de Pamplona sede Principal conocen los efectos del uso de auriculares en la dimensión psicológica con un porcentaje de 76,25\%; por otra en la dimensión física no conocen los efectos que trae el uso de estos en un $87,5 \%$ y referentes a la dimensión social con un resultado del $78,75 \%$ respectivamente desconocen los efectos.

Gráfica 72. Uso de auriculares y conocimiento de los efectos en la salud en estudiantes de Química.

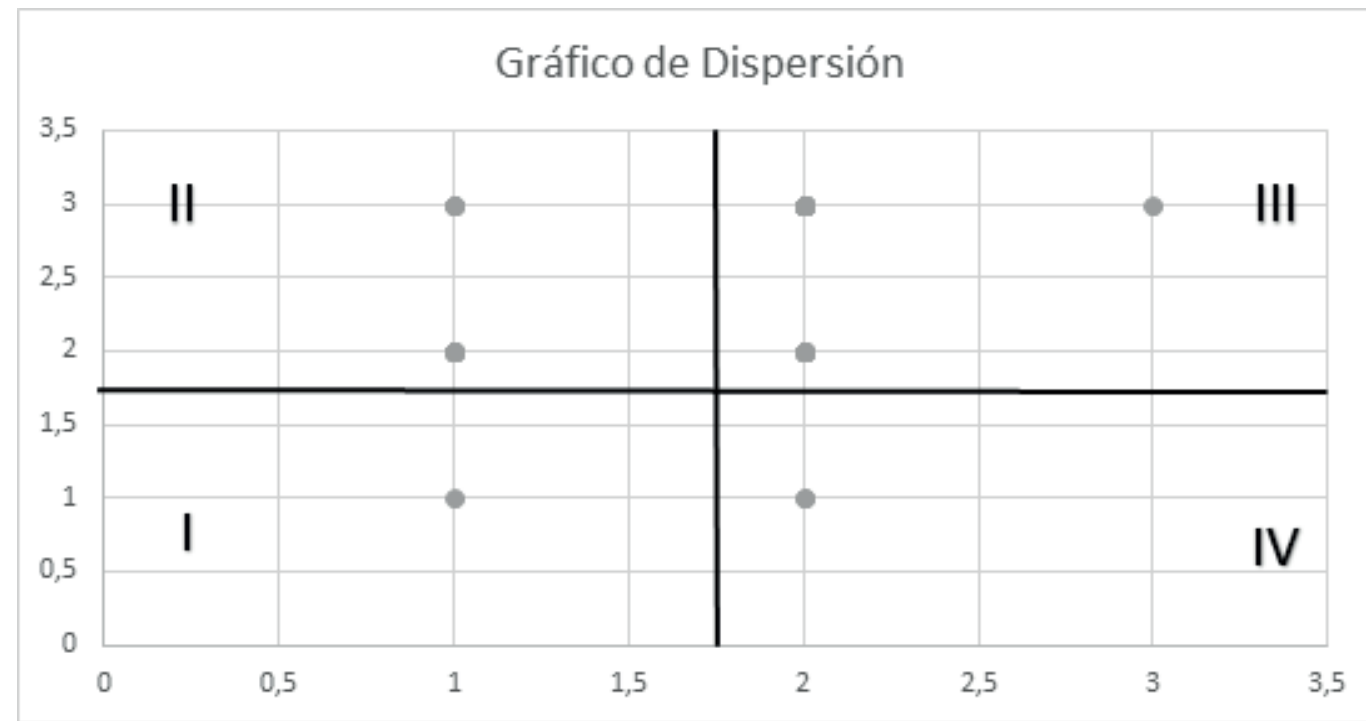

Fuente: Los Autores. 
Los estudiantes de Química de la Universidad de Pamplona sede Principal el 33, hacen uso inadecuado y no conocen los efectos que causan el uso de los auriculares, el $68 \%$ hacen uso inadecuado, pero conocen los efectos de los auriculares, sin embargo, no hay estudiantes que hagan un uso adecuado y conozcan los efectos de igual manera tampoco hay estudiantes que hagan un uso adecuado, pero no conozcan los efectos.

\section{FISICA}

Gráfica 73. Género estudiantes del proqrama de Fisica.

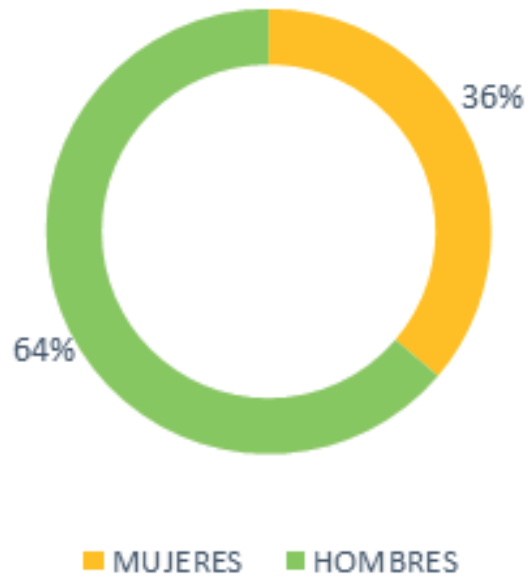

Fuente: Los Autores.

Para una muestra de 80 estudiantes pertenecientes al programa de Física en donde se encontró que el $64 \%$ son hombres y un $36 \%$ son mujeres, se observa que una proporción mayor de la población está representada por hombres y en menor medida por mujeres. por otro lado, las edades de la muestra están representadas de manera porcentual en ek grafico a continuación.

Gráfica 74. Edades en estudiantes de Física.

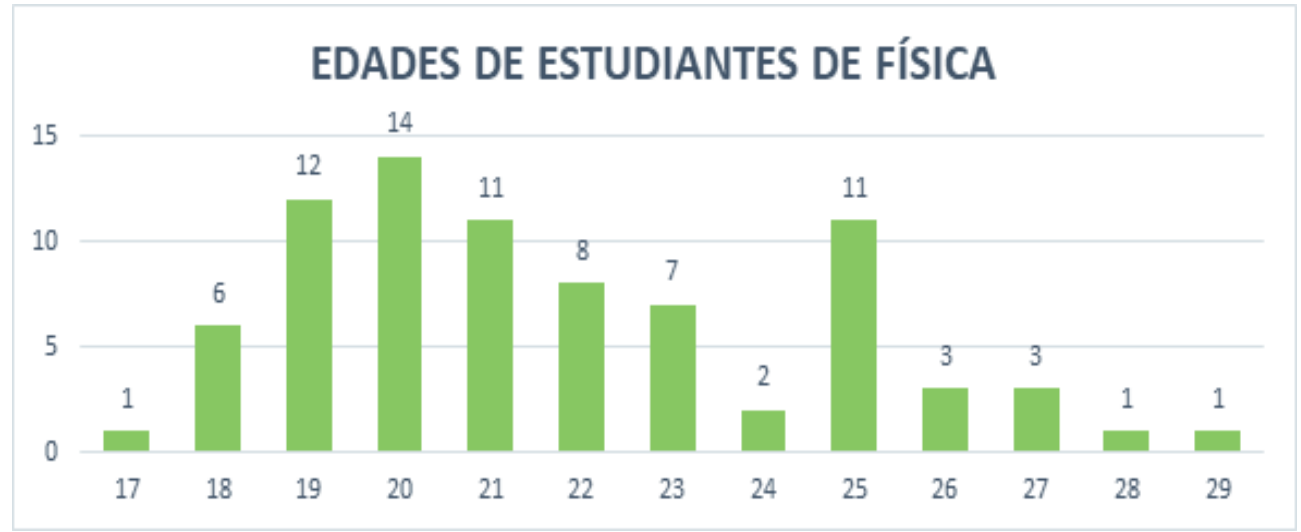

Fuente: Los Autores.

Las edades que predominan en la carrera de Física de la universidad de pamplona están entre los 17

Revista Científica Signos Fónicos, 2019,5(2): 97-150. ISNN 2422-1716. 
a los 20, el mayor número de estudiantes se encuentra en una edad entre 19 a 21 años, comienza a disminuir hasta los 24 años, en la edad de 25 existe un número significativo de estudiantes (11) y de 26-29 la frecuencia de los datos es mínima.

Gráfica 75. Valoración de uso de Auriculares en estudiantes de Física.

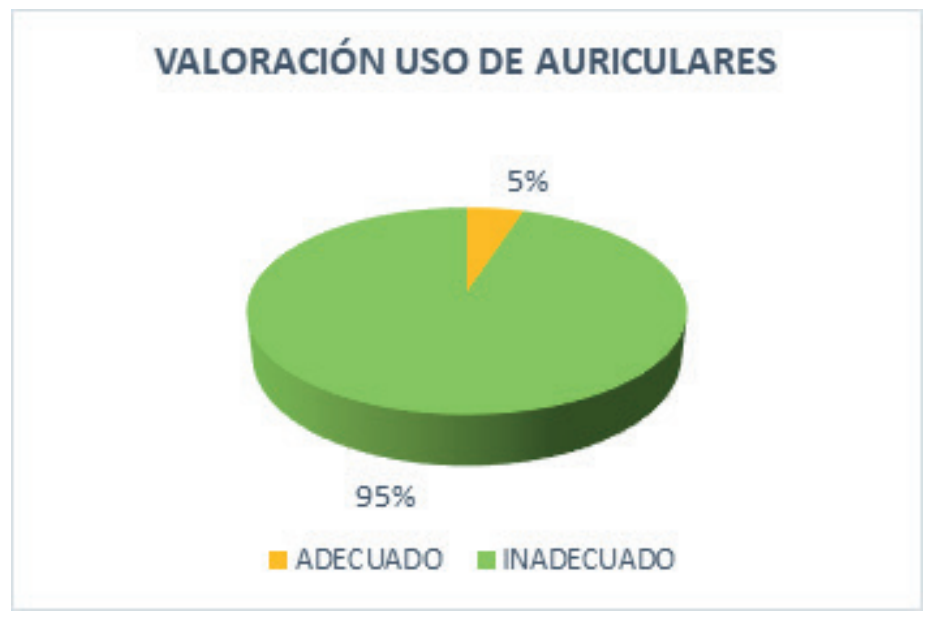

Fuente: Los Autores.

Los estudiantes de física de la Universidad de Pamplona sede principal hacen uso inadecuado de los auriculares, representado por un $95 \%$ de la muestra total tomada para el estudio; en contraste solo el $5 \%$ de los estudiantes de estas carreras hacen un uso adecuado.

Gráfica 76. Tipo de auriculares que utilizan los estudiantes de Física.

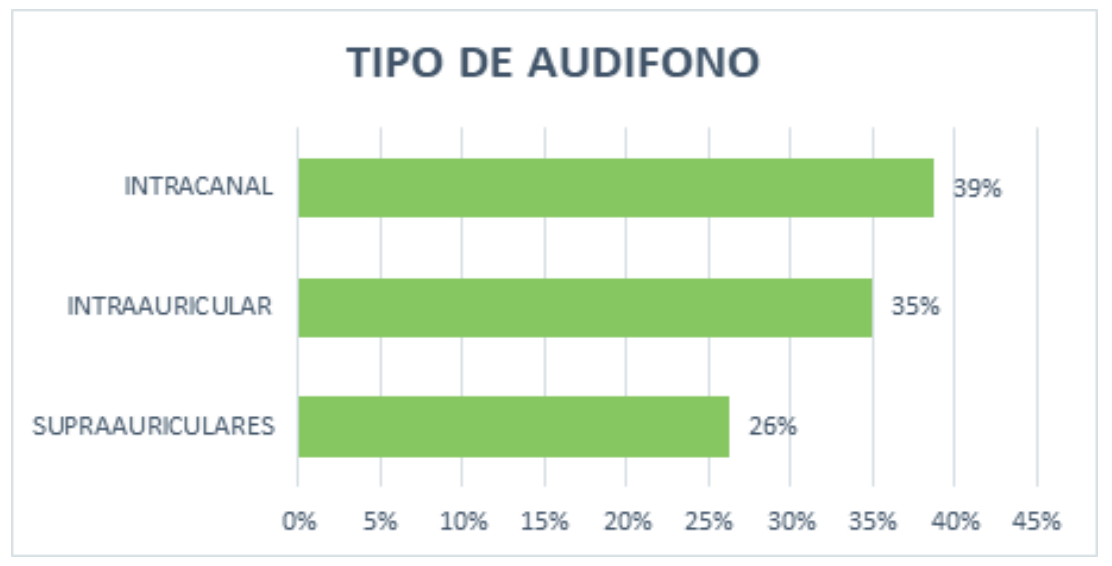

Fuente: Los Autores.

Así mismo, Los estudiantes de Física en mayor medida hacen uso de los auriculares de tipo intracanal en una proporción representada por 39\%, seguido se encuentra el uso de intrauricular con un $35 \%$ y por último se encuentran aquellos estudiantes que utilizan tipo supraauricular que está dado por un $26 \%$. 
Gráfica 77. Horas de uso diarias de uso de auriculares en estudiantes de Física.

\section{HORAS DIARIAS DE USO DE AURICULARES}

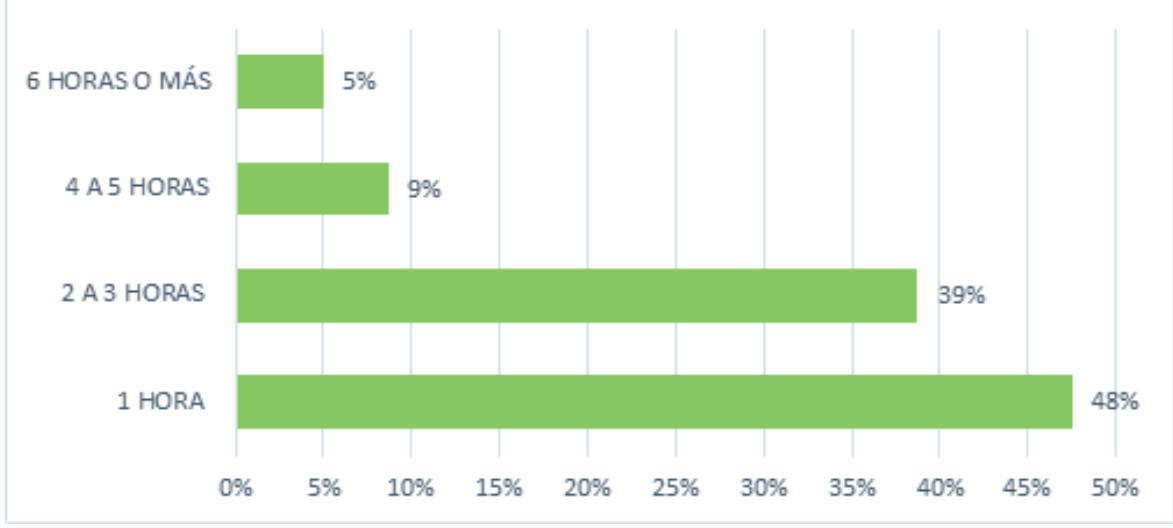

Fuente: Los Autores.

Los estudiantes de Física de la Universidad de Pamplona sede principal en su mayoría utilizan los audífonos 1 hora diaria (48\%), seguido de aquellos que hacen uso 2 a 3 horas diarias con un (39\%) y de 4 a 5 horas con un (9\%), por último, se encuentran aquellos estudiantes que utilizan los audífonos 6 horas o más horas al día están representadas por el (5\%).

Gráfica 78. Conocimiento de los efectos del uso de auriculares en estudiantes de Fisica.

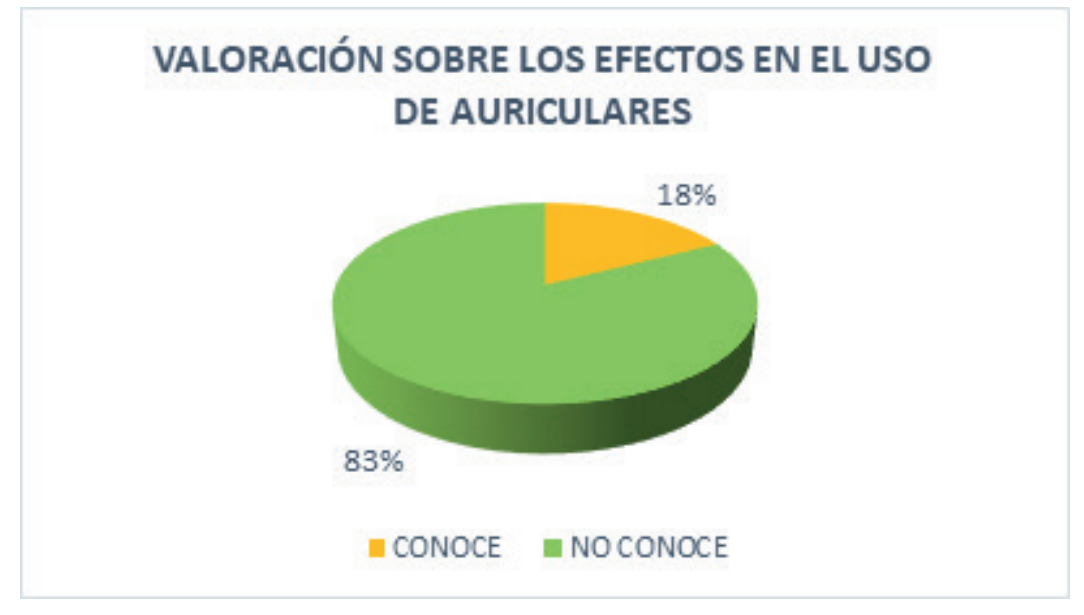

Fuente: Los Autores.

Los estudiantes de Física de la Universidad de Pamplona sede principal no conocen sobre los efectos que tiene el uso de auriculares con un porcentaje del $83 \%$, por otro lado, los estudiantes que no conocen sobre los efectos en la salud que genera el uso de auriculares repercute al $18 \%$. 
Gráfica 79. Conocimiento Sobre los efectos del uso de Auricular de los estudiantes de Física.

\section{CONOCIMIENTO SOBRE LOS EFECTOS DEL USO DE AURICULARES SEGÚN DIMENSIONES}

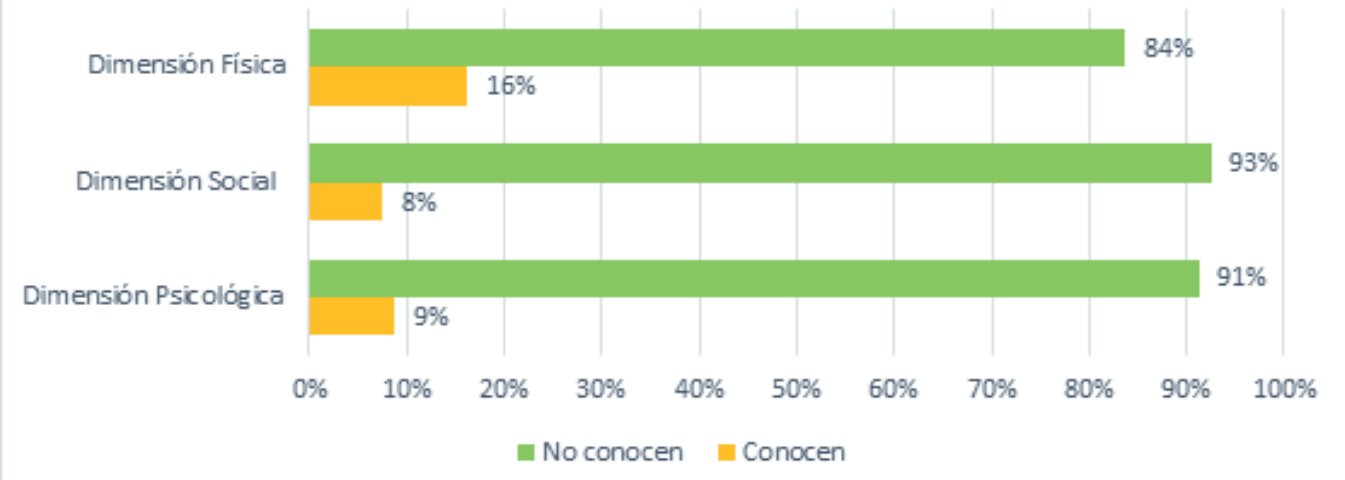

Fuente: Los Autores.

Los estudiantes de Física de la Universidad de Pamplona sede Principal no conocen los efectos que generan en la salud el uso excesivo de auriculares, en la dimensión física con un resultado del $84 \%$, en la dimensión social con un resultado (93\%) y referentes a la dimensión psicológica con un $9 \%$.

Gráfica 80. Uso de auriculares y conocimiento de los efectos en la salud en estudiantes de Fisica.

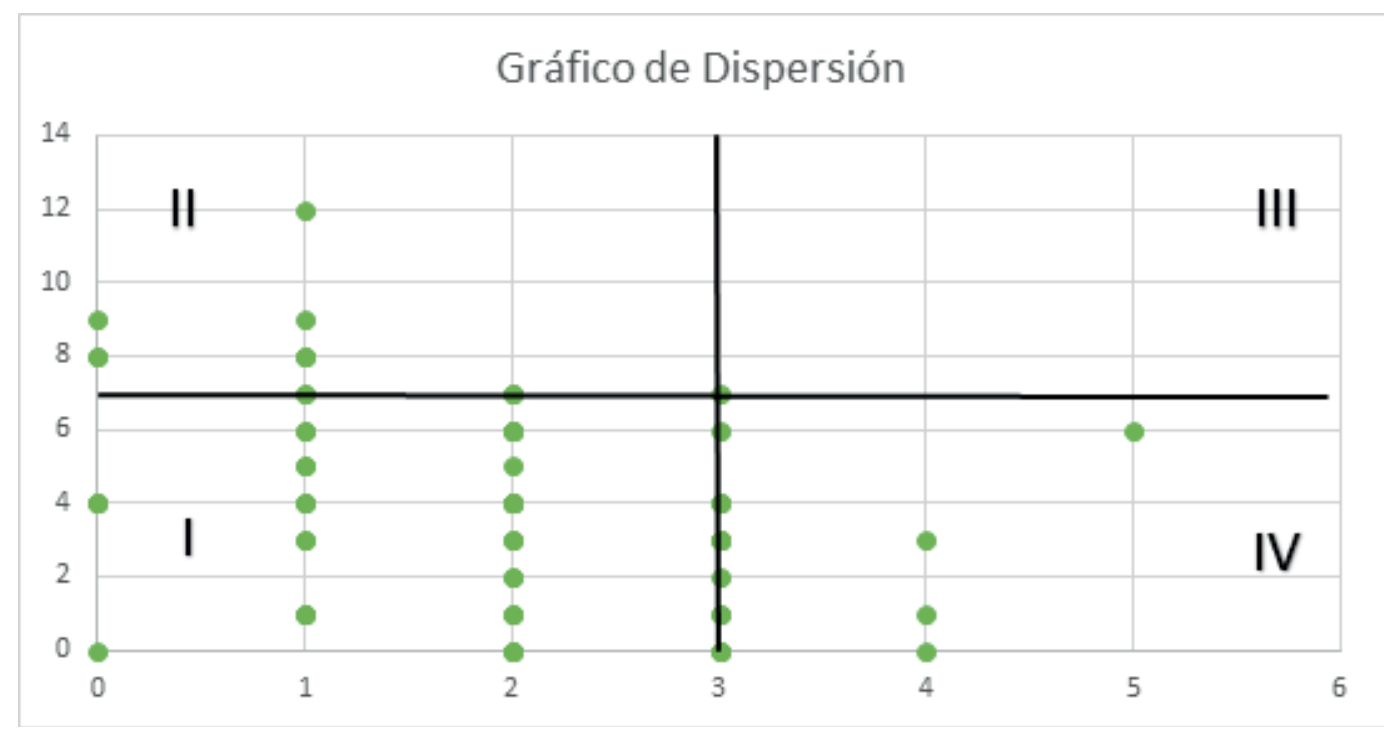

Fuente: Los Autores.

Los estudiantes de Física de la Universidad de Pamplona sede Principal el $78 \%$, hacen uso inadecuado y no conocen los efectos que causan el uso de los auriculares, el $18 \%$ hacen uso inadecuado, pero conocen los efectos de los auriculares, por otra parte, no hay estudiantes que no hacen uso adecuado, pero conocen los efectos que estos causan y por último el $5 \%$ de los estudiantes hacen un uso adecuado, pero no conocen los efectos que estos dispositivos pueden llegar a causar. 


\section{COMPARATIVO ENTRE LA FACULTAD DE ARTES Y HUMANIDADES, SALUD Y CIENCIAS BÁSICAS}

Grafica 81. Valoración uso de auriculares en las facultades de Salud, Ciencias Básicas y Artes y Humanidades.

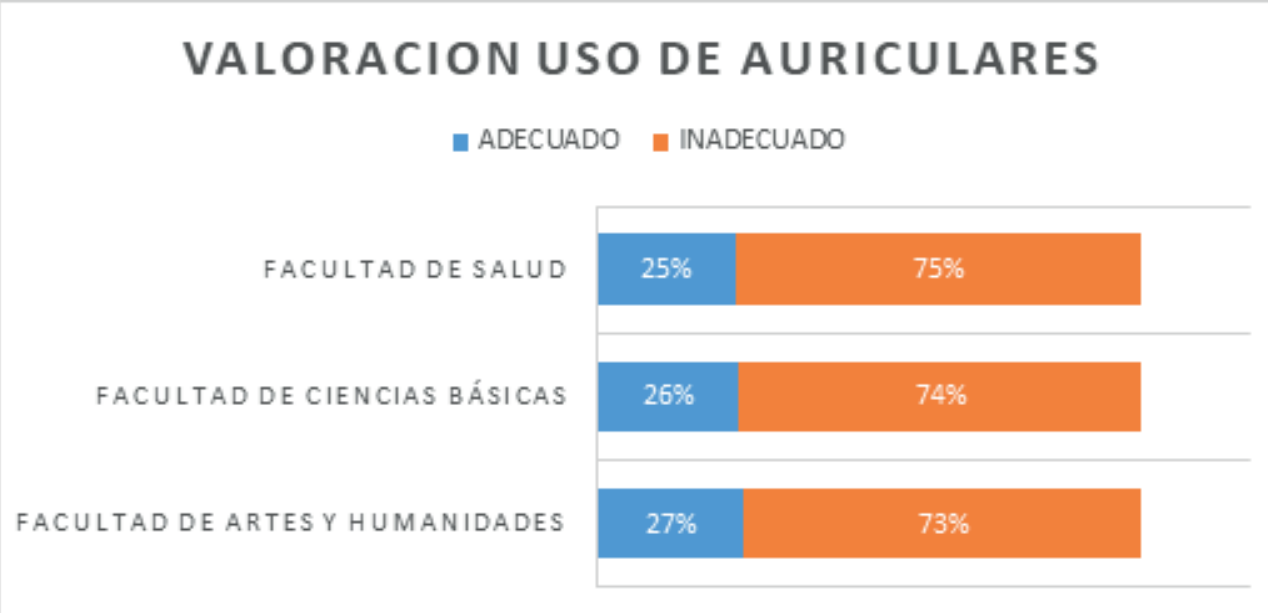

Fuente: Los Autores.

En la valoración sobre el uso de auriculares, se evaluó el uso adecuado e inadecuado del mismo en donde se realizaron encuestas en la Facultad de Salud, Ciencias Básicas y Artes y Humanidades, encontrado lo siguientes resultados, el mayor uso inadecuado se presenta en la Facultad de Salud con un $75 \%$ seguido de la Facultad de Ciencias Básicas con un $74 \%$ y por ultimo Humanidades con $73 \%$; estos datos permiten afirmar que el uso inadecuado presenta un comportamiento similar en las tres facultades evaluadas.

Grafica 82. Valoración sobre los efectos en uso de auriculares en las facultades de Artes y Humanidades, Salud y Ciencias Básicas.

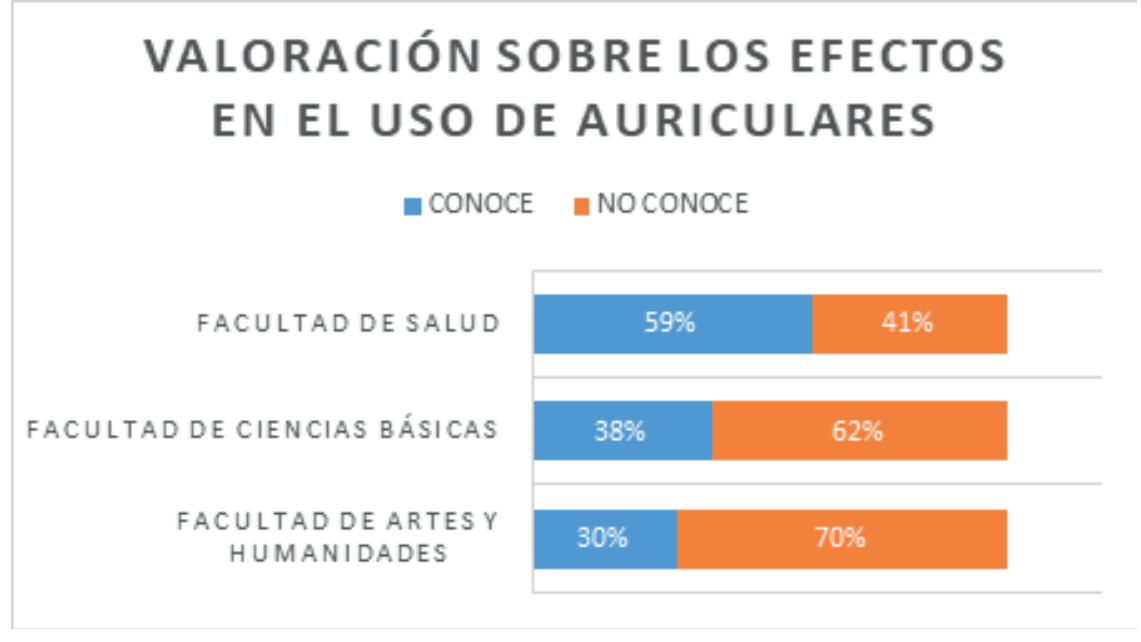

Fuente: Los Autores.

En la valoración sobre los efectos que trae el uso de auriculares, se evaluó el conocimiento o no del mismo en donde se realizaron encuestas en la Facultad de Salud, Ciencias Básicas y Artes y Humani- 
dades, encontrado lo siguientes resultados, el mayor descornamiento se presenta en la Facultad de Artes y Humanidades con $70 \%$ de la muestra poblacional tomada, seguido de la Facultad de Ciencias Básicas con un $62 \%$ y por último se encuentra la Facultad de Salud, en ella el descornamiento sobre los efectos en el uso de auriculares alcanza el $41 \%$ por lo que permite concluir que la Facultad que más conocimiento tiene sobre los efectos es la Facultad de Salud, pero aun así en un margen muy pequeño.

Grafica 83. Valoración sobres los factores psicológicos en las Facultades de Salud, Artes y Humanidades y Ciencias Básicas.

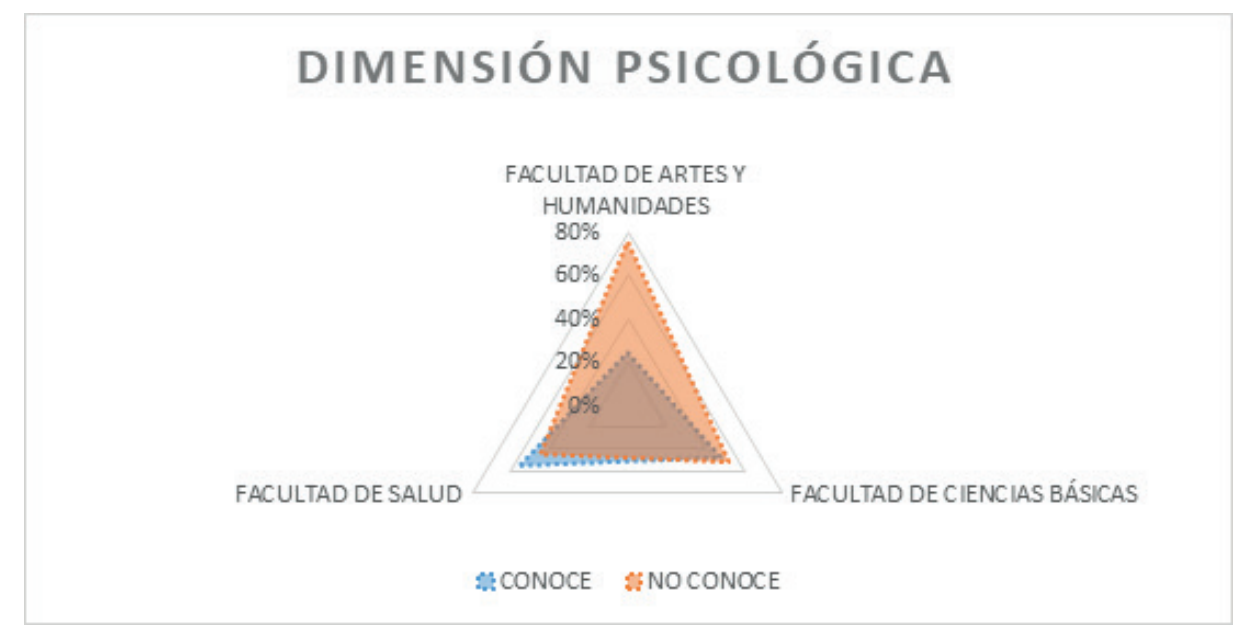

Fuente: Los Autores.

En la dimensión psicológica se encuentra que en la Facultad de Humanidades no conoce los efectos que trae el uso de auriculares, en la Facultad de Ciencias Básicas el conocimiento o no de los efectos se comporta de forma similar; por otro lado, en la Facultad de Salud existe un mayor conocimiento sobre los efectos psicológicos que trae el uso de auriculares.

Grafica 84. Valoración sobres los factores sociales en las Facultades de Salud, Artes y Humanidades y Ciencias Básicas.

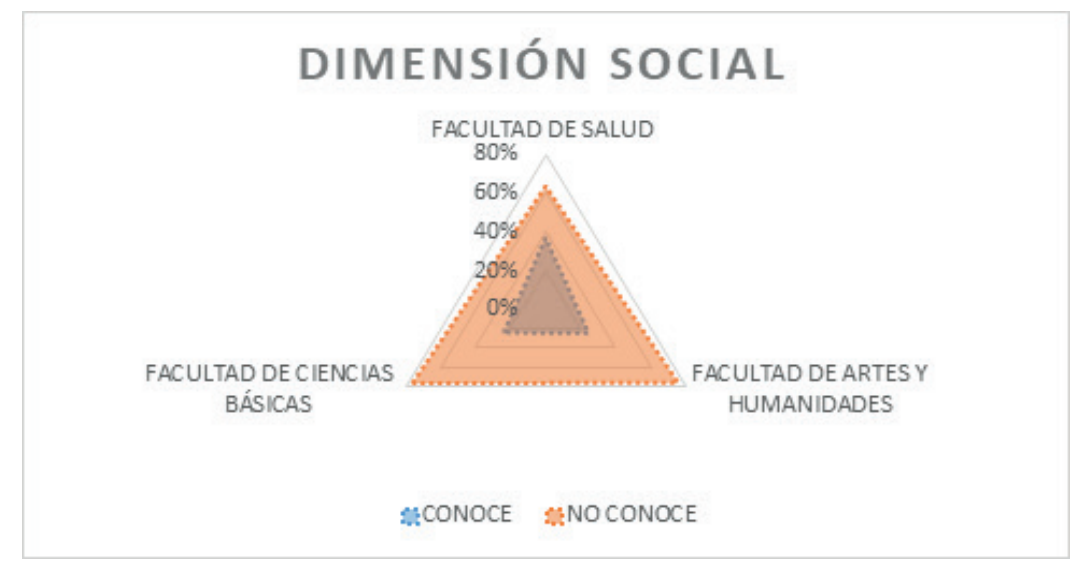

Fuentes: Los Autores.

Revista Científica Signos Fónicos, 2019,5(2): 97-150. ISNN 2422-1716. 
En la dimensión social se encuentra que en mayor proporción la Facultad de Humanidades, Ciencias Básicas y Salud no conoce los efectos sociales que trae el uso de auriculares.

Grafica 85. Valoración sobre el factor físico en las Facultades de Salud, Artes y Humanidades y Ciencias Básicas.

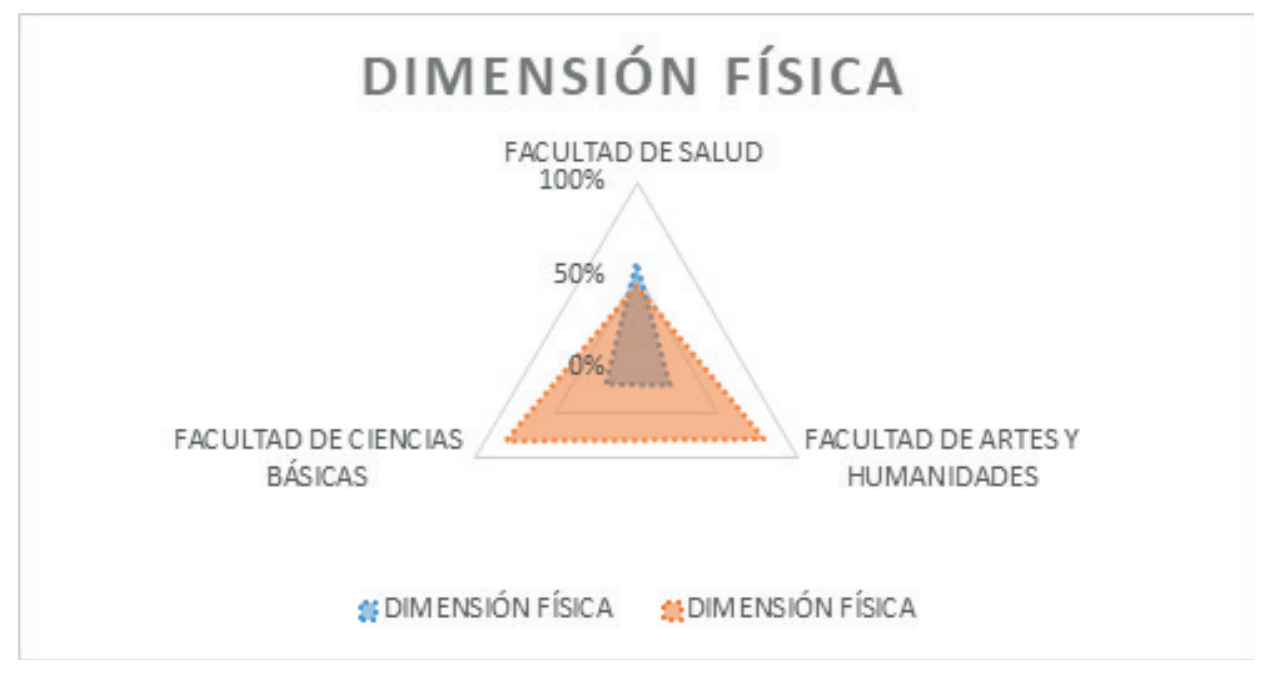

Fuente: Los Autores.

En la dimensión física se encuentra que en la Facultad de Humanidades y Ciencias Básicas en su mayoría no conoce los efectos que trae el uso de auriculares, por otro lado, en la facultad de Salud existe un mayor conocimiento sobre los efectos físicos que trae el uso de auriculares.

Grafica 86. Valoración sobres las horas diarias de uso de auriculares en las Facultades de Salud, Artes y Humanidades y Ciencias Básicas.

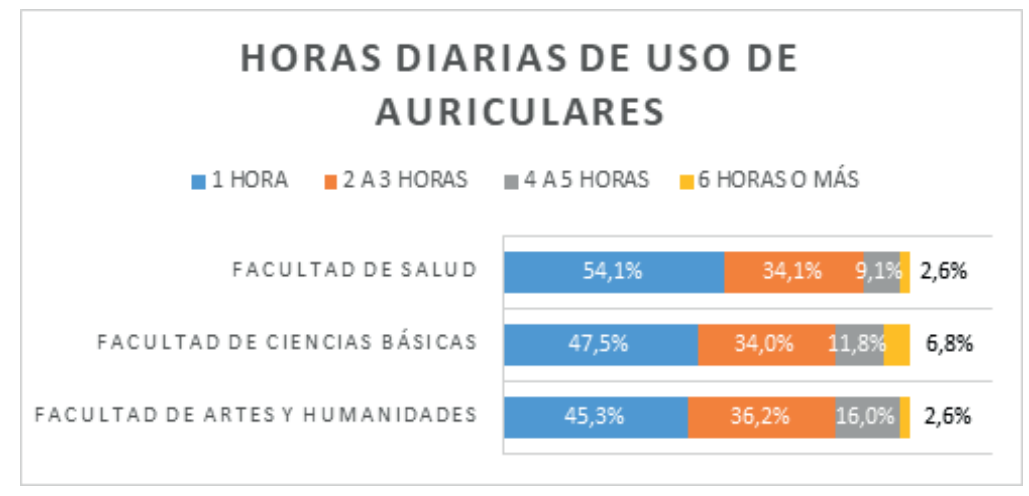

Fuente: Los Autores.

En las horas diarias de uso de auriculares las tres facultades: Humanidades, Ciencias Básicas y Salud usan 1 hora los audífonos en proporciones similares 54,1\% 47,5\% y 45,3\% respectivamente, el uso de 2 a 3 horas también presenta resultados similares, aunque la Facultad de Artes tiene un mayor uso $36,2 \%$ seguido de Salud y Ciencias Básicas que tienen el mismo porcentaje 34\%. En el uso de 4 a 5 horas diarias si existen marcadas diferencias en las 3 facultades, Artes y Humanidades presenta el mayor

Revista Científica Signos Fónicos, 2019,5(2): 97-150. ISNN 2422-1716. 
porcentaje de uso 16\% seguido de Ciencias Básicas con 11,89\% y por último se encuentra la Facultad de Salud 9,1\%; por último se encuentran aquellos estudiantes que utilizan 6 horas o más los audífonos, estos están respetados por una pequeña parte de la muestra poblacional en las tres facultades, la Facultad de Ciencias Básicas 6,8\%, la Facultad de Salud y Artes y Humanidades hacen uso en este tiempo de forma similar $2,6 \%$.

\section{ANÁLISIS Y DISCUSIÓN}

De este modo en la investigación se encontró, que, en los programas de Música, Comunicación Social, Filosofía, Artes Visuales, hacen mayor uso de los auriculares a la hora de realizar trabajos académicos y en los momentos libres o de ocio, sin embargo, se observó que los estudiantes del programa de Derecho utilizan en menor medida estos dispositivos en las actividades mencionadas anteriormente. Estos resultados se asemejan a lo hallado por Gómez A, Reyes J,(7)(8) quienes encontraron que el 94\% de la población estudiada tiende al uso de dispositivos móviles de audio.(9) En un estudio realizado por (Chaves Peñaranda, 2010), refieren que muchos jóvenes son considerados como población vulnerable debido al uso reproductores de audio digital (RAD).(10)(11)

Según la Organización Mundial de la Salud mencionan que cerca de 1100 millones de jóvenes de todo el mundo están en riesgo de sufrir pérdida de audición debido a prácticas auditivas perjudiciales por el uso prolongado de estos reproductores de audio. Colombia no es ajena a esta problemática, en un estudio realizado por (Chaves Peñaranda, 2010), refieren que muchos jóvenes son considerados como población vulnerable debido al uso reproductores de audio digital (RAD). (12)(13)(14)

De acuerdo a los resultados se observó que los estudiantes de los programas de Comunicación Social, Derecho y Filosofía tienen un uso adecuado de los auriculares según las dimensiones de tiempo ya que los utilizan una hora al día, por el contrario, los estudiantes de Música y Artes Visuales utilizan de manera inadecuada estos dispositivos de audio debido a que los manipulan de 2 a 3 horas al día. De acuerdo a la OMS, el tiempo permitido de uso de auriculares a bajo volumen sería una hora al día, lo que si supera este tiempo estaría ocasionando daño en la persona,(15)(16) de acuerdo a la investigación se evidencia que, el tiempo de uso de los auriculares es el permitido en los estudiantes de Comunicación Social, Derecho y Filosofía y probablemente no puede llegar a causar un problema en la audición, sin embargo los estudiantes de Música y Artes Visuales exceden las horas requeridas para el uso de estos dispositivos. De acuerdo a investigaciones realizadas por José Rodríguez y Carmen Peña manifiestan que los dispositivos de audio pueden utilizarse a intensidades adecuadas: menos del $60 \%$ de su potencia máxima y durante $60 \mathrm{~min}$ cada vez, de lo contrario repercuten en el equilibrio biopsicosocial del individuo(17) De igual forma, Biassoni y Col., en el 2005, estudiaron los efectos de la explosión al ruido recreativo en los adolescentes y concluyeron que el uso excesivo tanto en volumen como en tiempo, de un reproductor de audio personal provoca pérdida de la audición.(18)

Por otra parte, los auriculares intracanales son los de mayor preferencia en los programas de Derecho, Artes Visuales, sin embargo, los estudiantes de Comunicación Social, Música y Filosofía tienen predilección por los auriculares de tipo intraaricular. Según González la principal característica de estos dos tipos, es que, al estar ligeramente separados del oído generan una mayor sensación natural del campo estéreo y una reproducción de frecuencias más lineal y precisa. Tanto unos como otros pueden ser abiertos o cerrados. Esta última característica se refiere al aislamiento físico de las señales acústicas exteriores, los abiertos permiten el paso del sonido ambiente, mientras que en los cerrados la interferencia exterior es filtrada físicamente.(19)

De igual manera se halló que los estudiantes del programa de Comunicación Social desconocen los efectos en las dimensiones físicos y sociales; seguidos por los estudiantes de Música, Filosofía y Artes Visuales quienes desconocen los efectos psicológicos, por el contrario, los estudiantes de Derecho desconocen los efectos en las dimensiones físicos, sociales y psicológicos. Estos resultados pueden confrontarse con lo encontrado por Huisacayna F, Aguilar Y, Flores A, Yupanqui R1(20)(21) quienes estudiaron acerca del conocimiento del daño a la salud por el uso excesivo de auriculares al momento de escuchar música el cual el 99,09\% refieren no conocer esta serie de riesgos.

Los casos analizados en la investigación revelan que los estudiantes pertenecientes a los programas de la Facultad de Artes y Humanidades manifiestan síntomas tales como tinnitus, cefalea y otalgia con frecuencia después de escuchar música. Así mismo los estudiantes manifestaron que últimamente su capacidad auditiva no ha disminuido.

En cuanto a los efectos psicológicos como el estrés, insomnio, los problemas de concentración y el bajo

Revista Científica Signos Fónicos, 2019,5(2): 97-150. ISNN 2422-1716. 
rendimiento académico fueron manifestados en gran porcentaje por todos los estudiantes de la facultad de artes y humanidades sin embargo los estudiantes no atribuyen estos efectos al uso de auriculares; respecto a los efectos sociales, los estudiantes de los programas de la facultad artes y humanidades presentan dificultad para comunicarse socialmente y se sienten bien consigo mismo al momento de escuchar música con los auriculares. Para finalizar los estudiantes manifiestan no sentir ninguna necesidad de recurrir con urgencia a la utilización de estos dispositivos musicales. Por otra parte, estos resultados no se asemejan a el alcance del fenómeno estudiado por Harrison el cual va más allá de la repercusión orgánica, ya que el impacto se extiende también a la esfera psicosocial, la irritabilidad, el aislamiento y el insomnio, son algunos de los síntomas encontrados.(22)

Por otra parte, se encontró que, en los programas de Física, Química, Microbiología hacen mayos uso de los auriculares a la hora de realizar trabajos académicos y en los momentos libres y de ocio, sin embargo, se observó que los estudiantes de los programas de Matemáticas y Biología utilizan en menor medida estos dispositivos en las actividades mencionadas anteriormente. Según (Colombo, Majul, \& Casa prima, 2012).(23)(24) En los últimos años el uso de dispositivos de audio personales, tales como reproductores $\mathrm{mp} 3$ y teléfonos móviles con música, se han vuelto más populares, sobre todo en los adolescentes y los jóvenes. De igual manera en una investigación realizada por Francisco Lorenzo Carrasco refiere que existe una preocupación por el alarmante crecimiento de los problemas de la audición en los jóvenes. Su causa son los hábitos perniciosos de oír música con auriculares, la moda de asistir a locales cerrados con un nivel de ruido ensordecedor.(25)(26)

Conforme a los resultados se obtuvo que los estudiantes de los programas Física, Química, Matemáticas y Biología, hacen uso adecuado de los auriculares según la dimensión de tiempo ya que los utilizan 1 hora al día, contrario a esto se encuentran los estudiantes de Microbiología realizan uso inadecuado de estos dispositivos de audio debido a que el periodo de tiempo que manipulan es de 2 a 3 horas al día. Según Fligor y Cox en el 2004, en el estudio que realizó con reproductores CD cuando se usan auriculares, los oyentes deben limitar la duración del tiempo en que los utilizan a 1 hora por día, con un ajuste de volumen del $60 \%$ del nivel de volumen máximo, a la que llamaron la regla del 60-60.(27) (28) Así mismo (Noguéz Trejo \& Martínez Wbaldo, 2002) (29)(30)(31) refiere que el uso continuo de auriculares para escuchar música contribuye al daño irreversible en las células ciliadas debido a la presión sonora que ejerce el nivel de volumen cerca del oído ocasionando pérdida de la audición, ésta se considera una enfermedad silenciosa, ya que se instala lentamente.(32)(33)

No obstante, los auriculares intracanales son los de mayor preferencia en los programas de Física, Química, Microbiología y Matemáticas, sin embargo, los estudiantes de Biología tienen predicción por auriculares intrauricular. En los estudios realizados por (BREINBAUER $\mathrm{H}$, ANABALON J.)(34) se afirma respecto a los audífonos, que los intraauriculares tienen una mayor salida. Además, los supraauriculares suman un efecto de atenuación del ruido ambiental, mejorando la relación señal/ruido y, por ende, logrando una escucha confortable con menor presión sonora.(35)(36)

Asimismo, se evidenció que los estudiantes de los programas de Microbiología, Química Matemáticas y Biología desconocen los efectos en las dimensiones físicas y social, por el contrario, los estudiantes de Física desconocen los efectos tanto físicos como sociales y psicológicos.(37)(38) Así como lo menciona Hector Hernandez (2007)(39) se habla de una generación de ruido gracias a que los jóvenes realizan uso excesivo de los reproductores de música individuales,(32) esto puede llevar a producir un sentimiento de aislamiento en los participantes y múltiples percepciones de rechazo dentro del entorno al que corresponde, lo que puede producir una respuesta de encierro interno.(40)

Tras el análisis de los resultados se halló que los estudiantes pertenecientes a los programas de la faculta de Ciencias Básicas manifiestan síntomas tales como, tinnitus, cefalea y otalgia con frecuencia después de escuchar música, sin embargo, no presentan disminución en la agudeza auditiva. Autores de un estudio realizado en México, (41)(42)afirman que mientras mayor exposición, intensidad de volumen y susceptibilidad de los adolescentes por uso de auriculares mayor será la presencia de acúfenos como primer síntoma, deterioro transitorio o permanente del umbral auditivo, y como síntomas no auditivos: trastornos ansiosos, depresivos y cefalea, pérdida de concentración y memoria. (43)(44)(45)

Según los resultados obtenidos sobre el uso de auriculares, se evaluó el uso adecuado e inadecuado del mismo, donde se evidencia mayor uso inadecuado en la Facultad de Salud, seguido de la Facultad de Ciencias Básicas y por último la Facultad de Artes y Humanidades.(46) Estos datos permiten afirmar que los resultados son equivalentes en las tres Facultades. Según (Voguel y cols., 2008),(47) el uso de auricular depende del tipo de actividades a las que la persona se encuentra sometida durante el día, además de que, al no mostrarse correlaciones significativas entre el uso de reproductores portátiles de

Revista Científica Signos Fónicos, 2019,5(2): 97-150. ISNN 2422-1716. 
entretenimiento y algún padecimiento auditivo, parece desestimarse la conexión entre la adecuada percepción de la posibilidad de que haya un daño.(48)(49)(50)

En la valoración sobre los efectos que trae el uso de auriculares, se evaluó el conocimiento o no del mismo en donde se encontró que el mayor descornamiento se presenta en la Facultad de Artes y Humanidades, seguido de la Facultad de Ciencias Básicas sin embargo la Facultad de Salud presenta mayor conocimiento sobre los efectos que pueden llegar ocasionar estos dispositivos. (51)(52) Según el estudio realizado por los autores Dr Cesar Rodríguez Medrano y Dr Rubén Rodríguez Medrano, mencionan que, en el proceso de la audición, el sonido es convertido de variaciones en la presión del aire a una serie de impulsos nerviosos; por lo tanto, el sonido no es un asunto solamente físico, sino también mental, dada la interpretación que el cerebro hace del sonido y de las reacciones de las personas ante él.(53)(54)

De acuerdo con el conocimiento de las dimensiones evaluadas se observó que la Facultad de Artes y Humanidades y la Facultad de Ciencias Básicas, no conocen los efectos correspondientes a las dimensión psicológica, dimensión física y dimensión social. (55)(56) Contrario a esto la facultad de salud, la cual presenta un conocimiento adecuado de las tres dimensiones mencionadas anteriormente. Según una investigación realizada en México,(57) afirman que mientras mayor exposición, intensidad de volumen y susceptibilidad de los adolescentes por uso de auriculares mayor será la presencia de acúfenos como primer síntoma, deterioro transitorio o permanente del umbral auditivo, y como síntomas no auditivos: trastornos ansiosos, depresivos y cefalea, pérdida de concentración y memoria.(58)(59) (60)

En las horas diarias de uso de auriculares, se obtuvo como resultado que, en el tiempo de 1 hora, se encuentra primeramente la Facultad de Artes y Humanidades, seguido de la Facultad de Ciencias Básicas y por Ultimo se encuentra la Facultad de Salud. Seguidamente en el tiempo de 2 a 3 horas la Facultad de Artes y Humanidades presenta el mayor porcentaje, sin embargo, las Facultades de Salud y Ciencias Básicas manifiesta el mismo nivel de uso, por ultima de 4 a 6 horas en la facultad de salud con mayor porcentaje manipulación de estos dispositivos es la Facultad de artes y humanidades, continuando con la Faculta de Ciencias Básicas y la Faculta de Salud. Al contario del estudio realizado por Córdoba se encontró que un $63 \%$ de los estudiantes se expone a 4 horas diarias y un $13 \%$ de estudiantes supera las 4 horas.

\section{CONCLUSIONES}

Como conclusión general se observa un alto índice de uso excesivo de auriculares musicales en los estudiantes de la facultad de artes y humanidades, seguidamente se encuentra la facultad de ciencias básicas. Por ello radica la importancia de concientizar a los estudiantes sobre los efectos nocivos causados por el uso excesivo de auriculares y contribuir al diagnóstico temprano en caso de que exista algún tipo de alteración auditiva para la mejora de una óptima salud auditiva.

Se evidencio que los estudiantes de la facultad de salud de la universidad de pamplona tienen conocimiento en el área sobre las repercusiones que pueden llegar a ocasionar el uso excesivo de auriculares sin embargo hacen un mayor uso sin las debidas precauciones en tiempo y tipo. Los estudiantes de Las Facultades de Ciencias Básicas y Artes y Humanidades tiene conocimiento general del uso de auriculares pero no conocen los efectos en cada una de las dimensiones caracterizadas y aun así hacen menor uso en tiempo de estos dispositivos.

Según los resultados obtenidos sobre el uso de auriculares musicales se determinó que existe una equivalencia entre los estudiantes de la Faculta de Salud, Facultad de Artes y Humanidades y la Facultad de Ciencias Básicas teniendo en cuenta el gran porcentaje de manipulación de estos dispositivos en la población mencionada anteriormente.

Para finalizar según el conocimiento de los efectos que pueden llegar a causar los dispositivos musicales Se concluye que la Facultad de Artes y Humanidades y la Facultad de Ciencias Básicas, no conocen los efectos correspondientes a las dimensión psicológica, dimensión física y dimensión social. Contrario a esto la facultad de salud, la cual presenta un conocimiento adecuado de las tres dimensiones mencionadas anteriormente.

El uso de auriculares musicales en los estudiantes de las facultades de Ciencias Básicas y Artes y Humanidades de la universidad de pamplona es inadecuado con respecto al tiempo y al tipo de auriculares

Revista Científica Signos Fónicos, 2019,5(2): 97-150. ISNN 2422-1716. 


\section{REFERENCIAS BIBLIOGRÁFICAS}

1. Cañas SJA, Redondo AL, Nieto ÁPA, Portilla EMP, Rangel RLE. Metodologia: Tamiz Auditivo Neonatal. Rev Científica Signos Fónicos [Internet]. 2017 Oct 25;2(3).

2. García Zmc. Conocimiento De Los Adolescentes Sobre La Pérdida Auditiva Inducida Por Ruido. 2013;97.

3. Andres N, Flores O, Edith K, Perez P. Frecuencia De Uso De Reproductores Personales De Música. 2011;9:9-11.

4. Villena Ehh. Factores Que Influyen En La Audición De Estiudiantes Preuniversitarios Usuarios De Dispositivos Musicales De Uso Personal. 2018;68.

5. Gutiérrez-Farfán I, Alonso-Luján L, Hernández Sl. Correlación De Test Sobre Exposición A Ruido Y Hallazgos Audiológicos Evaluados En Niños Y Adolescentes Mexicanos. An Medicos. 2008;53(3):143-8.

6. Gallego CAM, Parada YPJ, Nieto APA, Brito YR, Redondo AL, Ascanio J, et al. Determinantes Sociales En Salud: Construccion De Conocimiento A Traves De La Cartografia Social. Rev Científica Signos FónicoS [Internet]. 2015 Oct 1;1(3).

7. Abraham Mg, Roggio I, Villalobo Jp, Hinalaf M, Ester C, Serra Mr. Adolescentes. 2011;Xxx:1-4.

8. Amaierako G, Trabajo L, Grado F De. Encuesta Sobre Hábitos Y Uso De Aparatos Electrónicos Con Auriculares En Adolescentes. 2018;

9. Moya MP. Lactancia Materna Y Su Contribución Al Adecuado Desarrollo Del Sistema Estomatognático Y Sus Funciones. Rev Científica Signos Fónicos [Internet]. 2015 Nov 11;1(2).

10. Castro Cf, Liliana S, Velandia G, Yanneth A, Pinilla J. Estado Auditivo De Jóvenes Usuarios De Reproductores De Audio Digital. Available From: Http://Repositorio.Iberoamericana.Edu.Co/Bitstream/001/390/5/Artículo.Pdf

11. Garcia MV, Melo PAH, Guerrero DFF, Claro AKP. Línea Funcional Como Herramienta De Screening Para La Evaluación De La Deglución En Líquidos. Rev Científica Signos Fónicos [Internet]. 2016 Apr $1 ; 2(1)$.

12. Breinbauer K Ha, Anabalón B Jl, Gutiérrez C D, Caro L J. Estimación De Riesgos Y Hábitos De Uso De Reproductores De Música Personal En Una Muestra De Población Chilena. Rev Otorrinolaringol Y Cirugía Cabeza Y Cuello. 2011;71(1):31-8.

13. Rojas Va, Villalba Hg, Villalba G. Factores De Riesgo Audiológicos En Estudiantes De Medicina Evaluados Con Otoemisiones Acústicas. Rev Científica Cienc Médica. 2015;18(2):28-31.

14. Profile See. Neuropsicología Del Daño Cerebral Adquirido Infantil : Evaluación Y Rehabilitación. 2016;(January 2008).

15. Estudiantes: Isidro Pulido Y David Rivas, Asesores: Servín Rivas Y Rabadán Malda. Instituto Politecnico Estudio De La Perdida De Audición Por El Uso De Reprouctores Portatiles De Audio. 2010; Available From: Http://Tesis.Ipn.Mx/Jspui/Bitstream/123456789/11683/1/2.Pdf

16. Díaz Drac, Goycoolea M, Cardemil F. Hipoacusia : Trascendencia, Incidencia Y Prevalencia Hearing Loss : Transcendence , Incidence And Prevalence. Rev Clínica Las Condes. 2016;27(6):731-9.

17. Navia HJR, Capacho EER, Reyes GVP. Análisis Discursivo de la Motricidad Orofacial en Colombia. Rev Científica Signos Fónicos [Internet]. 2015 Jan 30;1(1).

18. Kogan P, Carlos M, Sosa V. Adaa 2009 Portátiles De Música Por Adolescentes. 2009;1-17. Available From: Www.Sennheiser.Com

19. Castro A P, Drápela Jb, García D G, Marín G F, Tomicic G P. Hábitos Auditivos Recreacionales Y Umbral Tonal En La Frecuencia Audiométrica 6.000 Hz En Jóvenes Universitarios. Rev Otorrinolaringol Y Cirugía Cabeza Y Cuello. 2018;78(1):43-51.

20. Microbiología Zc, Microbiología C. Universidad Privada Antenor Orrego. 2008;1-60. Available From: Http://Www.Gonzalezcabeza.Com/Documentos/Crecimiento_Microbiano.Pdf

21. Carolina S, Parra C. Hipoacusia Causada Por El Uso De Estéreos Personales De Audio Por Presión Sonora En Jóvenes De La Institución Educativa Pablo Tarso Y Estrategias Para Disminuir Esta Problemática

Revista Científica Signos Fónicos, 2019,5(2): 97-150. ISNN 2422-1716. 
En Salud Ambiental. 2013;82.

22. Espinoza P, Serpa D, Toral G. Hipoacusia Inducida Por Ruido Recreativo. Panor Med [Internet]. 2014;8(1):70-5. Available From: Http://Dspace.Ucacue.Edu.Ec/Bitstream/Reducacue/5550/3/Hipoacusia Inducida Por Ruido Recreativo.Pdf

23. Ospina Santillán Mk. Uso De Auriculares Y Su Repercusión En La Audición En Estudiantes. Unidad Educativa Francisco Febres Cordero. Cuenca. 2016. 2017;124. Available From: Http://Dspace.Utb.Edu. Ec/Bitstream/49000/2372/1/P-Utb-Fcjse-Ebas-000118.Pdf

24. Crespo N, Rivera E, Figueroa F, Chacón K, López L, Gonzalez S. Métodos De Evaluación De La Voz En Docentes Una Revisión Sistemática. Rev Científica Signos Fónicos [Internet]. 2018 Jun 7;3(1).

25. Gallego CAM, Redondo AL, Cabeza JAM, Gil DMD, Carvajal SMY, Clavijo ZA, et al. Discapacidad: Una Perspectiva Desde Los Ejes De Desigualdad. Rev Científica Signos Fónicos [Internet]. 2017 Oct 25;2(3).

26. Fallis A. Vol. 53, Journal Of Chemical Information And Modeling. 2013. 1689-1699 P.

27. Breinbauer K Ha, Anabalón B Jl. Reproductores De Música Personal: Una Conducta De Riesgo Emergente. Rev Otorrinolaringol Y Cirugía Cabeza Y Cuello. 2009;69(3):213-20.

28. Revisi Cde, Central Hm, Habana L. Reproductores De Música Personal Y Su Influencia Sobre La Salud Auditiva Personal Music Player And Their Influence About The Auditory Health. 1(2):46-58.

29. Colombo M, Majul L. Resultados De Estudios Audiométricos Y Hábitos Auditivos En Jóvenes Universitarios. Result Estud Audiométricos Y Hábitos Audit En Jóvenes Univ [Internet]. 2012;1:77. Available From: Http://Redi.Ufasta.Edu.Ar:8080/Xmlui/Bitstream/Handle/123456789/181/2012_F_002.Pdf?Sequence $=1$

30. Escobedo M, Humberto E, Galindo R, Karina E, Ibarra C, Patricia G, Et Al. De Entretenimiento : Patrones De Uso En Adolescentes Portable Entertainment Players : Use Patterns In Teens. 2012;

31. Gómez Mercado A, Reyes Mendoza Jm. Estudio Del Daño Auditivo Por Uso Excesivo De Auriculares. Rev Tectzapic [Internet]. 2015;(1):10. Available From: Http://Www.Eumed.Net/Rev/Tectzapic/2015/01/ Auriculares.Html

32. Redondo AL, Gallego CAM, Florez LLP, Machuca YGC, Mejia KLH, Jerez LVM, et al. Relacion Entre La Discapacidad Y La Desigualdad De La Clase Social. Rev Científica Signos Fónicos [Internet]. 2017 Oct $25 ; 2(3)$.

33. Rodríguez Elu, Macías Jwm. Reproductores De Audio Portátiles Y Su Repercusión En El Deterioro Auditivo Extra Laboral En Jóvenes. 2017;145. Available From: Http://Repositorio.Ug.Edu.Ec/Handle/Redug/36920

34.Barreras Rivera D, Peña Casal C, Arnold Alfonso M, Alfonso Rodríguez J, Llerena Suárez J. Impacto Bio-Psico-Social Del Uso Indiscriminado De Dispositivos De Audio. Rev Médica Electrónica. 2016;38(5):677-88.

35. Tajadura-Jiménez A, Pantelidou G, Rebacz P, Västfälll D, Tsakiris M. El Uso De Reproductores Portátiles De Música Ayuda A Reducir Nuestro Espacio Personal. 2012;21-3. Available From: Http://Lowendmac.Com/Orchard/06/Sony-Walkman-Origin.Html.

36. Carlos M, Sosa V, Martinez A, Kogan P. Encuesta Sobre El Uso De Auriculares En Adolescentes. Vi Congr Iberoam Acústica - Fia 2008. 2008;1-9.

37. Diego J. Universidad Central Del Ecuador Facultad De Filosofía , Letras Y Ciencias De La Educación Del Primer Semestre De La Carrera Inglés , Facultad De Filosofía , Letras Y Ciencias De La Educación De La Universidad Central Del Ecuador . Propuesta Tecnológica Pr. 2016;165.

38. Guayaquil Desde, Medicina Cde. Facultad De Ciencias Médicas De La Ucsg Periodo B 2014-2015. 2015;

39. Acosta L, Garrido Ma. Las Experiencias Pilotos Andaluzas : Las Titulaciones De La Facultad De Filosofía Y Letras De La Universidad De Cádiz . 2005;(November).

40. Ribeiro Aa, Angelo Df, Soares Lm. Original Research Article Programa De Conservação Auditiva : Enfoque No Uso Adequado Dos Equipamentos De Proteção Personal Protective Equipment . 2016;1.

41. Rodríguez D. El Conocimiento De Los Jóvenes Sobre Los Efectos Nocivos Del Ruido. 2012; Available

Revista Científica Signos Fónicos, 2019,5(2): 97-150. ISNN 2422-1716. 
Jaimes V Z; Arevalo S L; Pinto M A; Ramos Y P; Romero, M F; Sierra E Y; Vega, M G. Revista Científica Signos Fónicos, 2019,5(2): 97-150.

From: Http://Redi.Ufasta.Edu.Ar:8080/Xmlui/Handle/123456789/181

42. Murolo NI. Escuchando Música En El Transporte Público - Sobre Usos De La Telefonía Móvil Por Parte De Jóvenes. Intercom Rev Bras Ciências Da Comun. 2015;38(2):81-98.

43. Weezel A Van, Benavides C. Uso De Teléfonos Móviles Por Los Jóvenes Use Of Mobile Telephones By Young People. Cuad Inf [Internet]. 2009;5-14. Available From: Http://Www.Redalyc.Org/Articulo. Oa?ld=97112696002\%0ahttp://Www.Redalyc.Org/Articulo.Oa?ld=97112696002sl

44. Morgado B, López E. Arte, Sonido E Internet: El Net.Sound Art Frente A La Experimentación Sonora De Las Vanguardias Y Neovanguardias. Universum. 2016;31(1):191-208.

45. Hanen C, Terapeuta A V. Terapia Auditivo Verbal . 1939;

46. Orellana V, Torres P. Audífonos: Características, Selección Y Adaptación. Rev Médica Clínica Las Condes. 2003;14(Figura 1).

47. Ríos-Checa A, Barraza Jv. La Lectura Y La Audición, Tienen Efecto En La Escritura De Estudiantes Universitarios? Rev Mex Investig Educ. 2018;23(79):1149-69.

48. Fuentes L E, Rubio M C, Cardemil M F. Pérdida Auditiva Inducida Por Ruido En Estudiantes De La Carrera De Odontología. Rev Otorrinolaringol Y Cirugía Cabeza Y Cuello. 2013;73(3):249-56.

49. Gómez Mercado A, Reyes Mendoza Jm. Estudio Del Daño Auditivo Por Uso Excesivo De Auriculares. Rev Tectzapic [Internet]. 2015;10. Available From: Http://Www.Eumed.Net/Rev/Tectzapic/2015/01/ Auriculares.Html

50. Puyuelo M. Tratado De Audiología. Vol. 26, Revista De Logopedia, Foniatría Y Audiología. 2006. 62 P.

51. Zenker F, Altahona Mp, Barajas Jj. La Exposición A Ruido Por Actividades De Ocio En Adolescentes. Rev Logop Foniatría Y Audiol [Internet]. 2001;21(4):173-80. Available From: Http://Dx.Doi.Org/10.1016/ S0214-4603(01)76206-7

52. Morton Pja. Notas Sobre El Ruido. Aplicación De Las Teorías De Florence Nightingale Al Entorno Actual Del Paciente. Nurs (Ed Española) [Internet]. 2014;31(2):39-42. Available From: Http://Dx.Doi. Org/10.1016/J.Nursi.2014.04.014

53. Avila Eam, Carrillo Map, Marín lyp, Bohorquez Lm, Dávila Kcd, Guevara Ssg, Et Al. Estrategia De Comunicación En Salud \&Quot;Liga Superfono\&Quot; Rev Científica Signos Fónicos [Internet]. 2015 Jan 30 [Cited 2018 Nov 15];1(1)

54. Capacho Eer, Moncada Mbg, Echaez Md, Parada Zcb, Villalba Amg, Murcia Yps, Et Al. Prevalencia De Respiración Oral En Estudiantes Universitarios. Rev Científica Signos Fónicos [Internet]. 2016 Apr 1 [Cited 2018 Nov 15];2(1).

55. Departamento De Salud Y Servicios Humanos De Los Ee. Uu. Audición Y Equilibrio Audífonos. 994340 S. 2013;

56. Portilla Portilla Em, Rangel Navia H, Soto Jc, Montes Gallego Ca, Ayala Nieto Á, Rodríguez Brito Y, Et Al. Co-Construcción De Una Ruta Metodológica Para Incorporar La Cartegoría Frontera A La Cartografía Social Aplicada A Los Determinantes Sociales De La Salud. Rev Científica Signos Fónicos [Internet]. 2018 Sep 28 [Cited 2018 Nov 15];3(2)

57. Smith Rd, Jerome Alpiner Meg, Mulvey M. La Decisión Sobre Los Audífonos Respuestas A Sus Múltiples Preguntas. Available From: Www.Oiresclave.Org

58. Aguilar Alonso A, Cid Rodríguez Jm., Aguilar Mediavilla Em. Ruido Ambiental Y Capacidad Auditiva En Estudiantes Universitarios. Rev Logop Foniatría Y Audiol. 2001;21(4):166-72.

59. Galarza Muñoz Mm. Cómo Incide El Desconocimiento De Los Daños Que Causa A Futuro El Uso De Audífonos En Adolescentes De 11 A 15 Años De Octavo, Noveno Y Décimo Año Del Colegio Instituto Coello De La Ciudad De Guayaquil. 2017; Available From: Http://Repositorio.Ug.Edu.Ec/Handle/Redug/20194

60. Mesa Payan D, Berdasco Gomez A, Rubi Alvarez A. Estudio Longitudinal De Crecimiento Y Desarrollo De 0 A 2 Años De Edad. I: Peso Y Talla. Rev Cubana Pediatr. 1987;59(4):541-54. 